UNIVERSIDAD POLITÉCNICA DE MADRID

DEPARTAMENTO DE INGENIERÍA CIVIL:

HIDRÁULICA, ENERGÍA Y MEDIO AMBIENTE

POLITÉCNICA

ESCUELA TÉCNICA SUPERIOR DE

INGENIEROS DE CAMINOS, CANALES Y PUERTOS

Doctorado en Sistemas de Ingeniería Civil (DOSIC)

\title{
OBRAS PÚBLICAS, EVOLUCIÓN Y PAISAJE COSTERO. DE LA SITUACIÓN EN ESPAÑA AL GIGANTISMO ASIÁTICO
}

\section{TESIS DOCTORAL}

AUTOR: MARIO MARTÍN ANTÓN Ingeniero de Caminos, Canales y Puertos Máster en Sistemas de Ingeniería Civil

DIRECTOR: VICENTE NEGRO VALDECANTOS Dr. Ingeniero de Caminos, Canales y Puertos

CODIRECTOR: JOSÉ MARÍA DEL CAMPO YAGÜE Dr. Ingeniero de Caminos, Canales y Puertos 



\title{
TESIS DOCTORAL
}

\section{OBRAS PÚBLICAS, EVOLUCIÓN Y PAISAJE COSTERO. DE LA SITUACIÓN EN ESPAÑA AL GIGANTISMO ASIÁTICO}

\author{
AUTOR: $\quad$ MARIO MARTÍN ANTÓN \\ Ingeniero de Caminos, Canales y Puertos \\ Máster en Sistemas de Ingeniería Civil \\ DIRECTOR: $\quad$ VICENTE NEGRO VALDECANTOS \\ Dr. Ingeniero de Caminos, Canales y Puertos \\ CODIRECTOR: JOSÉ MARÍA DEL CAMPO YAGÜE \\ Dr. Ingeniero de Caminos, Canales y Puertos
}

Tribunal nombrado por el Mgfco. Y Excmo. Sr. Rector de la Universidad Politécnica de

Madrid, el día

de

de

Presidente:

Secretario:

Vocal:

Vocal:

Vocal:

Realizado el acto de defensa y lectura de la Tesis el día de

de 2018 en la E.T.S. de Ingenieros de Caminos, Canales y Puertos de la U.P.M.,

acuerdan otorgarle la calificación de

En Madrid, a de de 2018.

EL PRESIDENTE EL SECRETARIO LOS VOCALES 



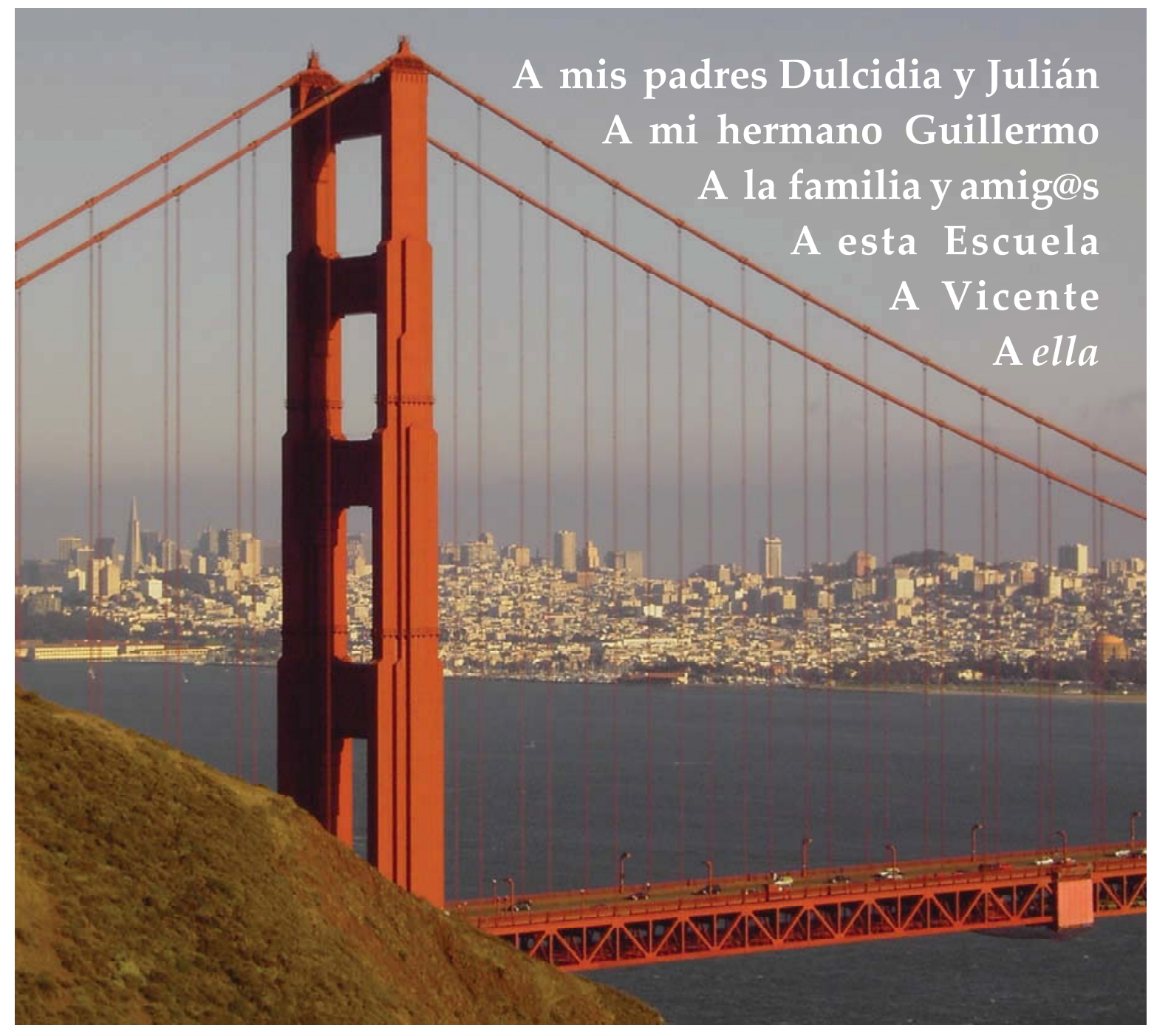





\section{$\underline{\text { ÍNDICE }}$}

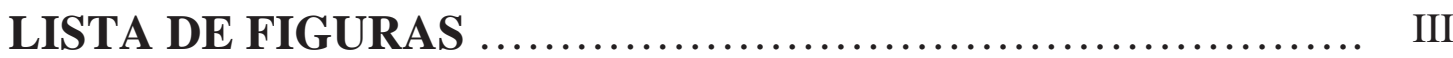

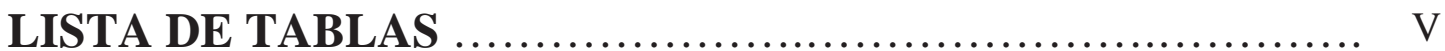

AGRADECIMIENTOS ..................................... VII

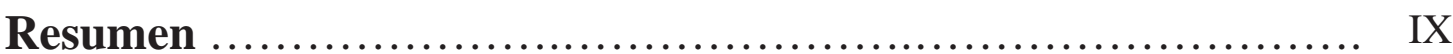

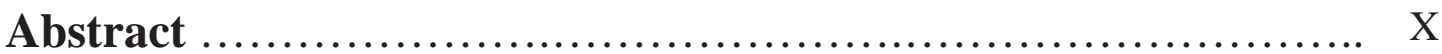

ESTRUCTURA Y ORGANIZACIÓN DEL DOCUMENTO ..... XIII

CAPÍTULO 1: INTRODUCCIÓN Y OBJETIVOS ........ 1

1.1. Introducción ...................................... 1

- 1.1.1. El arte de construir ............................... 1

- 1.1.2. Obras Civiles y Obras Públicas ....................... 3

- 1.1.3. La utilidad de las Obras Públicas ..................... 4

- 1.1.4. Ingeniería Civil y Sociedad: La simbología de las Obras Públicas ............................................ 7

- 1.1.4.1. Las obras Públicas en el deporte ........................ 7

- 1.1.4.2. Las Obras Públicas en el Cine ......................... 10

- 1.1.4.3. Las Obras Públicas en la música ...................... 12

- 1.1.4.4. Las Obras Públicas en emisiones oficiales ................ 13

- 1.1.5. La evolución de las Obras Públicas .................... 14

1.2. Objetivos de la tesis doctoral ......................... 17

CAPÍTULO 2: ESTADO DEL ARTE Y

METODOLOGÍA DE LA INVESTIGACIÓN ........ 19

2.1. Estado del arte del paisaje ............................. 19

2.2. Definiciones de paisaje ............................... 28

2.3. Ejemplos de Paisaje y Obras Públicas ................. 31

- 2.3.1. Paisaje natural ................................... 31

- 2.3.2. Paisaje construido en España ....................... 34

- 2.3.3. Paisaje costero destruido en España .................. 37

- 2.3.4. Paisaje oculto .......................................... 38

- 2.3.5. Paisaje aéreo ......................................... 40

- 2.3.6. Paisaje aéreo urbano: el urbanismo .................... 43

- 2.3.7. Paisaje evolutivo ................................... 45

- 2.3.8. Paisaje construido en Reino Unido .................... 47

- 2.3.8. Paisaje destruido en Asia .......................... 50 
CAPÍTULO 3: RESULTADOS Y DISCUSIÓN ............ 51

- 3.1. ARTÍ́CULO 1 Y 2 .................................. 53

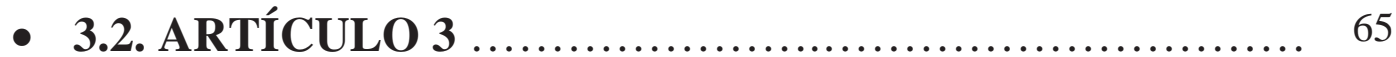

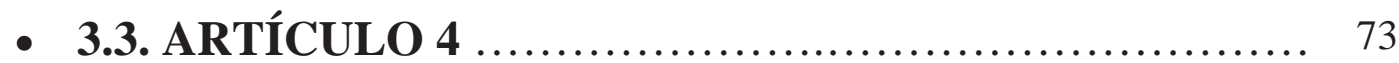

• 3.4. ARTÍCULO 5 Y 6 ..................................... 89

• 3.5. ARTÍ́CULO 7 ....................................... 101

CAPÍTULO 4: CONCLUSIONES Y FUTURAS

LÍNEAS DE INVESTIGACIÓN ....................... 115

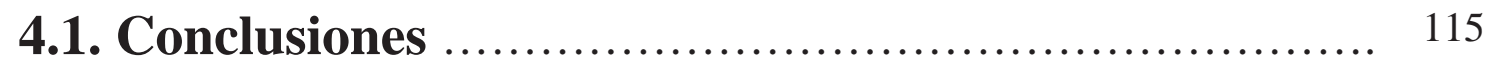

4.2. Futuras líneas de investigación ........................ 117

4.3. Reflexión final ............................................ 119

CAPÍTULO 5: REFERENCIAS BIBLIOGRÁFICAS ...... 121

APÉNDICES (en soporte digital) .............................. 129

Apéndice A: Indicios de calidad: Artículos publicados y congresos

- Artículo 1

- Artículo 2

- Artículo 3

- Artículo 4

- Artículo 5

- Artículo 6

- Artículo 7

- Ponencia 1

- Ponencia 2

- Póster 1

Apéndice B: Planos y gráficas

Apéndice C: Apéndice fotográfico 


\section{LISTA DE FIGURAS}

\begin{tabular}{|c|c|}
\hline & Pág. \\
\hline Figura 1: Acueducto Romano de Segovia & 1 \\
\hline Figura 2: Poblaciones fenicias, griegas y cartaginesas del Mar Mediterráneo & 2 \\
\hline Figura 3: Puente de Amritapuri, India. & 4 \\
\hline Figura 4: Presa del Pontón Alto, Segovia. & 4 \\
\hline Figura 5: Fuente pública en Tsiroanomandidy, Madagascar. & 5 \\
\hline Figura 6: Planta de tratamiento de residuos de Los Huertos, Segovia. & 5 \\
\hline Figura 7: Vía Verde de la Sierra, Cádiz & 6 \\
\hline Figura 8: Jardín en la estación de Atocha, Madrid & 6 \\
\hline $\begin{array}{l}\text { Figura 9: Sala de exposiciones del antiguo depósito de agua de Plaza de Castilla, } \\
\text { Madrid }\end{array}$ & 6 \\
\hline Figura 10: Parque en el antiguo aeropuerto de Tempelhof, Berlín, Alemania & 7 \\
\hline $\begin{array}{l}\text { Figura 11: Carriles bici ocupando antiguos carriles de vehículos de motor, } \\
\text { Madrid }\end{array}$ & 7 \\
\hline Figura 12: Puente Verrazano en la maratón de Nueva York & 8 \\
\hline $\begin{array}{l}\text { Figura 13: Pelotón del Tour de Francia en la última etapa en los Campos } \\
\text { Elíseos-Arco del Triunfo }\end{array}$ & 8 \\
\hline Figura 14: Passo Stelvio, Cima Coppi del Giro de Italia & 9 \\
\hline Figura 15: Circuito y puerto de Yas Marina en Abu Dhabi & 9 \\
\hline Figura 16: Puerto Deportivo de Valencia de la Copa del América 2007 & 9 \\
\hline Figura 17: Escena final de Doctor Zhivago en Aldeadávila & 10 \\
\hline Figura 18: Carteles de películas con puentes & 11 \\
\hline Figura 19: Ejemplos de portadas de discos con Obras Públicas & 12 \\
\hline Figura 20: Tren AVRIL en el Pasaporte español & 13 \\
\hline Figura 21: Ejemplos de sellos con Obras Públicas & 13 \\
\hline Figura 22: Ejemplos de monedas con Obras Públicas & 14 \\
\hline Figura 23: Ejemplos de billetes con Obras Públicas & 14 \\
\hline $\begin{array}{l}\text { Figura 24: Evolución de los puentes. Puente micénico de Arkadiko, Puente } \\
\text { Romano de Alcántara, Arcos de Alconétar de la A-66 sobre el río } \\
\text { Tajo }\end{array}$ & 15 \\
\hline $\begin{array}{l}\text { Figura 25: Evolución de los canales. Diolkos, Canal de Corinto, Canal de } \\
\text { Panamá }\end{array}$ & 15 \\
\hline $\begin{array}{l}\text { Figura 26: Proyecto del Stad Ship Tunnel y Puente Flotante de Nordhordland } \\
\text { (Noruega) }\end{array}$ & 16 \\
\hline $\begin{array}{l}\text { Figura 27: Ascensor de barcos "Falkirk Wheel”, Escocia; y pistas de prueba del } \\
\text { tren magnético Transrapid, Alemania }\end{array}$ & 16 \\
\hline Figura 28: Concepto de lugar & 24 \\
\hline Figura 29: Componentes del lugar & 24 \\
\hline Figura 30: Paisaje: componente territorial y de percepción & 25 \\
\hline Figura 31. Definiciones del Convenio Europeo del Paisaje & 28 \\
\hline $\begin{array}{l}\text { Figura 32. Paisaje natural (garganta del Jabalí, Valdeascas, Navarredonda de } \\
\text { Gredos) y paisaje construido (Pozo de las Paredes, Navacepeda de } \\
\text { Tormes) }\end{array}$ & 30 \\
\hline Figura 33: “Contrafuertes” de la Playa de las Catedrales, Lugo & 31 \\
\hline $\begin{array}{l}\text { Figura 34: "Dique" (acantilados del faro de la Plata) y "puerto natural abrigado" } \\
\text { de Pasaia, Gipuzkoa }\end{array}$ & 31 \\
\hline Figura 35: "Presa y embalse" de la Laguna Grande de Gredos, Ávila & 32 \\
\hline
\end{tabular}




\begin{tabular}{|c|c|}
\hline & Pág. \\
\hline Figura 36: "Puente" de Puentedey, Burgos & 32 \\
\hline $\begin{array}{l}\text { Figura 37: “Terrenos ganados al mar (land reclamation)” en el tómbolo de } \\
\text { Trafalgar, Cádiz }\end{array}$ & 32 \\
\hline $\begin{array}{l}\text { Figura 38: "Salto de agua para aprovechamiento hidráulico" en el Chorrón del } \\
\text { Río Razón, Soria }\end{array}$ & 32 \\
\hline Figura 39: "Puerto de mercancías" con la puesta de huevos de las tortugas & 33 \\
\hline Figura 40: "Dique" vivo de la Gran Barrera de Coral & 33 \\
\hline Figura 41: "Presa" realizada por castores & 33 \\
\hline $\begin{array}{c}\text { Figura 42: “Caminos" en las veredas realizadas por el ganado en la Cañada Real } \\
\text { Soriana Occidental, Trescasas, Segovia }\end{array}$ & 33 \\
\hline Figura 43: Torre de Hércules, A Coruña. & 34 \\
\hline Figura 44: Estación de tren de Somport, Huesca & 34 \\
\hline Figura 45: Dique romano de Ampurias, Girona & 34 \\
\hline Figura 46: Puente Carlos Fernández Casado en Barrios de Luna, León & 35 \\
\hline Figura 47: Viaducto Martín Gil, Zamora & 35 \\
\hline Figura 48: Presa de Aldeadávila, Salamanca & 35 \\
\hline Figura 49: Carretera de Sa Calobra, Mallorca, Baleares & 35 \\
\hline Figura 50: Muelle de Riotinto, Huelva & 36 \\
\hline Figura 51: Caminito del Rey, Málaga & 36 \\
\hline Figura 52: Playa de Los Cancajos, La Palma, Canarias & 36 \\
\hline Figura 53: Carretera LZ-67 hacia Timanfaya, Lanzarote & 36 \\
\hline Figura 54: Puerto de Langosteira, A Coruña & 37 \\
\hline Figura 55: Dique Cabo Torres, Gijón, Asturias & 37 \\
\hline Figura 56: Aeropuerto de San Sebastián & 37 \\
\hline Figura 57: Puerto de Burriana, Castellón & 38 \\
\hline Figura 58: La Manga del Mar Menor, Murcia & 38 \\
\hline Figura 59: Bahía de Algeciras & 38 \\
\hline Figura 60: Puentes de Portomarín, Lugo & 39 \\
\hline Figura 61: Puentes de Maderuelo, Segovia & 39 \\
\hline Figura 62: Líneas de Nazca (Perú) & 40 \\
\hline Figura 63: Aeropuerto de Orlando (EEUU) & 40 \\
\hline Figura 64: Paso del Cristo Redentor (Chile) & 40 \\
\hline Figura 65: Circuito de Fórmula 1 de Shanghai & 41 \\
\hline Figura 66: Enlace de la "Y asturiana" (A66-A8) (Asturias) & 41 \\
\hline Figura 67: Enlace de carreteras en Doha (Qatar) y Dubai (EAU) & 41 \\
\hline Figura 68: Enlace en el puente de la bahía de Hangzhou, China & 41 \\
\hline Figura 69: "Palm Jumeirah" y "The World" de Dubai, EAU & 42 \\
\hline Figura 70: Puerto seco de Hamburgo, Alemania & 42 \\
\hline Figura 71: Puerto de Tazacorte, Isla de la Palma, Canarias & 42 \\
\hline Figura 72: Puerto de Rotterdam, Países Bajos & 42 \\
\hline $\begin{array}{l}\text { Figura 73: Rotonda en Taipei (Taiwan) y “Magic Roundabout” en Swindon } \\
\text { (UK) }\end{array}$ & 43 \\
\hline Figura 74: Urbanismo en Palmanova (Italia) y Neuf-Brisach (Francia) & 43 \\
\hline Figura 75: Urbanismo de Canberra, Australia & 43 \\
\hline Figura 76: Urbanismo en Brasilia, Brasil & 44 \\
\hline Figura 77: Urbanismo en Nueva Delhi, India & 44 \\
\hline Figura 78: Plan Cerdá de Barcelona, España & 44 \\
\hline Figura 79: Urbanismo de París, Francia. Avenida de los Campos Elíseos & 44 \\
\hline
\end{tabular}




\begin{tabular}{|l|c|}
\hline & Pág. \\
\hline Figura 80: Puentes sobre el río Ízbor en Acebuches, Granada & 45 \\
\hline Figura 81: Puentes de Newcastle, Inglaterra & 45 \\
\hline Figura 82: Puentes de Jaraicejo (A-5 con río Almonte), Cáceres & 46 \\
\hline Figura 83: Puentes ferroviarios del Río Ulla, A Coruña-Pontevedra & 46 \\
\hline Figura 84: Puentes del río Golmayo en Soria & 46 \\
\hline Figura 85: Presa de Puentes 3 y 4, Murcia & 46 \\
\hline Figura 86: Puente Craigellachie (Thomas Telford, 1814), Craigellachie, Escocia & 47 \\
\hline Figura 87: Puente colgante de Conwy (Thomas Telford, 1826), Conwy, Gales & 47 \\
\hline Figura 88: Puente colgante de Menai (Thomas Telford, 1826), Menai Bridge, \\
Gales & 47 \\
\hline Figura 89: Puente de Forth (Fowler \& Baker, 1890), Escocia & 48 \\
\hline Figura 90: Presa Craig-Goch (1904), Elan Valley, Gales & 48 \\
\hline Figura 91: Presa Ladybower (1943), Peak District, Inglaterra & 48 \\
\hline Figura 92: Dique de Arbroath, Escocia & 48 \\
\hline Figura 93: Rellenos portuarios en la Bahía de Bohai, China & 49 \\
\hline Figura 94: Puerto de Shanghai, China & 49 \\
\hline Figura 95: Proyecto de ciudad ganada al mar de Diyar Al Muharraq, Bahrein & 49 \\
\hline Figura 96: Presa de las Tres Gargantas, China & 50 \\
\hline Figura 97: Peaje en una autopista cerca de Pekín, China & 50 \\
\hline Figura 98: Terminal petrolífera del Puerto de Singapur & 50 \\
\hline Figura 99: Industria metalúrgica en Hebei, China & 50 \\
\hline Figura 100: Evolución de Barangaroo, Sydney, en los últimos siglos & 118 \\
\hline Figura 101: Paisaje Reconstruido en Barangaroo, Sydney & 119 \\
\hline Figura 102: Nueva concepción del paisaje de Sydney introduciendo el concepto & 119 \\
\hline de Paisaje Reconstruido & \\
\hline
\end{tabular}

\section{LISTA DE TABLAS}

\begin{tabular}{|l|c|}
\hline & Pág. \\
\hline Tabla 1: Clasificación del paisaje cultural & 20 \\
\hline Tabla 2: Vidas útiles mínimas, naturaleza de las mercancías y usos portuarios & 21 \\
\hline Tabla 3: Formas de analizar el concepto de paisaje & 23 \\
\hline Tabla 4: Relaciones entre los conceptos de paisaje & 23 \\
\hline Tabla 5: Criterios de análisis del paisaje (componente, denominación y autores) & 25 \\
\hline Tabla 6: Criterios de percepción y su origen & 26 \\
\hline
\end{tabular}




\section{AGRADECIMIENTOS}

- A Vicente Negro Valdecantos. Esta tesis no hubiera sido posible sin él. Gracias a su apoyo incondicional, sus ideas y la confianza que ha depositado en mí desde el primer momento, este proyecto ha salido adelante. Esta conexión, que a veces se tiene con algunas personas, ha sido el motor de una relación que ha traspasado el ámbito académico, llegando al personal. Conocí a Vicente como alumno en la asignatura de Puertos y Costas y, desde entonces, ha sido un referente para mí en la Escuela y fuera de ella. Durante la redacción y publicación de los diferentes artículos que conforman la tesis, Vicente siempre ha estado ahí, levantándome el ánimo cuando no me publicaban y facilitándome el conocimiento de todo el mundo de la investigación: artículos, congresos, etc. Vicente más que profesor y tutor, es un amigo, y le estaré siempre agradecido de lo que ha hecho por mí.

- A la Fundación Agustín de Betancourt por la financiación de esta investigación gracias a las "Becas para el fomento de la investigación entre doctorandos" que he disfrutado durante 3 años.

- Al Grupo de Investigación “Medio Marino, Costero y Portuario y otras Áreas Sensibles” por su ayuda.

- A José María del Campo Yagüe, el codirector de la tesis, por su apoyo y guía en el desarrollo de este documento.

- A José Santos López Gutiérrez y María Dolores Esteban Pérez por su gran ayuda desde el principio, orientándome en este mundo de la investigación, para mí nuevo. Ellos me han facilitado mucho el trabajo, sobre todo en los primeros momentos y me han enseñado mucho.

- A Adrián Escobar Pastor por su amistad y confianza hacia mí, a veces mayor que la mía propia.

- A Jorge Luengo Frades y César Sastre Gil por compartir buenos momentos en el laboratorio de Puertos, por su amistad, su compañía y su apoyo.

- A la Escuela de Caminos, Canales y Puertos por ser mi "casa" durante estos 10 últimos años. - A la Dirección de la Escuela por contar conmigo para hacer de esta Escuela una escuela mejor: Juan Santamera, Paco Martín Carrasco, José Miguel Atienza, Pablo de la Fuente†, Alejandro Enfedaque, Felipe Gabaldón.

- A Andrés Monzón y Rosa Arce por confiar en mí hace unos años para formar parte del equipo de investigación de TRANSyT con el proyecto ASCIMER.

- A mis compañeros durante los 6 años de carrera (en especial a Alicia Bragado, Adrián Sierra, Sergio Sierra, Guillermo Muñoz, Susana Provencio y demás camineros segovianos) y los que conocí después (Rubén Rodríguez, Javier Arévalo).

- A Delegación de Alumnos por su gran trabajo desinteresado y a las asociaciones por hacernos ver que hay vida fuera de las aulas: Club de Montaña Caminos, Asociación Fotográfica, Cooperación, correOcaminos (A Lara Rueda, Natalia Ávila, Carlos Romero, Javier Burrieza Galán, Juan Antonio Rebollo, Alberto Garcés, Álvaro Hernando, Javier Alcaraz, Sara Ballesteros, Marta Melcón, Mar del Corral, Diego Solano, José Luis Orts).

- A los profesores que me han enseñado de verdad y han conseguido que amara esta profesión: Miguel Marchamalo, Jesús Fraile Ardanuy, Miguel Aguiló, Jorge Bernabéu, Samuel Carpintero, Manuel Pastor, Manuel Melis, Alfredo Granados, Ildefonso Lucea†, María José Suárez, Luis Moreno.

- En especial quería agradecer a Jesús Fraile Mora por todo lo que ha supuesto para mí. Mi vocación de ser profesor empezó con él, con sus clases, con su forma de pensar en los alumnos. En el ámbito personal es una magnífica persona y un referente como docente. El último día de clase nos leía la emocionante "Tragedia del Profesor Universitario" y nos inculcaba otros valores en la vida, como la honradez. Espero seguir su ejemplo.

- A mis amig@s por compartir su tiempo conmigo y su compañía en los buenos y malos momentos. A mis profesores del colegio y del instituto por su contribución en mi educación (A Pepe y a Gloria). A mis parejas que me apoyaron y me animaron a seguir con la tesis. 
- A mi familia, pilar fundamental de mi vida.

- A mis abuelos. A mi abuela María, que siempre me pregunta "si apruebo o no apruebo los estudios", para decirle finalmente que sí que he "aprobado".

- A mi padrino Jesús de Miguel†, por el granito de arena que me ha aportado en mi pasión por las Obras Públicas y por las obras de ingeniería. Para que sepa que esas cartas que me mandaba periódicamente cuando yo era pequeño con recortes de periódicos sobre grandes proyectos de la ingeniería civil mundial han hecho su efecto.

- A mi tía Ifigenia, por darme alojamiento durante varios años, para que mi vida en Madrid fuera más fácil.

- A mi hermano Guillermo. A él le debo esta pasión por la profesión. Como buen hermano pequeño fui cogiendo las aficiones de mi hermano mayor. Todo empezó en ese montón de tierra donde construimos nuestra ciudad con sus carreteras y túneles. Por esos grandes viajes de furgoneta donde compaginábamos Arte y Obras Civiles.

- A mis padres, Julián y Dulcidia. A ellos les debo todo: su educación, su cariño y su apoyo incondicional. Gracias a ellos mi pasión por las Obras Públicas fue creciendo hasta el día de hoy. Gracias por esos viajes por España y el extranjero para visitar grandes puentes, presas, ferrocarriles, etc. Han sido la pieza fundamental en el desarrollo de esta tesis. Me han apoyado en los peores momentos y esta tesis está dedicada a ellos.
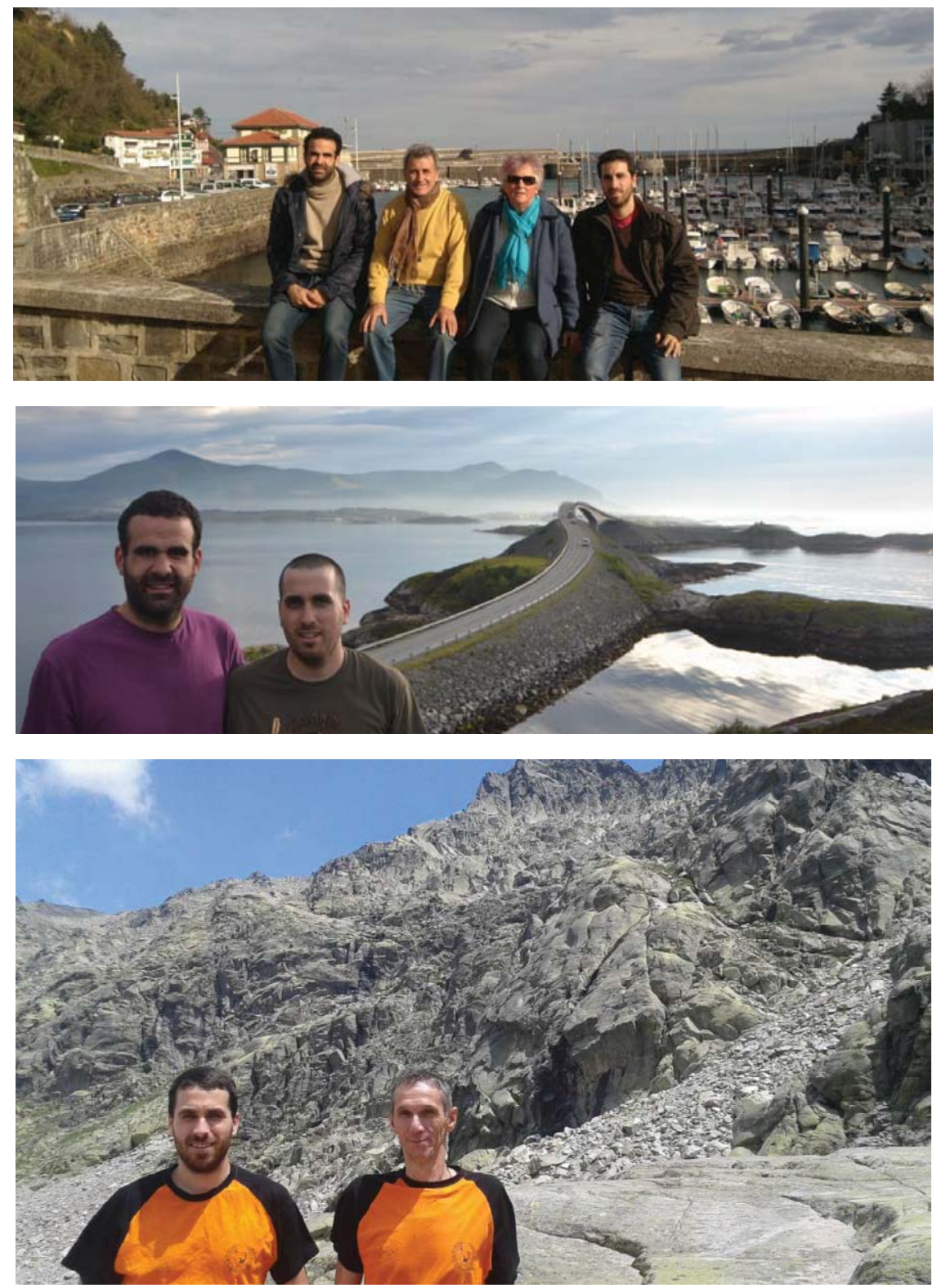


\section{TESIS DOCTORAL}

\section{OBRAS PÚBLICAS, EVOLUCIÓN Y PAISAJE COSTERO. DE LA SITUACIÓN EN ESPAÑA AL GIGANTISMO ASIÁTICO}

"Los ingenieros que ignoran el pasado poco pueden hacer por el futuro". G.F.W. Hauck

\section{Resumen}

Esta investigación es una introspección del ser humano en el mundo, una reflexión sobre la naturaleza, las construcciones y el paisaje. Es la manifestación del hombre, su presencia en el territorio y su vivencia, por eso construir es un "arte". El medio natural es salvaje, dinámico, simbólico, tan lento en su evolución como dramático en sus cambios por catástrofes y desastres. La humanidad está presente en el planeta con un sentido: construir y "estar en el mundo".

Su acción, a través de las obras de ingeniería civil y arquitectura, y la expansión de las ciudades, es una huella, cicatriz o agresión que modifica el entorno. Sin embargo, el paisaje solo aparece si existe civilización. Esta relación ha pasado por cuatro etapas: sumisión, adaptación, conquista y respeto. Así es como aparece el concepto de paisaje natural, paisaje construido, paisaje destruido, y en un futuro, el "paisaje reconstruido". Sobre ellos existen los niveles de percepción y las componentes estéticas y subjetivas, perspectivas sobre el paisaje que trata esta tesis doctoral, descartando los aspectos legales y de gestión.

Para concretar la investigación, se repasan distintos casos donde se observan aspectos como la conquista (grandes rellenos portuarios, edificios singulares subiendo por escaleras hasta el cielo, grandes puentes) y el respeto (destacando en la obra marítima el espaldón de los diques de abrigo en su camino hacia la estética empleando el hormigón armado, jugando con la esbeltez y armonizando la forma). Finalmente, se resume el estudio con una megápolis como Sydney donde se sintetiza el paisaje natural, destruido y construido.

Se observa una diferencia entre la situación en Europa o España y en Asia, concretamente en China o el Golfo Pérsico. Mientras aquí los recursos económicos limitados y la legislación ambiental no suelen permitir grandes realizaciones que destruyan reiteradamente el paisaje; en China, desde principios de este siglo, su gran desarrollo en infraestructuras debido al cambio del centro de gravedad del desarrollo económico mundial ha provocado la conquista del mar (puertos, rellenos e islas artificiales), la atmósfera (rascacielos) los valles (puentes y presas) y las montañas (túneles), lo que se llama en esta Tesis "gigantismo". El tiempo dirá si este ritmo de construcción y de desarrollo puede ser sostenible medioambiental y económicamente.

De momento solo se puede analizar la situación y reflexionar sobre el impacto de las obras públicas en el paisaje y el espíritu que lo impregna transformando en sueño el medio físico hasta dotarlo de sentimiento. 


\section{Abstract}

This research is an introspection of the human being in the world, a reflection on nature, constructions and landscape. It is the demonstration of human being, his presence in the territory and his experience; that is why building is an "art". Nature is wild, dynamic, symbolic, and as slow in her evolution as she is dramatically quick in her catastrophes and disasters. Humanity is present on the planet with one meaning: to build and "to be in the world".

Its action, through works of civil engineering and architecture, and the expansion of cities, is a mark, scar or aggression that modifies the environment. However, the landscape only appears if civilization exists. This relationship has gone through four phases: submission, adaptation, conquest and respect. This is how the concept of natural landscape, built landscape, destroyed landscape and, in the future, the "reconstructed landscape" appears. On them there are the levels of perception and the aesthetic and subjective components, perspectives on the landscape treated by this $\mathrm{PhD}$ thesis, discarding the legal and management aspects.

To carry out the research, different cases are reviewed where aspects such as conquest (large port fillings, unique buildings reaching and touching the sky, large bridges) and respect (highlighting in the maritime work the crown wall of breakwaters in the way towards aesthetics using reinforced concrete, playing with the slenderness and harmonizing the shape) are observed. Finally, the study is summarized with a megalopolis like Sydney where the natural, destroyed and constructed landscape is synthesized.

There is a difference between the situation in Europe or Spain and in Asia, specifically in China or the Persian Gulf. Whilst here the limited economic resources and the environmental legislation do not usually allow great constructions that repeatedly destroy the landscape; in China, since the beginning of this century, its great development in infrastructures due to the change in the centre of gravity of the world economic development has led to the conquest of the sea (ports, reclamation areas and artificial islands), the atmosphere (skyscrapers), the valleys (bridges and dams) and the mountains (tunnels), what is called in this Thesis "gigantism". Time will tell whether this rate of construction and development could be environmentally and economically sustainable.

At the moment, the only thing possible is to analyze the situation and reflect on the impact of public works on the landscape and the spirit that impregnates it, transforming the physical environment into a dream until endowed with feeling. 
"Hay tantas realidades como puntos de vista. El punto de vista crea el panorama"
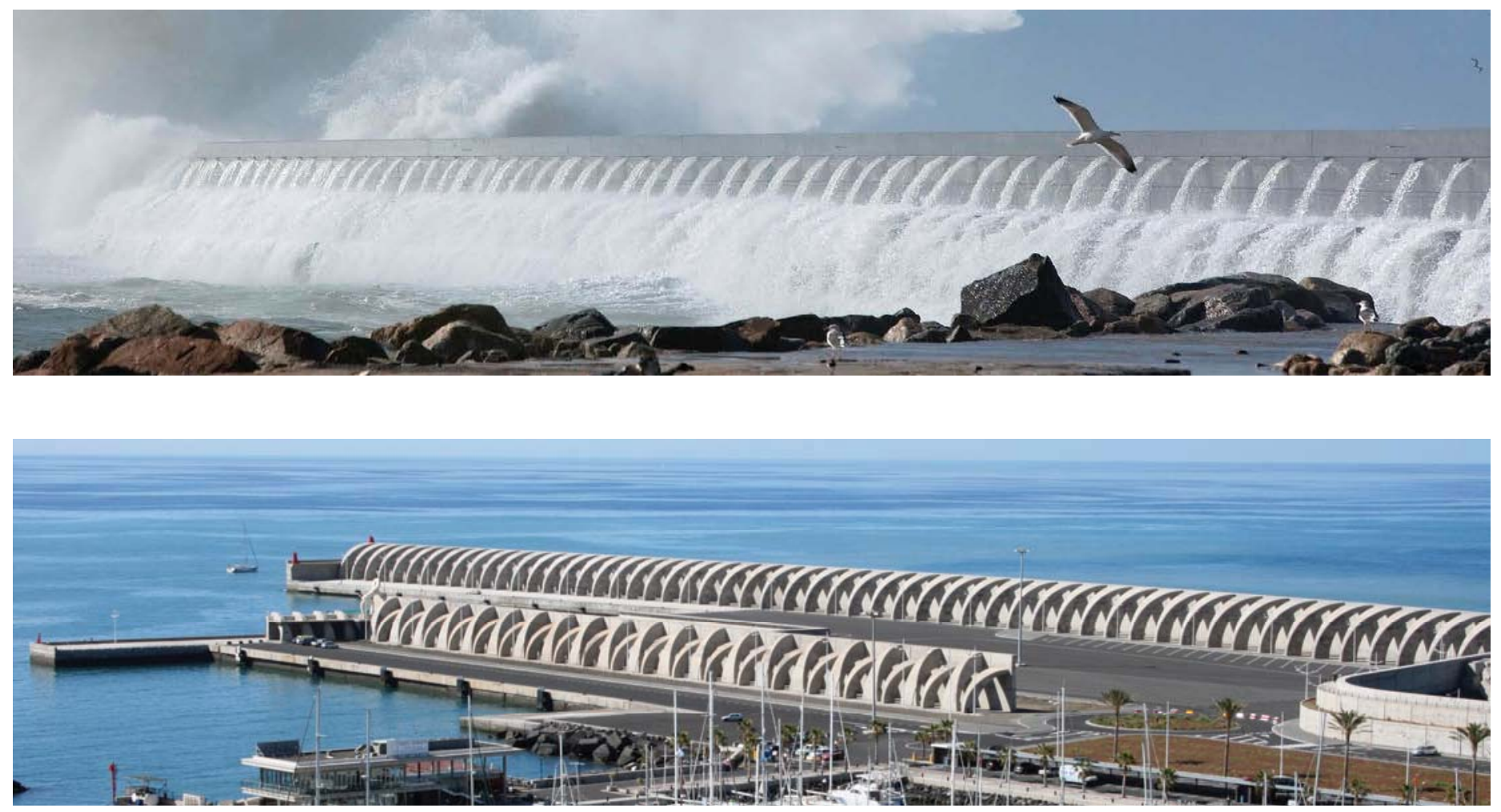

"Es mejor crear que aprender. La creación es la esencia de la vida"

Julio César 


\section{ESTRUCTURA Y ORGANIZACIÓN GENERAL DEL DOCUMENTO}

Esta Tesis Doctoral del programa de Doctorado en Sistemas de Ingeniería Civil de la Universidad Politécnica de Madrid está escrita en la modalidad o forma de artículos indexados y comunicaciones en Congresos internacionales con doble arbitraje y de jornadas y/o conferencias de índole nacional. Por ello, su estructura es ligeramente diferente, como lo es el tema de estudio, de una tesis "convencional" en el marco de la ingeniería civil.

Como se expone en la normativa del programa de doctorado, se aprueba la presentación de tesis doctorales por compendio de artículos siempre y cuando se cumplan los siguientes contenidos mínimos:

- Compendio de artículos, que debe ser precedido por una introducción a los mismos y su nexo con los objetivos de la tesis y la metodología.

- Cuatro (4) artículos, dos (2) de ellos publicados en revistas SCI y los otros dos (2) en otras revistas, o bien tres (3) artículos publicados en revistas SCI.

En este caso, en los artículos publicados en las revistas SCI, el doctorando figura como primer autor al menos en dos de ellos. En el resto de los artículos, el doctorando figura, al menos, como segundo autor. El director -o al menos uno de los codirectores, si es el caso- siempre son autor o coautor de los artículos que forman la tesis doctoral.

Estas condiciones son válidas hasta que la Comisión de Doctorado de la UPM apruebe una normativa que regule la presentación de la tesis doctoral por compendio de artículos, según se indica en el artículo 19 del Reglamento de elaboración y evaluación de la tesis doctoral en la Universidad Politécnica de Madrid (21/12/2011).

Se aplica a todas las tesis doctorales que comiencen su tramitación a partir de la fecha de aprobación, 19/05/2014 para el programa DOSIC R.D. 1393/2007 y 08/07/2014 para el programa DOSIC R.D. 99/2011.

Como resultado se tienen tres artículos indexados, dos no indexados, tres publicados en libros de ponencias de congresos (dos internacionales y uno nacional), dos ponencias en congresos internacionales y un póster en congreso nacional. Se cumplen, por lo tanto, los mínimos exigidos.

Es una investigación sin fórmulas. Es una búsqueda interior que recoge el aspecto humanista que debe tener un ingeniero para completar sus actuaciones en el mundo que lo rodea. Es más fácil actuar "a priori" que "a posteriori”; encajar que colocar, vertebrar que destrozar, sostener que desequilibrar, mirar la naturaleza sin distracción para resolver sus problemas y, con ellos, mejorar la vida de las poblaciones asentadas en ella.

La tesis doctoral se estructura de la siguiente manera:

\section{Capítulo 1: Introducción y objetivos.}

Se explica la motivación de este trabajo y los objetivos propuestos. Se habla del concepto de "arte de construir" y el proceso histórico de la construcción desde el inicio de la humanidad. Se tratan las motivaciones de las construcciones. Además, en la introducción, se hará una pequeña revisión del estado de las obras públicas en la actualidad desde un punto menos técnico, destacando la simbología que tienen para la sociedad en los últimos tiempos. 


\section{Capítulo 2: Estado del arte y metodología de la investigación}

Comprende una introducción teórica de los conceptos de paisaje a modo de estado del arte, para después introducir los términos básicos de "construido", "destruido" y "natural" así como las etapas de introspección del ser humano en el territorio (sumisión, adaptación, conquista y respeto).

El hilo metodológico de la investigación y, por ello, de los artículos se centra en las reflexiones de conceptos y etapas; ejemplos en distintas obras civiles de las mismas y la síntesis de todas las actuaciones en el ejemplo de la ciudad de Sídney. En esta búsqueda, también se plantean los escenarios futuros.

Las obras presentan una vida útil. Muchas de ellas ya se encuentran en situaciones residuales, por lo que su desmantelamiento y devolver la naturaleza a origen debe ser contemplada para restablecer el paisaje natural cuando el destruido o deteriorado lo permita. También puede aparecer el término de "paisaje reconstruido".

Horizontes "cero" o de no actuación no se contemplan en esta indagación interior sobre el territorio.

\section{Capítulo 3: Resultados y discusión}

Se presentan en este capítulo, las aportaciones en forma de indicios de calidad, artículos indexados, no indexados, comunicaciones internacionales con doble arbitraje, jornadas nacionales con arbitraje y póster, objeto de la tesis doctoral:

- Artículo 1: "The Impact of Public Works in Spain: Natural, Constructed and Destroyed Landscape" en la revista INDEXADA "Revista de la Construcción - Journal of Construction". PUBLICADO abril 2017.

Martín-Antón, M.; Negro, V.; del Campo, J.M., López-Gutiérrez, J.S., and Esteban M.D. (2017). "The Impact of Public Works in Spain: Natural, constructed and destroyed landscape". Revista de la Construcción - Journal of Construction, vol.16, n.1, pp.82-91. ISSN 0718915X. doi:10.7764/RDLC.16.1.82.

- Artículo 2: "El impacto de las obras públicas en España. Paisaje natural, construido y destruido" en la revista no indexada "Ingeniería Civil" del CEDEX. PUBLICADO 2016.

Martín-Antón, M.; Negro, V.; del Campo, J.M., López-Gutiérrez, J.S., and Esteban M.D. (2016). "El impacto de las obras públicas en España: paisaje natural, paisaje construido y paisaje destruido". Ingeniería Civil n184, pp 64-74. ISSN 0213-8468

- Artículo 3: "Review of Coastal Land Reclamation situation in the World" en la revista INDEXADA "Journal of Coastal Research". PUBLICADO marzo 2016:

Martín-Antón, M.; Negro, V.; del Campo, J.M., López-Gutiérrez, J.S., and Esteban M.D. (2016). "Review of coastal Land Reclamation situation in the World". In: Vila-Concejo, A.; Bruce, E.; Kennedy, D.M., and McCarroll, R.J. (eds.), Proceedings of the 14th International Coastal Symposium (Sydney, Australia). Journal of Coastal Research, Special Issue, No. 75, pp. 667671. Coconut Creek (Florida), ISSN 0749-0208. DOI: 10.2112/SI75-133.1

Este artículo fue presentado como ponencia en el Congreso Internacional "International Coastal Symposium, ICS 2016, Sydney, Australia" en marzo de 2016. 
- Artículo 4: "The Gigantism of Public Works in China in the Twenty-First Century" en la revista INDEXADA "Sustainability". PUBLICADO septiembre 2017.

Martín-Antón, M.; Negro, V.; del Campo, J.M.; López-Gutiérrez, J.S.; Esteban, M.D. (2017) "The Gigantism of Public Works in China in the Twenty-First Century". Sustainability, 9, 1581. Multidisciplinary Digital Platform Institute (MDPI). ISSN 2071-1050. doi:10.3390/su9091581

- Artículo 5: "Crown walls in mass and reinforced concrete: The way to aesthetics in maritime works" en el libro de ponencias del congreso internacional de doble arbitraje "ICE Conference Coasts, Marine Structures and Breakwaters 2017 (Liverpool, UK, september 2017)". PUBLICADO 2017

Negro, V.; Martín-Antón, M.; del Campo, J.M.; López-Gutiérrez, J.S.; Esteban, M.D. (2017) "Crown walls in mass and reinforced concrete: The way to aesthetics in maritime works". Proceedings of the ICE Conference Coasts, Marine Structures and Breakwaters 2017 (Liverpool, UK, September 2017). Thomas Telford Publishing.

Este artículo fue presentado como ponencia en el Congreso Internacional "ICE Conference Coasts, Marine Structures and Breakwaters 2017”, Liverpool, UK, septiembre 2017.

- Artículo 6: "Espaldones en hormigón en masa y armado. El camino hacia la estética en las obras marítimas" en el libro de ponencias del congreso nacional "XIV Jornadas Españolas de Ingeniería de Costas y Puertos, (Alicante, mayo 2017)". PUBLICADO 2017

Negro, V.; Martín-Antón, M.; del Campo, J.M.; López-Gutiérrez, J.S.; Esteban, M.D.; Revilla, Ignacio. (2017). "Espaldones en hormigón en masa y armado. El camino hacia la estética en las obras marítimas". Libro de ponencias de las XIV Jornadas Españolas de Ingeniería de Costas y Puertos, (Alicante 2017)

Este artículo fue presentado como póster en el Congreso Nacional "XIV Jornadas Españolas de Ingeniería de Costas y Puertos", Alicante, mayo 2017.

- Artículo 7: "Evolución del paisaje costero en Sydney (Australia)" en la revista no indexada "Revista de Obras Públicas". ACEPTADO PARA PUBLICACIÓN diciembre 2017.

Martín-Antón, M.; Negro, V.; del Campo, J.M. (2017) "Evolución del paisaje costero en Sydney (Australia)”, Revista de Obras Públicas, (2017). ISSN 0034 - 8619

\section{Capítulo 4: Conclusiones y futuras líneas de investigación}

Se exponen en este capítulo los principales argumentos, metas e hitos obtenidos a lo largo del trabajo, así como la propuesta de continuación de los mismos, derivado de los caminos explorados y que permiten alcanzar nuevos retos y techos en el desarrollo científico, técnico y humanístico.

\section{Capítulo 5: Referencias bibliográficas}

Se recogen las referencias de bibliografía empleadas en la redacción de los distintos artículos y en la memoria de la tesis.

\section{$\underline{\text { Apéndices }}$}

Finalmente se exponen una serie de apéndices donde se muestran los indicios de calidad (artículos publicados) y material relevante y sensible empleado en la elaboración del documento (gráficas y mapas y apéndice fotográfico). 


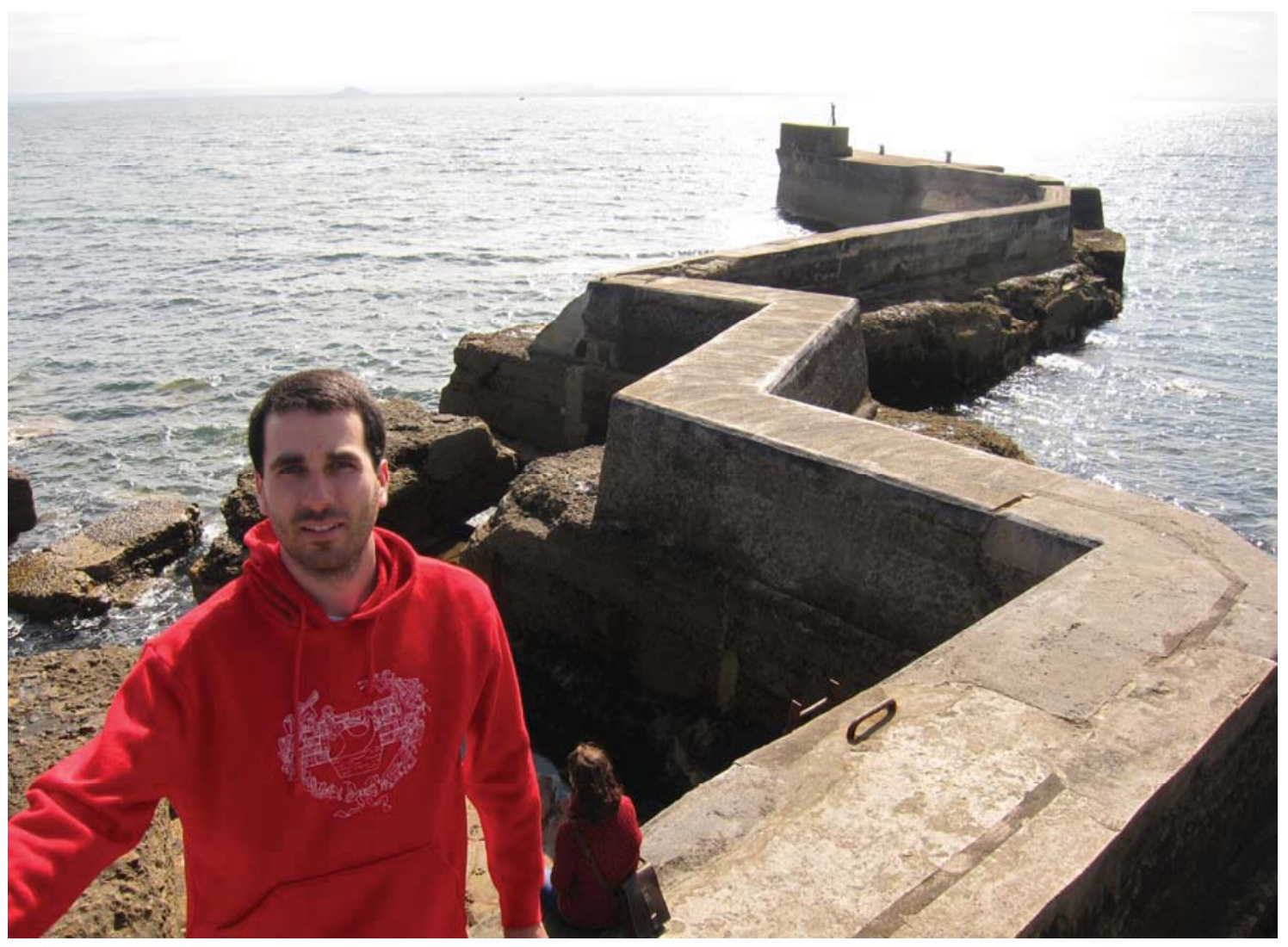

"Las tesis son como los diques o los barcos. Por muchos quiebros o cambios de rumbo que tengan, siempre llegan a buen puerto, sobre todo con un buen guía"

Mario Martín Antón, 2017 (Dique de St. Monans, Escocia) 


\section{CAPÍTULO 1: INTRODUCCIÓN Y OBJETIVOS}

\subsection{Introducción}

\subsubsection{El arte de construir}

Construir es un arte. Es la manifestación del ser humano de su vivencia, de su ahora, de su presencia en el territorio y la forma que se presenta en el mundo; por eso, el construir es ser y es la transformación del paisaje. El paisaje no existe sin el concepto de ser y estar en el territorio, no se concibe sin la presencia del ser humano.

Las civilizaciones nacieron lejos del mar, básicamente por el miedo a los agentes climáticos desconocidos y a la invasión. Cuanto más se acercaban al océano, avanzar desde tierra al agua era sinónimo de conquista, con ello, de poder. La historia demuestra que este paso es muy lento, atrevido y complicado técnicamente. Por eso, esta investigación es una profunda reflexión humana y de la relación con la ingeniería. Cuando Julio César hizo los cajones de Brindisi, a orillas del Adriático en la llanura salentina, no era para demostrar el control de las obras monolíticas o de las acciones del mar, sino para derrotar en tiempo récord a Pompeyo en la segunda guerra civil de la República, hecho además que no llegó a conseguir.

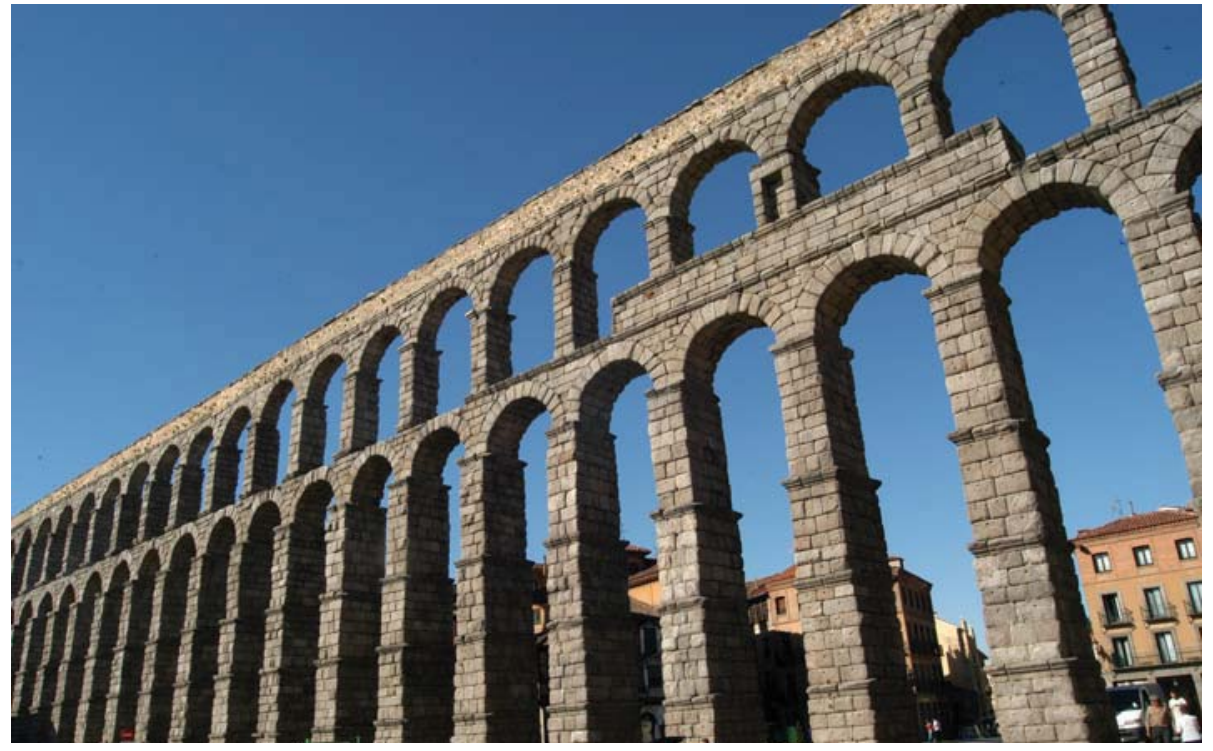

Figura 1: Acueducto Romano de Segovia (Foto: Mario Martín Antón)

El acueducto de Segovia (Figura 1) no nace (inicialmente) para mejorar las condiciones de vida de la población, sino como manifestación del poder, por tanto, de dominación. Es tan sencillo como analizar la historia de los ingenieros y ver que éstos pertenecían a cuerpos militares asociados primero a los emperadores en la antigua Roma (Julio César - Vitrubio), reyes en el Renacimiento (Carlos V - Juanelo Turriano) o a los cardenales (Richelieu - Melezeau). Por eso, parece que "lo nuevo es lo que ya está olvidado" como diría Alejo Carpentier. En España, la construcción nace bajo el Cuerpo de Ingenieros Militares que tienen su origen en 1711, mientras que los Ingenieros de Caminos aparecen en 1802, inspirados por la escuela francesa y el impulso de Agustín de Betancourt.

La ingeniería ha cambiado mucho desde sus orígenes, respondiendo a un estado evolutivo donde todos los círculos se cierran. Tal vez, el gigantismo asiático de hoy es el reflejo de la época romana de teatros, anfiteatros, circos, acueductos y obras de defensa. Langosteira con su puerto exterior abierto al Atlántico Norte es Caesar Augusta; el acueducto antiguo es hoy el 
propagandístico puente Russky en Rusia, pero el arte de construir es vertebrar un territorio y mejorar la calidad de vida de las personas.

La investigación nace sobre la reflexión del paisaje. Parte de la naturaleza y su percepción sensorial (no visual). Es un paisaje natural, desde el piornal cuando llega el verano en las montañas del Macizo Central de Gredos a la floración del cerezo en el valle del Jerte, o el olor a azahar en la Andalucía con sabor a sal y luz de oro.

El Mediterráneo no existe como tal, sino hubiese sido colonizado, por tanto, el territorio, el paisaje es la conexión con el ser humano. Se debe diferenciar de las componentes ambientales, e incluso de ordenación, porque lo que se hace es trasladar al medio físico su gestión, pretendiendo alcanzar una componente "sensible". Se gestiona territorio para generar percepción, con ello, paisaje.

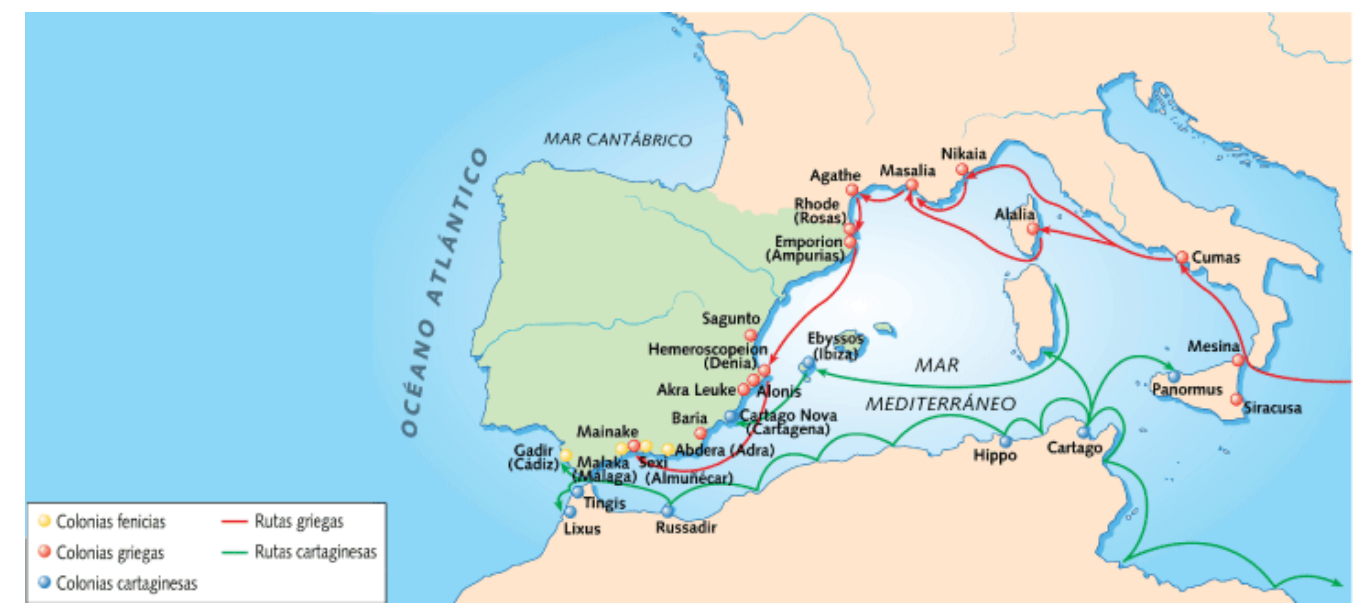

Figura 2: Poblaciones fenicias, griegas y cartaginesas del Mar Mediterráneo (Fuente: sites.oxy.edu)

Los asentamientos humanos empezaron a observar la naturaleza, básicamente con sorpresa y miedo. Es lo que se ha llamado etapa de sumisión. Las ciudades hoy marítimas estaban a varios kilómetros de la orilla del mar, Gandía, Valencia, Argel son algunos ejemplos de ello (Figura 2). Temporales, tormentas, piratas, invasiones, esclavos, guerras hicieron buscar promontorios, cabos, ensenadas, abras, bahías, radas, sitios elevados para protegerse y vigilar. El ser humano quiso navegar pero tardó muchos miles de años, hasta que en el 9000 a.C. los egipcios bordearon el litoral con maderas atadas y remos.

No se pretende hacer una historia de las civilizaciones ni de la navegación, sino de las etapas de percepción del medio físico, que pasa de "sitio" a "lugar" (en inglés, de "site" a "place"), de inerte a alma, al espíritu protector de lugar, al "genius loci" romano.

El progreso intelectual implica la pérdida del miedo. Las civilizaciones tienen tres motores espirituales: amor, tiempo y muerte. Tienen, además, dos formas de reacción: amor y miedo; pero su capacidad de olvido es instantánea.

Tras una profunda etapa de sumisión, se pasó a la adaptación, fundamentalmente, por la observación del ser humano de la naturaleza, la optimización de sus recursos defensivos y la combinación con los productos que se podría encontrar en los sitios que encontraba tras abandonar el nomadismo. Hay que defenderse bien, pero además hay que comer y desarrollar la agricultura. La naturaleza es un lugar para la emoción, para la creación artística, ambiental y respetuosa. El hacerse sedentario, el aumento de la población y el concepto de higiene (ingeniería sanitaria, recogida de fecales y depuración de las aguas residuales) fueron pequeños hitos en la historia de la humanidad, en la vertebración del territorio. 
Julio César no pensaba en el puente, sino en llegar a la orilla del río en el episodio del Rubicón. Pero, aparece la geometría del lugar, la aplicación algebraica de la obra y el sitio, para transformar en lugar en una aplicación biunívoca o biyectiva que relaciona la obra con el sentido, la construcción con el sentimiento, el encaje con el hola y adiós. Ejemplos de obra y emoción se recogen a continuación en estas puertas abiertas al concepto de paisaje natural paisaje construido.

\begin{tabular}{|c|}
\hline Ciudad - vivencia \\
Castillo - Defensa \\
Monasterio - Percibir el silencio \\
Camino - Movilidad \\
Puente - Vecindad \\
Puerto - Protección, refugio \\
Faro - Centinela del mar, guía \\
Presa - Almacenamiento de recursos \\
Túnel - Acortar distancias \\
\hline
\end{tabular}

Esta investigación, por tanto, es una indagación sobre el paisaje, su trascendencia y cómo el ser humano "ataca" la naturaleza sin respeto ni profundidad. El ser humano se preocupa de ella, sin darse cuenta que su contemplación imprime directamente la idea de dios; la instrumentaliza y preserva después de "destrozarla" durante etapas bajo nuevas doctrinas de salvaguardar el planeta o de nuevas amenazas entre las que se engloba el cambio climático.

\subsubsection{Obras Civiles y Obras Públicas}

Las construcciones para mejorar la sociedad siempre se han hecho buscando su beneficio. El concepto de Obra Civil y Obra Pública se suele utilizar indistintamente y en la actualidad tiene el mismo significado a efectos prácticos. Anteriormente había algún matiz que era importante.

Hasta hace dos siglos, el gran desarrollo en infraestructuras de cada estado o imperio se realizaba con fines militares fundamentalmente. Por eso los primeros ingenieros eran militares. En 1711 se produjo en España la creación del Cuerpo de Ingenieros (militares) por Jorge Próspero de Verboom, bajo el reinado de Felipe V.

En 1747 se crea la primera Escuela de Ingeniería Civil en el Mundo, la "École Royale des Ponts et Chaussées" de París, por Daniel-Charles Trudaine. En nuestro país se tuvo que esperar hasta el año 1802 para que el canario Agustín de Betancourt creara la primera Escuela de Ingeniería Civil en España, la "Escuela Oficial del Cuerpo de Ingenieros de Caminos", siendo la "Escuela Técnica Superior de Ingenieros de Caminos, Canales y Puertos de la Universidad Politécnica de Madrid" su heredera.

En cuanto al concepto de Obra Pública, en contraposición a "obra privada", se entiende como trabajos de construcción, infraestructuras o edificación, promovidos por una administración pública teniendo como objetivo el beneficio de la comunidad. Las obras públicas pueden ser:

- Infraestructuras de transporte: carretera, ferroviario, marítimo, fluvial, aéreo, y conductos.

- Estructuras, generalmente para las infraestructuras de transporte: puentes, túneles, etc.

- Infraestructuras hidráulicas y energéticas: presas, depuradoras, centrales de producción de electricidad, aerogeneradores, etc.

- Infraestructuras urbanas: calles, urbanismo, servicios urbanos, etc.

- Edificios públicos, estructuras de edificación. 
Una característica de las Obras Públicas es que son obras técnicas. Se requiere un conocimiento para su diseño y construcción, que se adquiere en la actualidad en las Escuelas Técnicas Universitarias. Esas enseñanzas proporcionan atribuciones profesionales como Ingeniero de Caminos, Canales y Puertos, Ingeniero de Obras Públicas, Ingeniero Civil, etc. Otro aspecto de las obras civiles es que están reguladas por normativa y reglamentos técnicos, sin los cuales no se podría llevar a cabo ninguna construcción de ese tipo según la legislación actual. Estos son Instrucciones de Hormigón y Acero (EHE, EAE), Recomendaciones de Obras Marítimas (ROM), Eurocódigos, Instrucciones de Carretera, Código Técnico de la Edificación, etc.

\subsubsection{La utilidad de las Obras Públicas}

El principal motivo de la construcción de las diferentes estructuras, infraestructuras de transporte o hidráulicas es que sean útiles para la sociedad y que mejoren la calidad de vida de los ciudadanos.

En un principio, una obra civil se construye para uno o varios fines: un puente para cruzar un río o canal (Figura 3), una presa para acumular agua (Figura 4), un dique para proteger un puerto, etc. $\mathrm{O}$ incluso una fuente para dar agua (Figura 5) o un centro para reciclar residuos (Figura 6).

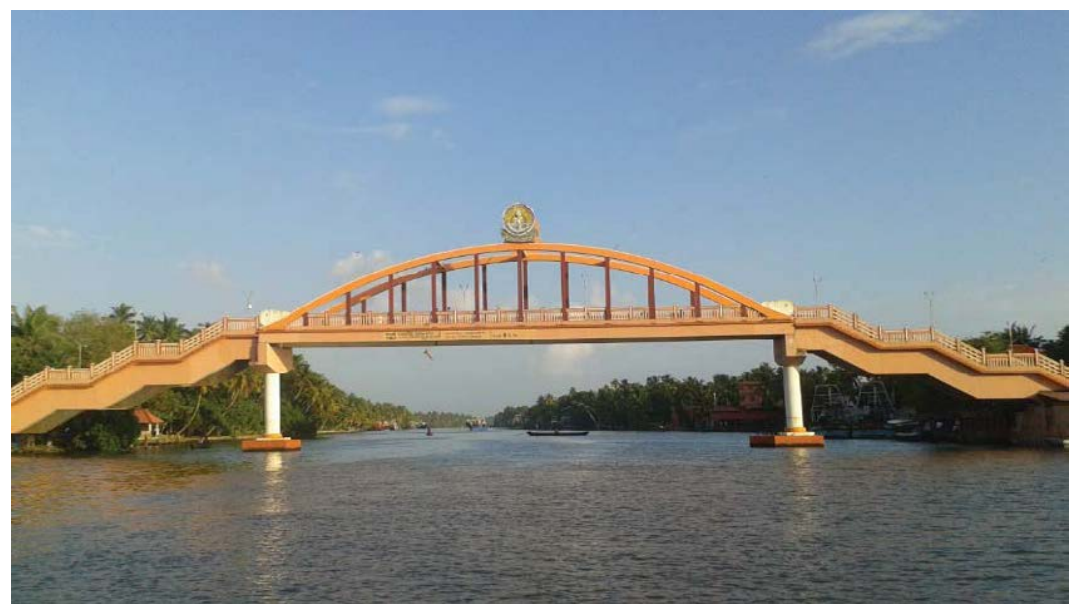

Figura 3: Puente de Amritapuri, India. Motivos: paso del canal y vía de evacuación frente a tsunamis (Foto: Mario Martín Antón)

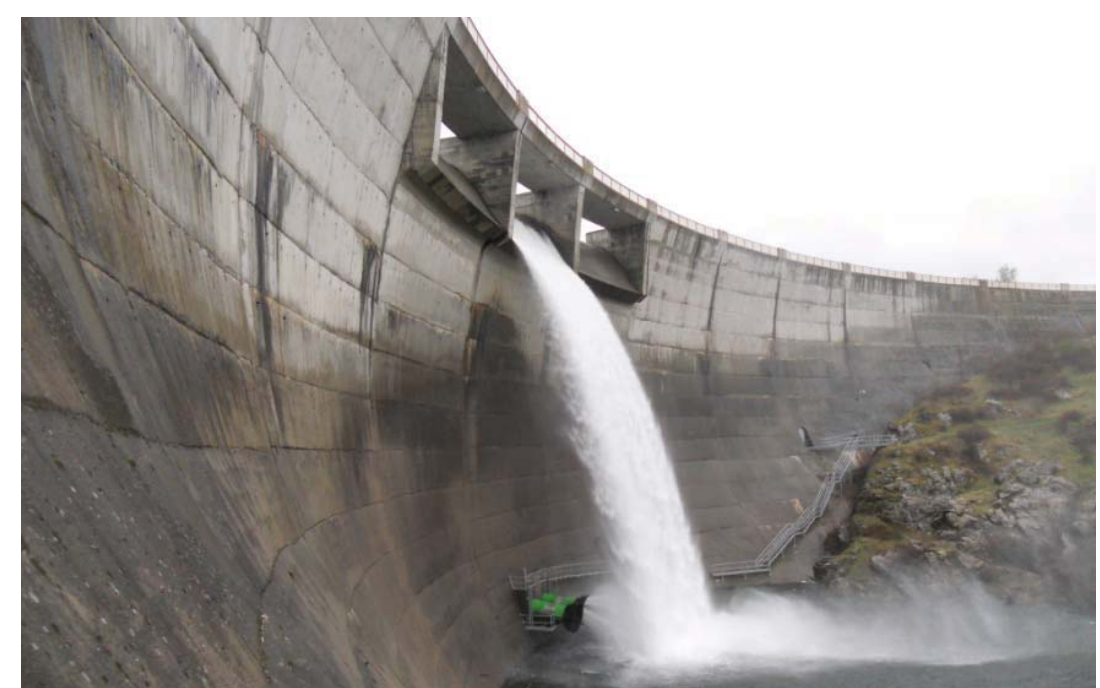

Figura 4: Presa del Pontón Alto, Segovia. Motivos: almacenamiento y regulación de agua (Foto: Daniel de Miguel Lobo) 


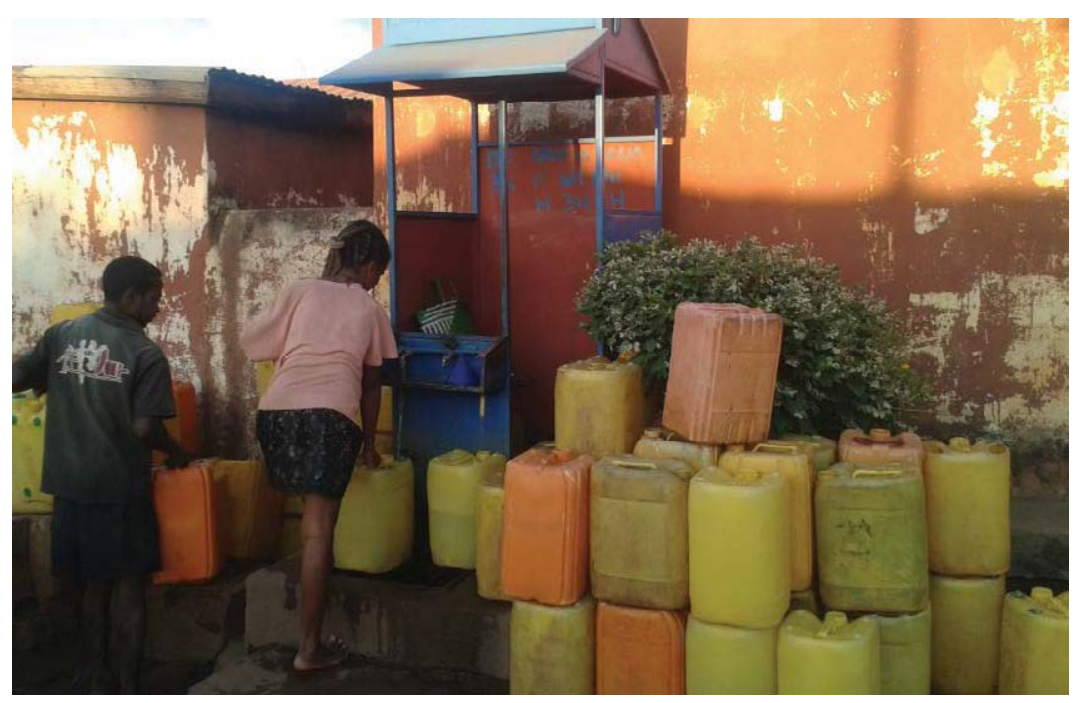

Figura 5: Fuente pública en Tsiroanomandidy, Madagascar. Motivos: proporcionar agua potable y evitar enfermedades a la población (Foto: Mario Martín Antón)

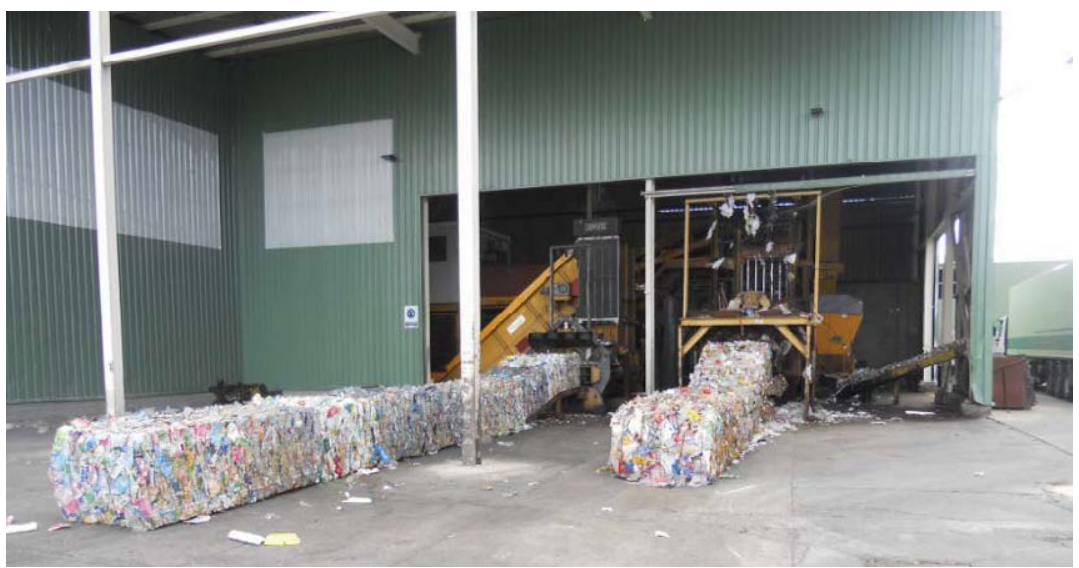

Figura 6: Planta de tratamiento de residuos de Los Huertos, Segovia. Motivos: reciclaje y eliminación de residuos (Foto: Daniel de Miguel Lobo)

La finalidad de las obras públicas no siempre perdura en el tiempo. Al igual que un edificio de oficinas que con los años se destina a un hotel, por ejemplo, lo mismo pasa con las infraestructuras, aunque en menor medida. Ese cambio genera otra simbología asociada, a veces con más fuerza que la anterior. El ejemplo más claro son las Vías Verdes (Figura 7), que transforman líneas de ferrocarril en desuso en carriles ciclistas y pedestres, eliminando parte de la infraestructura (catenaria, raíles, balasto), pero no así los puentes, túneles y plataforma. Muchos diques y muelles quedan en desuso cuando los nuevos superpuertos son expulsados de la ciudad. Muchas dársenas de mercancías se "refinan" y son destinadas para embarcaciones deportivas, y las naves se convierten en centros comerciales. Lo mismo pasa con estaciones de tren (Figura 8). Los túneles en desuso son un problema por la falta de seguridad. En el caso de túneles de ferrocarril, se pueden cerrar como ocurrió con el túnel de La Engaña o destinar a otros fines como el túnel de Somport, que ahora alberga el Laboratorio Subterráneo de Canfranc. Muchos depósitos de agua en desuso también se pueden emplear para otra cosa muy diferente, como por ejemplo sala de exposiciones (Figura 9). Otras infraestructuras como vías de ferrocarril urbanas y aeropuertos se han convertido en parques (Figura 10). O calles utilizadas durante años para vehículos de motor que han pasado a utilizarse exclusivamente por bicicletas (Figura 11). En episodios de guerra cuando el funcionamiento de muchas infraestructuras estaba parado, muchas instalaciones servían de refugio, como los túneles del Metro. 


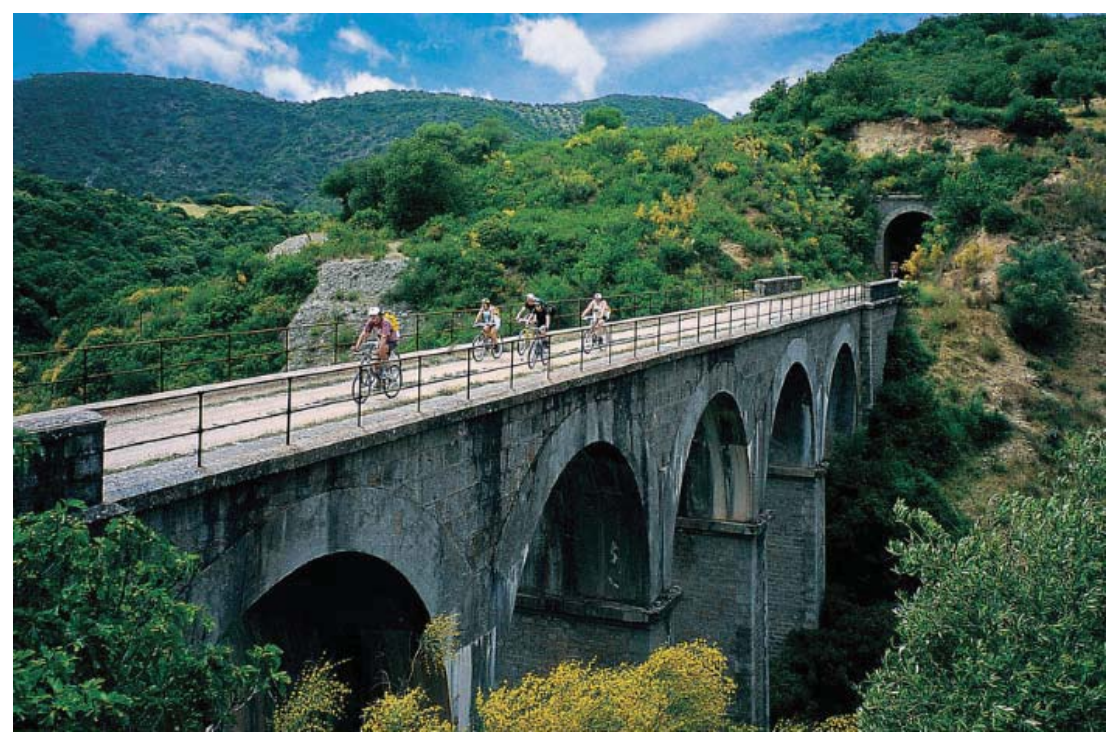

Figura 7: Vía Verde de la Sierra, Cádiz (Foto: viasverdes.com)

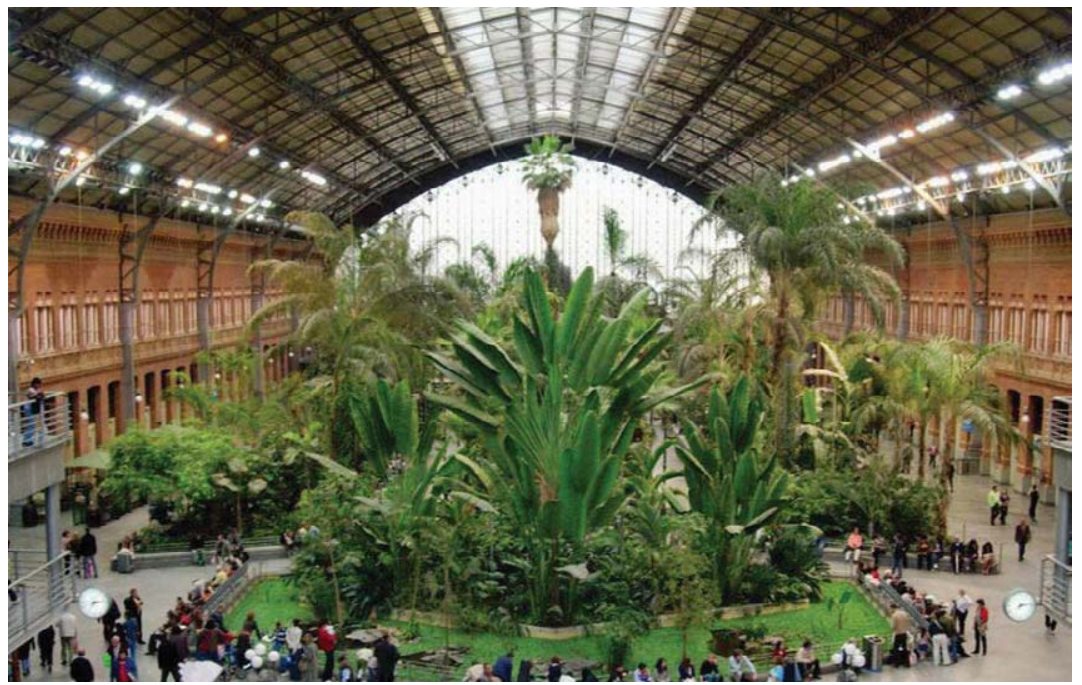

Figura 8: Jardín en la estación de Atocha, Madrid (Foto: Marta Pilar, minube.com)

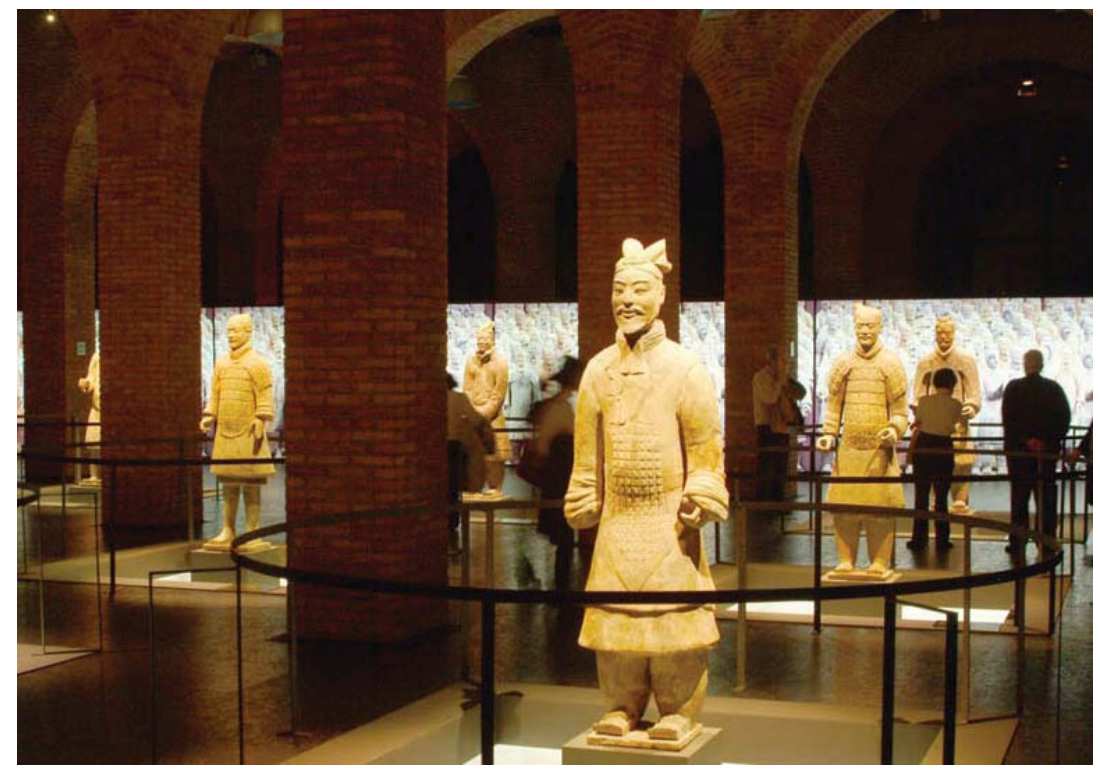

Figura 9: Sala de exposiciones del antiguo depósito de agua de Plaza de Castilla, Madrid (Foto: Canal de Isabel II) 


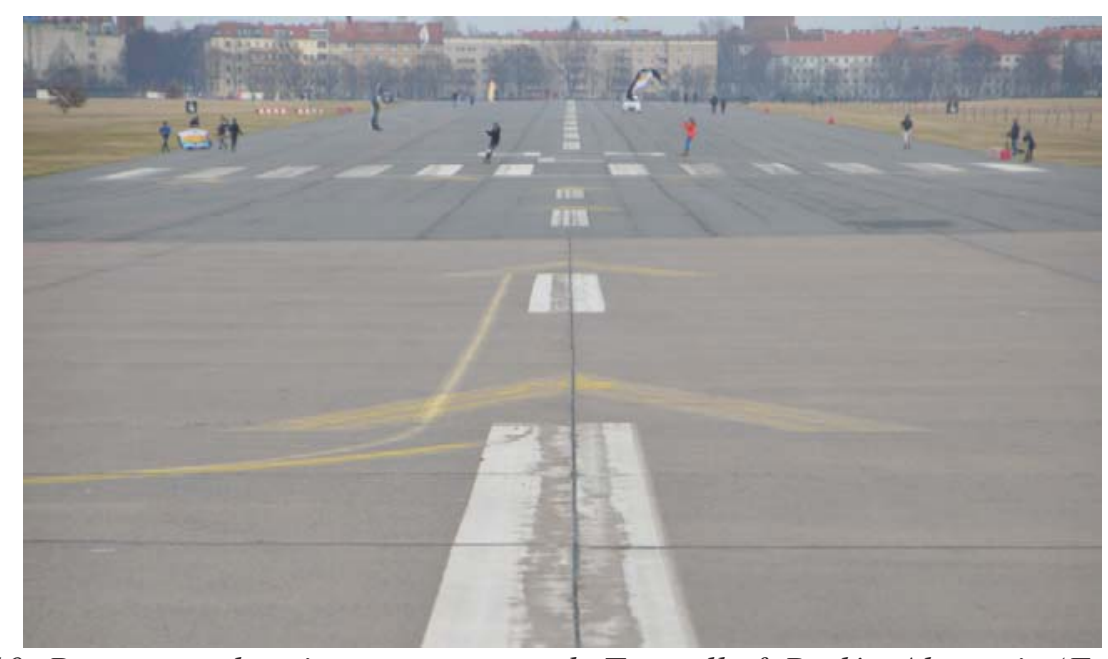

Figura 10: Parque en el antiguo aeropuerto de Tempelhof, Berlín, Alemania (Foto: Mario Martín Antón)

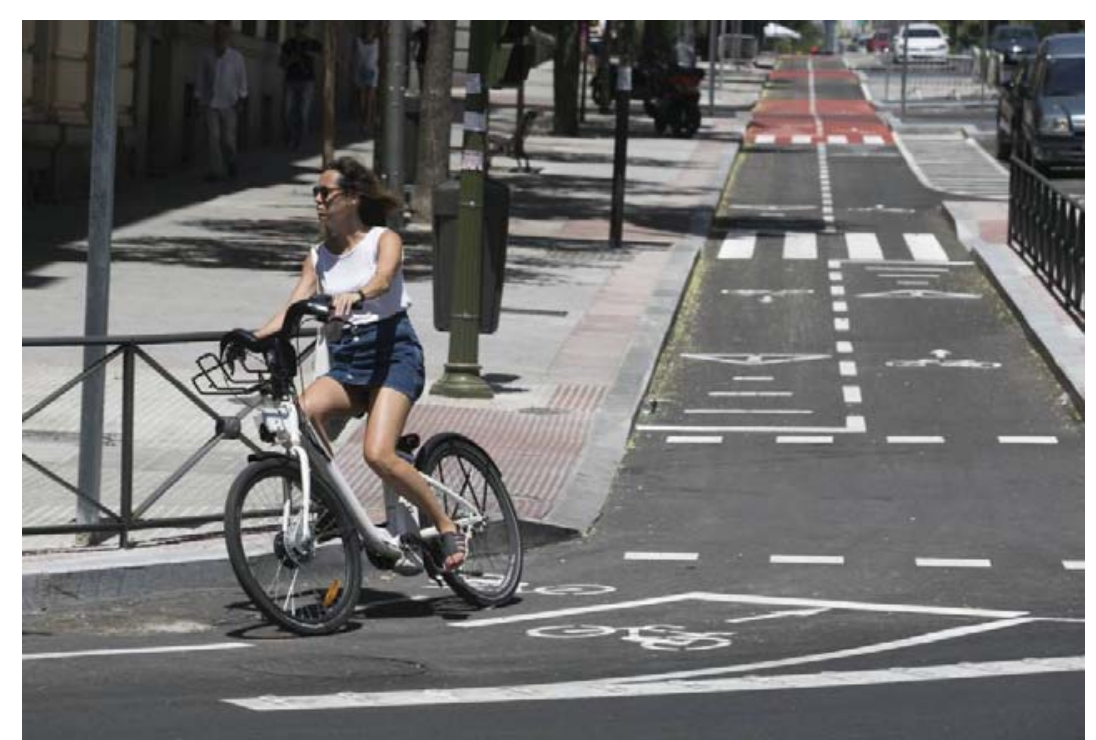

Figura 11: Carriles bici ocupando antiguos carriles de vehículos de motor, Madrid (Foto: madridiario.es)

\subsubsection{Ingeniería Civil y Sociedad: La simbología de las Obras Públicas}

La finalidad de las Obras Públicas, que es la utilidad, a veces puede sobrepasar ese concepto y llegar más lejos. Las obras públicas pueden adquirir un significado mucho mayor, ya sea como símbolo de una ciudad o zona, seña de identidad de un grupo social, monumento, elemento propagandístico, etc. Es lo que produce la relación entre la ingeniería civil y la sociedad y puede verse reflejado en actos sociales, políticos, deportes, cine, emisiones oficiales, monedas, billetes, sellos, etc.

\subsubsection{Las obras Públicas en el deporte}

Muchos son los acontecimientos deportivos que utilizan importantes obras civiles para ser el "escaparate" al mundo. Los deportes son retransmitidos en televisión y también en los periódicos y en internet se pueden encontrar imágenes y vídeos que reflejan lo importante que puede resultar combinar deporte e ingeniería. La prestigiosa Maratón de Nueva York empieza en el Puente Verrazano del ingeniero Othmar Ammann (Figura 12). También hay carreras que 
cruzan otros puentes como las medias maratones de Lisboa (25 de Abril y Vasco de Gama), el Tour de Francia acaba en la Avenida de los Campos Elíseos y en el circuito final se puede disfrutar del urbanismo parisino de Haussmann (Figura 13), los altos y empinados puertos de los Alpes y Pirineos sirven para dar dureza a las grandes carreras ciclistas (Figura 14). En los Juegos Olímpicos o Mundiales de fútbol se construyen estadios con unas estructuras impresionantes (Pekín 2008, Londres 2012, Qatar 2022), también los nuevos grandes circuitos de velocidad han construido estructuras impresionantes (China, Malasia, Abu Dhabi, Bahrein) (Figura 15) o reutilizado otras como puertos y aeropuertos (GP de Mónaco, GP de Europa en Valencia, Formula E en Tempelhof, Berlín), el Red Bull Air Race se celebra en algunas carreras cerca o por debajo de puentes famosos (Budapest, Porto), etc. Y, por supuesto, los puertos deportivos. El puerto deportivo de Valencia para la Copa del América en 2007 y 2010 y sus modernas instalaciones son un ejemplo de cómo el deporte puede cambiar un puerto y una ciudad (Figura 16).
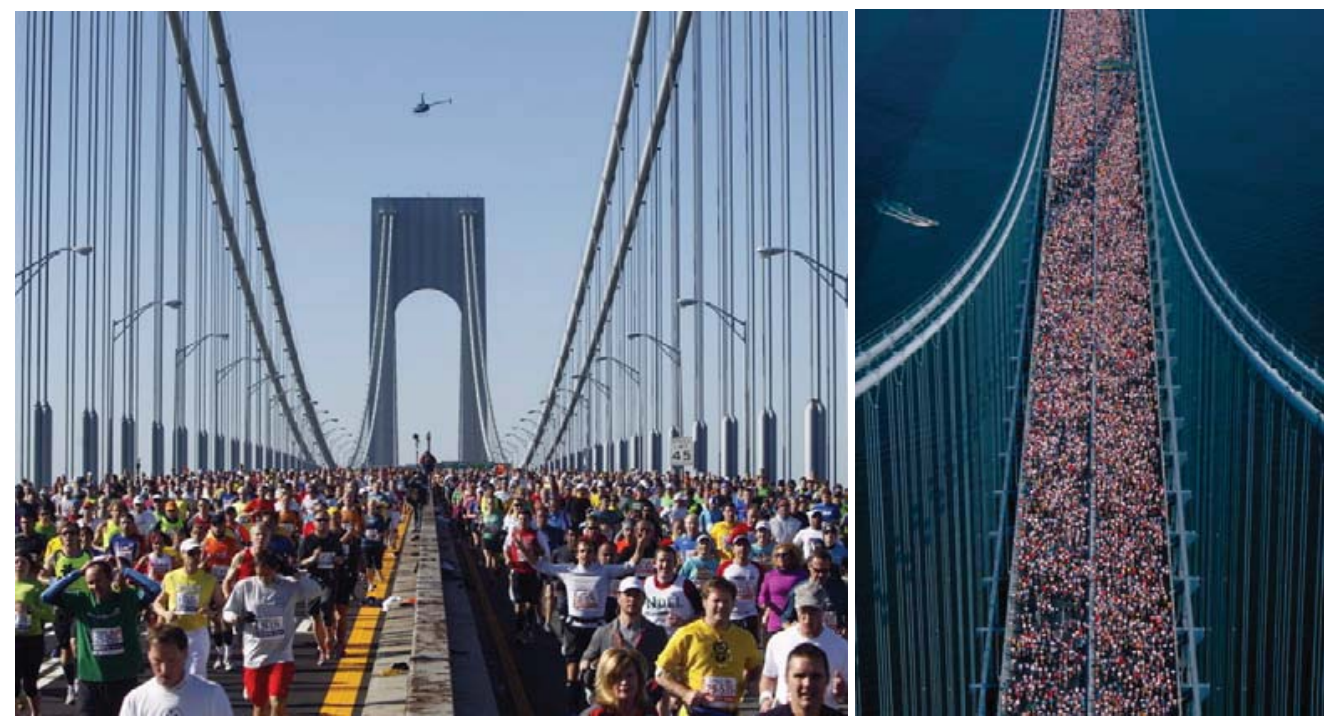

Figura 12: Puente Verrazano en la maratón de Nueva York (Foto: silive.com y jakerajs.photoshelter.com)

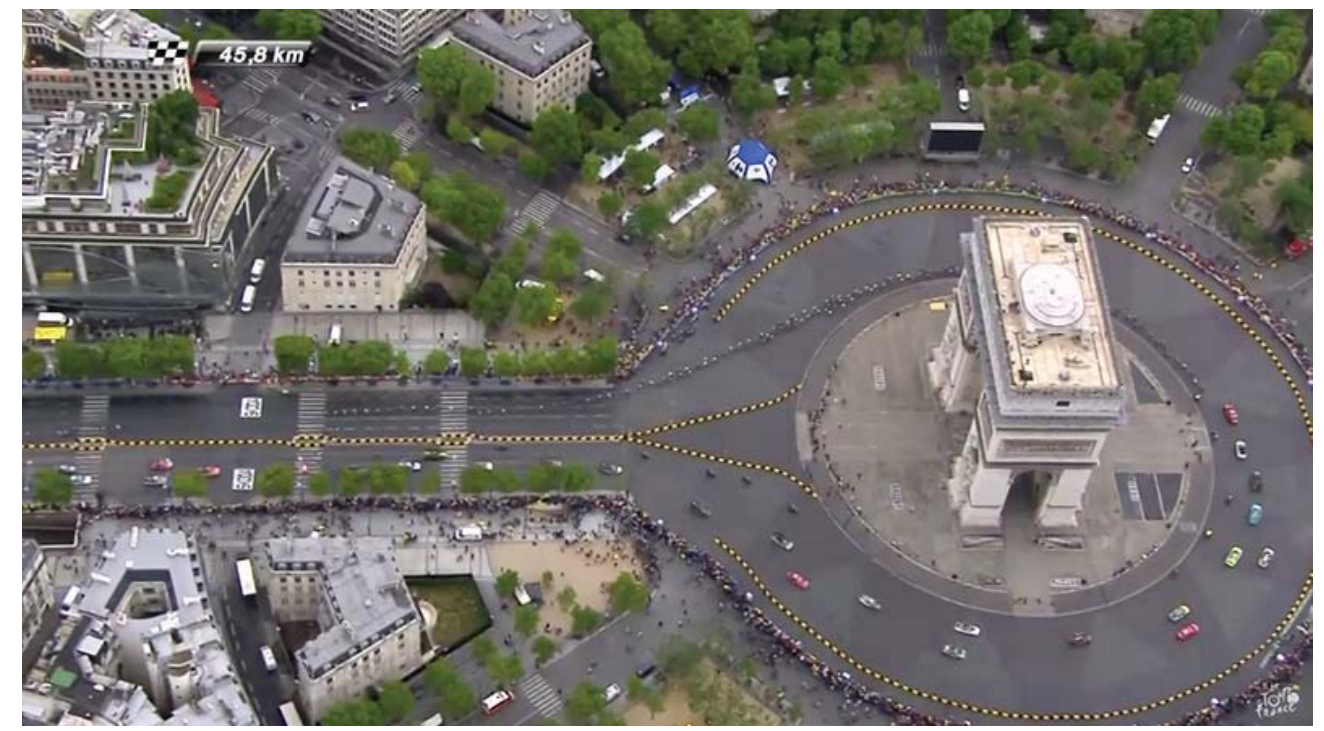

Figura 13: Pelotón del Tour de Francia en la última etapa en los Campos Elíseos-Arco del Triunfo (Foto: Le Tour de France) 


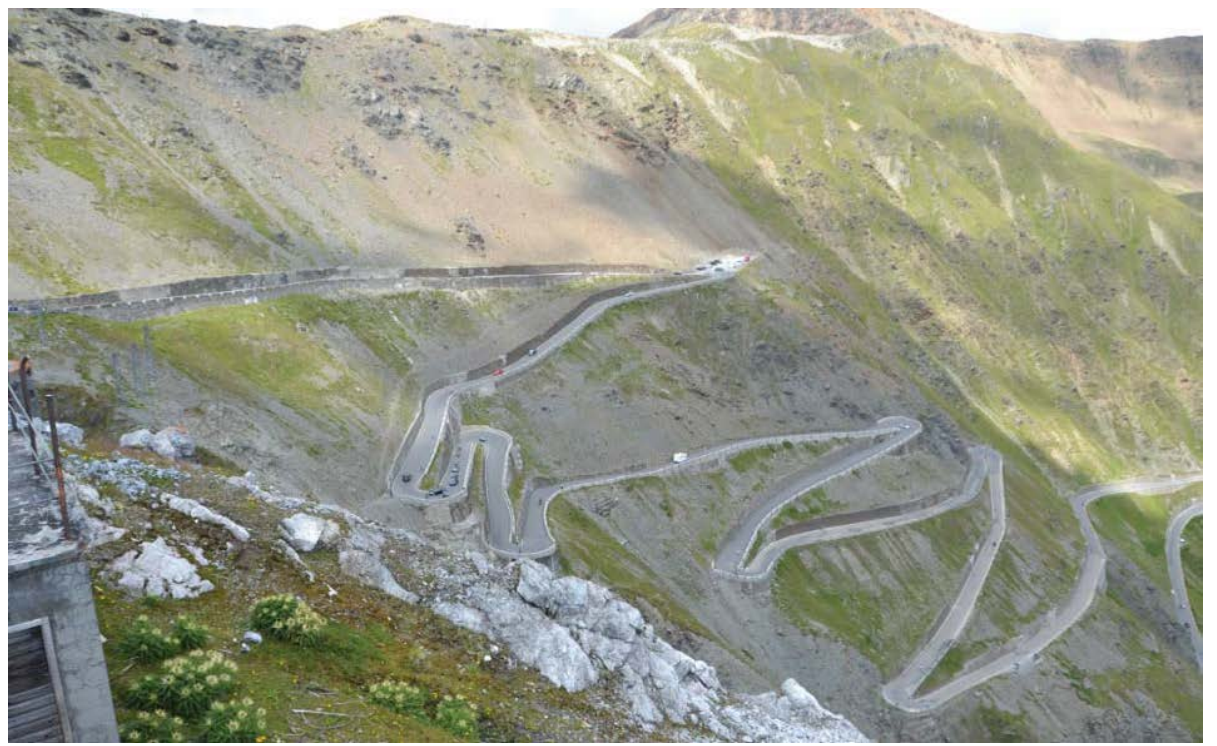

Figura 14: Passo Stelvio, Cima Coppi del Giro de Italia (Foto: Guillermo Martín Antón)

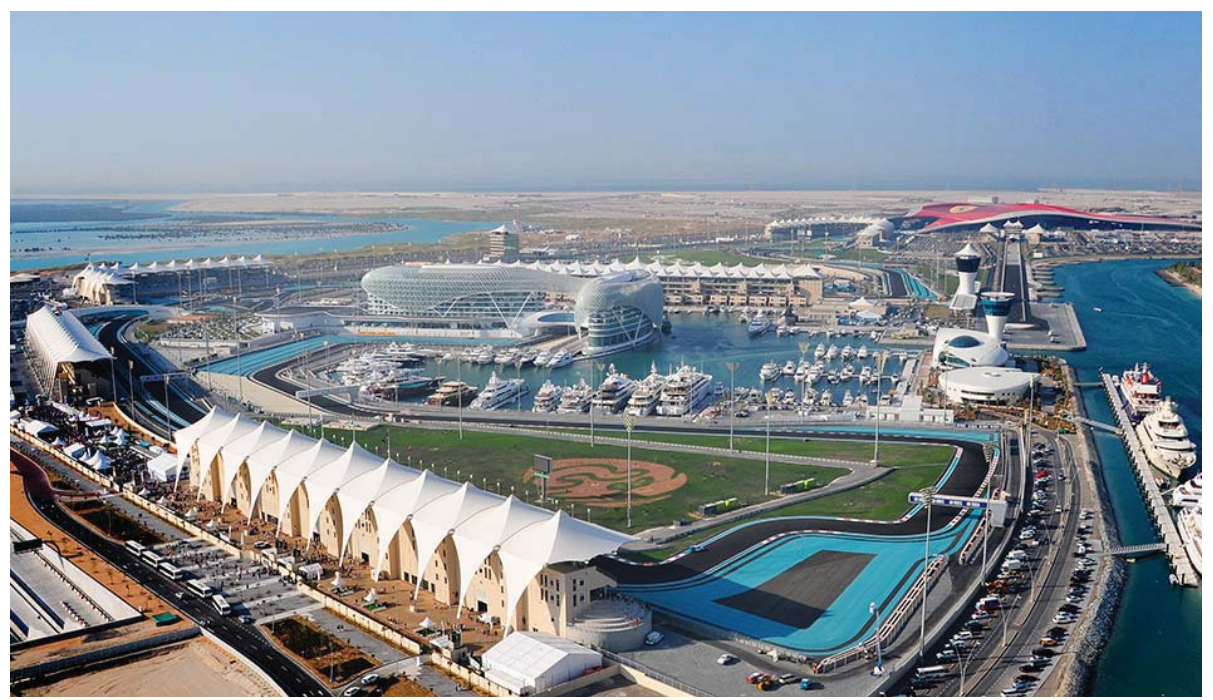

Figura 15: Circuito y puerto de Yas Marina en Abu Dhabi (Foto: desertrosetourism.com)

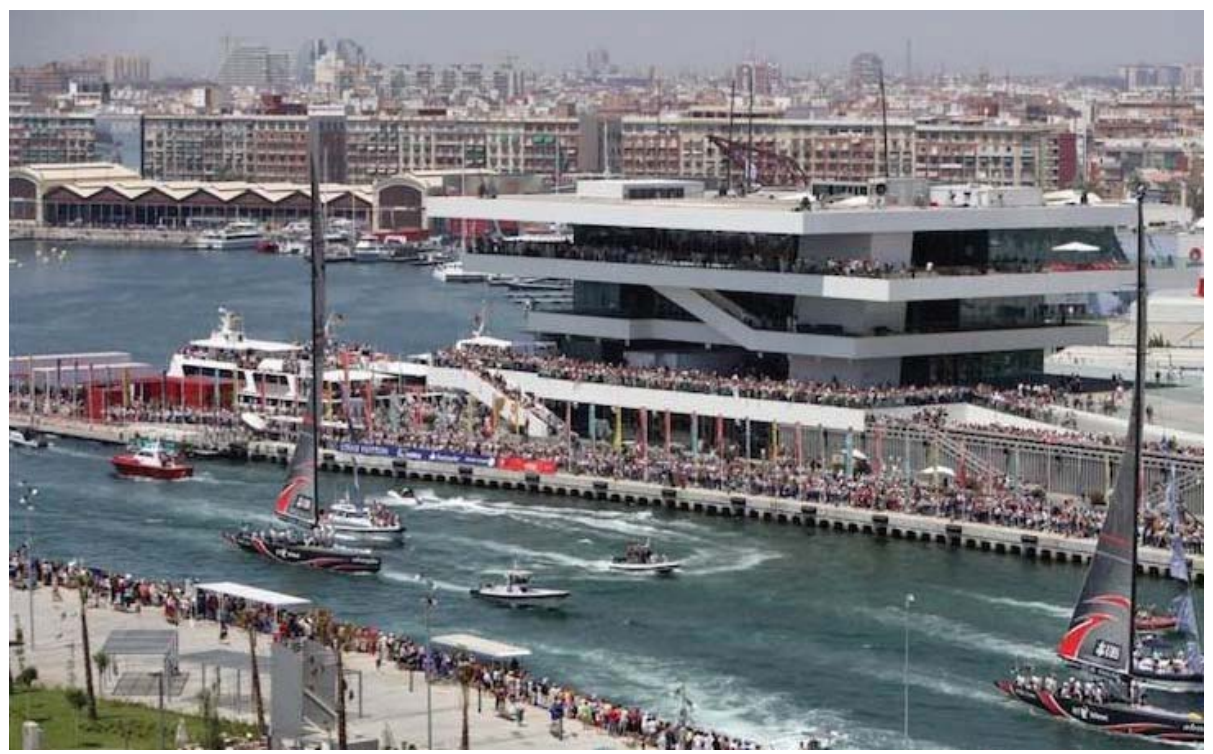

Figura 16: Puerto Deportivo de Valencia de la Copa del América 2007 (Foto: nauticalnewstoday.com) 


\subsubsection{Las Obras Públicas en el Cine}

La literatura desde hace varios siglos y el cine, desde hace poco más de 100 años, ha sido un buen método de transmisión de información a la ciudadanía. Sobre todo, el cine es un escaparate perfecto para promocionar cualquier cosa. Por eso, muchas veces los escenarios de las películas han tenido relación con las Obras Públicas. En 1896 los hermanos Lumière proyectaban la película "L'Arrivée d'un train à La Ciotat", que muestra durante un minuto con imagen fija cómo llega un tren a una estación y la gente baja al andén. "Panorama pris d'un train en marche", de Georges Méliès, se filmó en 1898 con una cámara situada en lo alto de un vagón de un tren. Edwin S.Porter, en 1903 estrenaba "The great train robbery", la primera película que articuló un lenguaje audiovisual con un guión coherente, que se desarrolla en un tren. El tren y el cinematógrafo constituían la apertura a una nueva sociedad y esto se le transmitía al espectador. La obra civil y la ingeniería que la hace posible son un referente clásico de la cultura cinematográfica. Muchas de las películas realizadas han tenido la facultad de hacer llegar a la sociedad la problemática que las obras y actuaciones de los ingenieros han generado a lo largo de la historia.

En 1925 aparece "El Acorazado Potemkin" del ruso Sergei M. Eisenstein que, aunque discurre en un barco la mayor parte del tiempo, también está rodada en el puerto de Odessa. "Metrópolis" de Fritz Lang en 1927 supone una revolución en el cine de ciencia ficción, con mucha relación a la arquitectura y a la ingeniería industrial, pero también con la civil, ya que relata el funcionamiento de una gran ciudad, los que mandan arriba y los que trabajan abajo.

Posteriormente, los puentes, sobre todo, fueron y siguen siendo los protagonistas de muchas películas. Sobre todo el Golden Gate de San Francisco y el Puente de Brooklyn de Nueva York. También se han hecho películas o series ambientadas en aeropuertos, carreteras, trenes, túneles, etc. El caso más importante de una Obra Pública española en el cine es, sin duda, la presa de Aldeadávila, que apareció en "Doctor Zhivago" en 1965 (Figura 17).

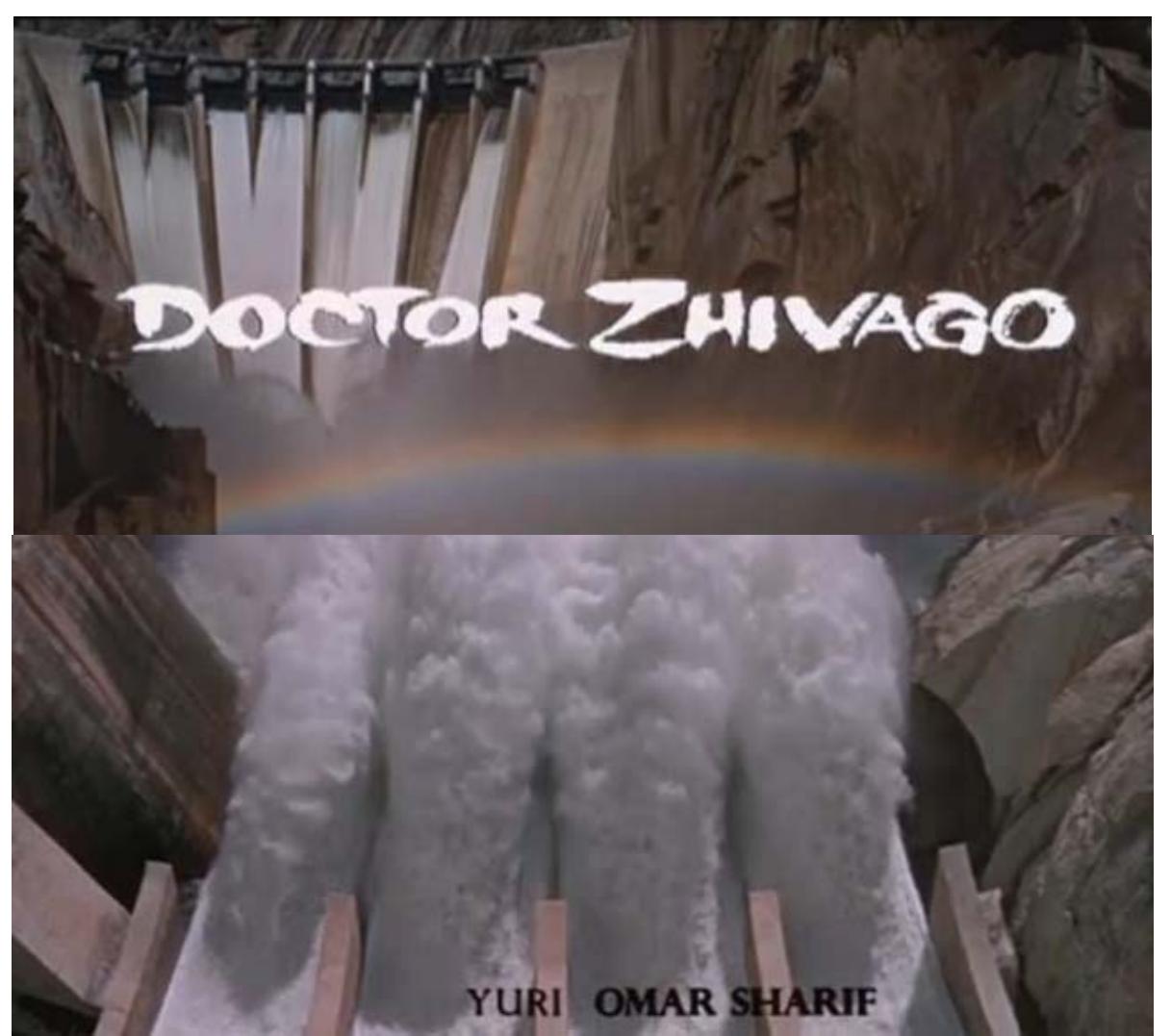

Figura 17: Escena final de Doctor Zhivago en Aldeadávila (Fuente: filmaffinity.com) 
Estos son carteles y escenas de algunas películas o series en los que aparecen Obras Públicas, puentes en concreto, muchas de ellas con el Golden Gate de San Francisco (Figura 18).
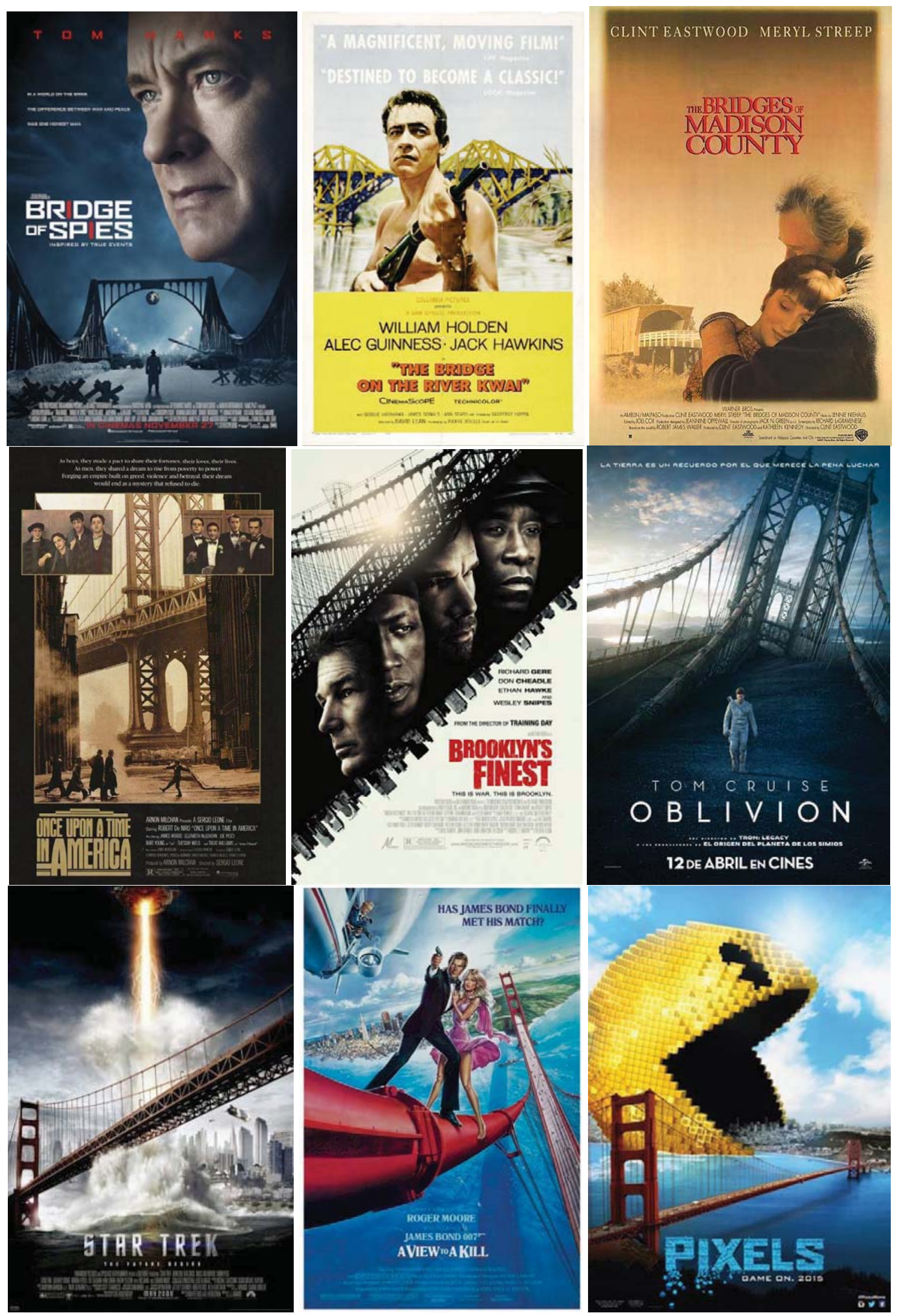

Figura 18: Carteles de películas con puentes (Fuente: filmaffinity.com) 


\subsubsection{Las Obras Públicas en la música}

La música no puede transmitir con esa facilidad esa pasión por las obras civiles, ya que no es visual. Igualmente, en algunas portadas de discos o títulos se pueden hacer referencias a algunas de ellas. Hay un caso muy interesante, que no tiene relación con una Obra Pública realizada por el hombre sino por una formación geológica que parece un túnel con hastiales regulares: Es la cueva de Fingal en la isla de Staffa (Escocia). Allí Mendelsohn se inspiró para componer en 1830 la Obertura de Las Hébridas. Por ejemplo, una portada mítica de la historia de la música es "Abbey Road", de los Beatles en 1969, con los cuatro integrantes del grupo cruzando un paso de cebra cercano a los estudios de grabación (Figura 19).

\section{MENDELSSOIIN}
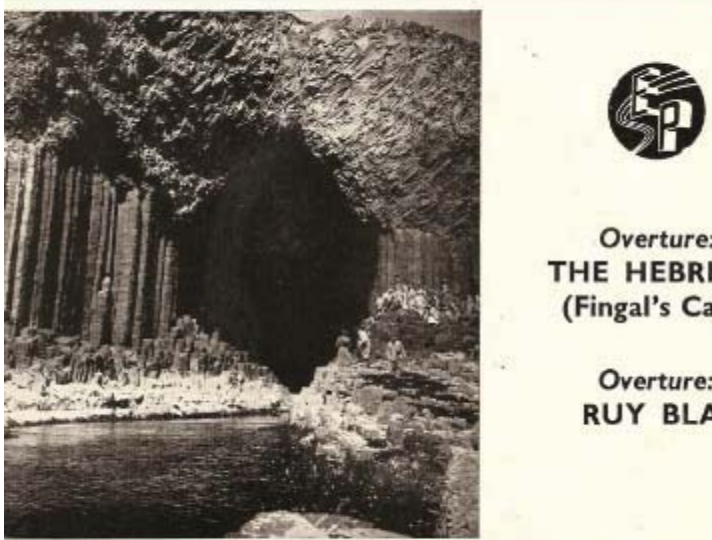

Overture:

THE HEBRIDES

(Fingal's Cave)

Overture:

RUY BLAS

\section{DIMITRI MITROPOULOS}

PHILIPS

THE PHILHARMONIC-SYMPHONY ORCHESTRA OF NEW YORK

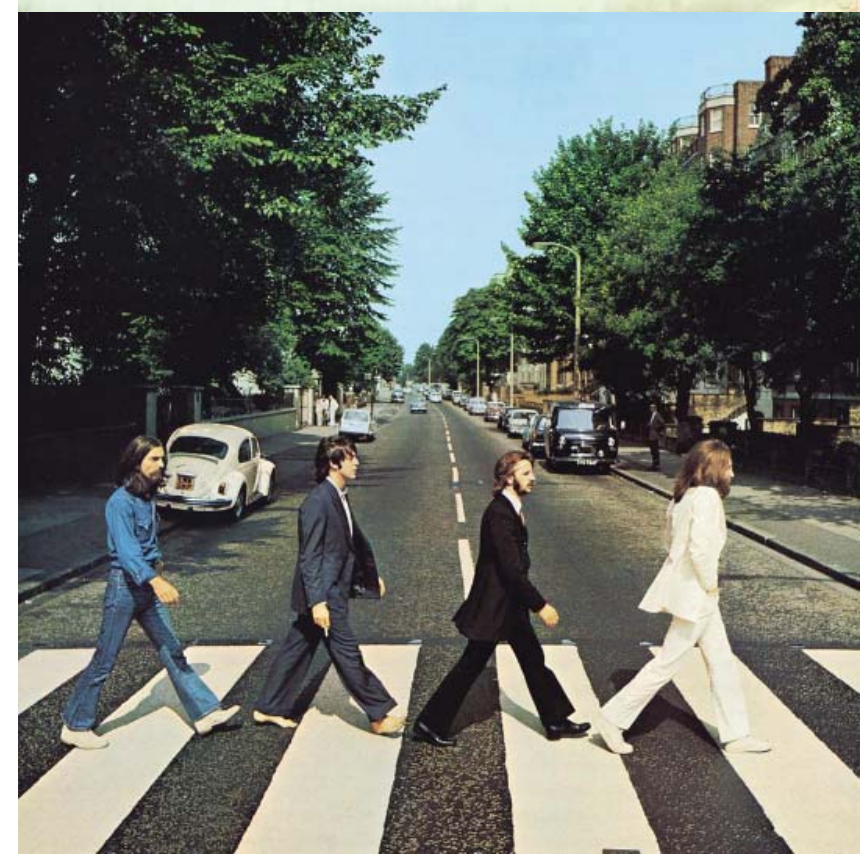

Figura 19: Ejemplos de portadas de discos con Obras Públicas (Fuente: billboard.com) 


\subsubsection{Las Obras Públicas en emisiones oficiales}

En la numismática y la filatelia también son muy importantes las Obras Públicas. Las monedas, billetes y sellos, que representan la parte más importante de emisión de la Fábrica Nacional de Moneda y Timbre, en el caso de España, son un buen "escaparate" para mostrar los distintos tipos de obras civiles de un país. Los reversos de los billetes de Euro muestran puentes de diferentes épocas, muchos sellos conmemoran aniversarios de grandes infraestructuras, las monedas son a veces diseñadas con puentes porque tienen perfiles fácilmente resaltables, etc. Incluso los documentos de identidad pueden hacer gala de las infraestructuras de un país, como es el caso del nuevo Pasaporte de España, donde en 2015 sustituyeron el tema "fauna" de las hojas de visados por el tema "medios de transporte españoles". En la última hoja aparece el nuevo tren AVRIL de Talgo y el transbordador de Leonardo Torres Quevedo del Monte Ulia en San Sebastián (Figura 20).

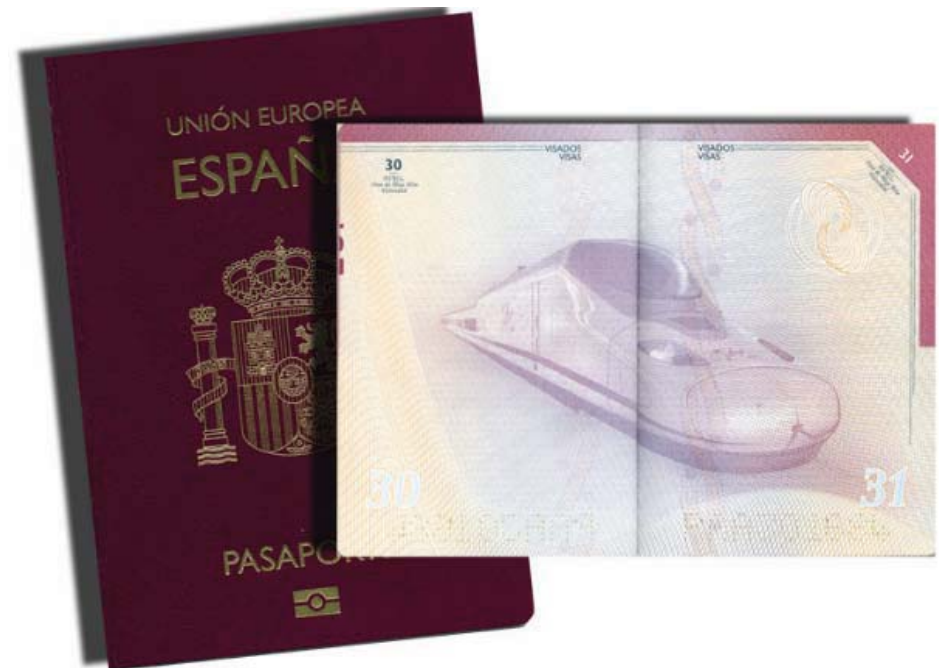

Figura 20: Tren AVRIL en el Pasaporte español (Foto: vialibre-ffe.com)

A continuación, se muestran ejemplos de sellos (Figura 21), monedas (Figura 22) y billetes (Figura 23) con motivos relacionados con la Ingeniería Civil.

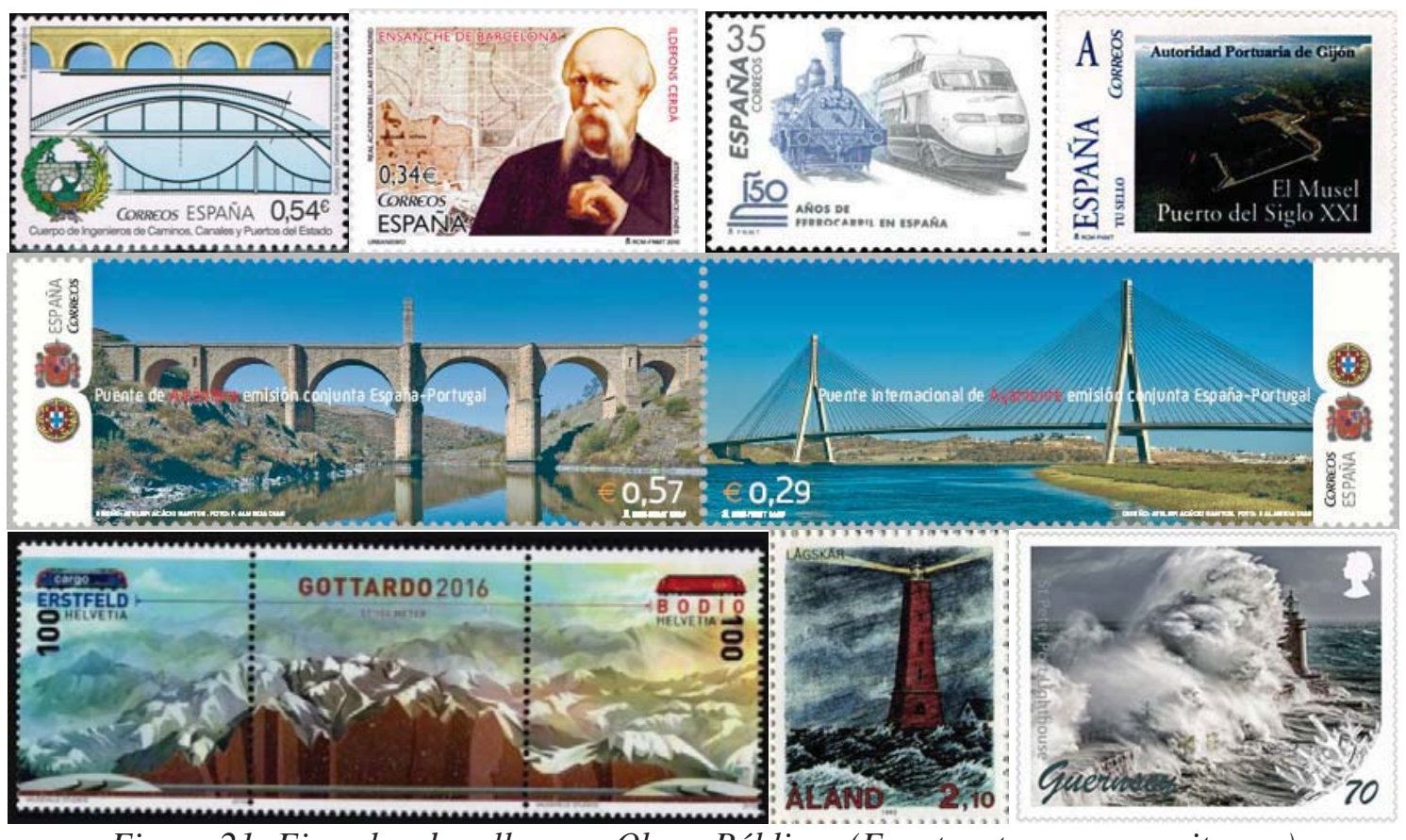

Figura 21: Ejemplos de sellos con Obras Públicas (Fuente: stampcommunity.org) 


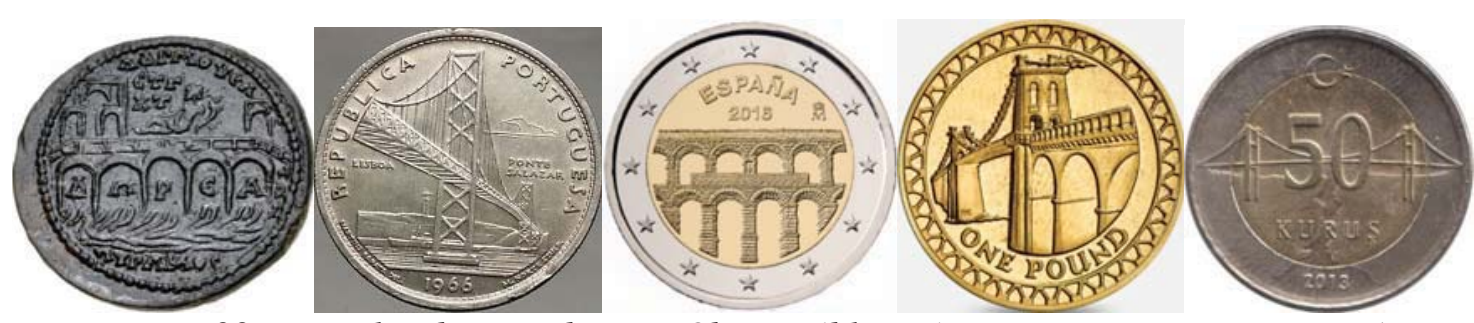

Figura 22: Ejemplos de monedas con Obras Públicas (Fuente: coincommunity.com)

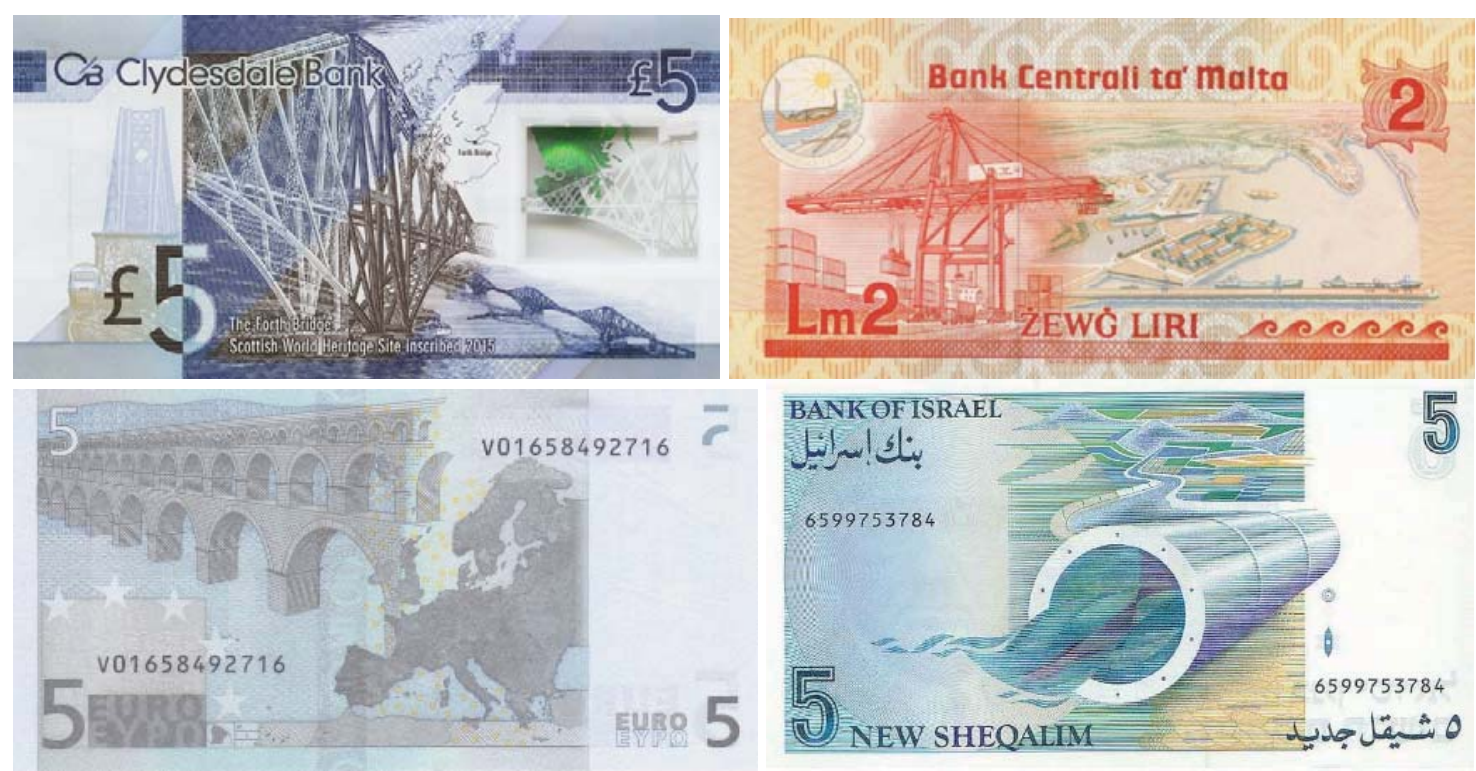

Figura 23: Ejemplos de billetes con Obras Públicas (Fuente: coincommunity.com)

\subsubsection{La evolución de las Obras Públicas}

La evolución del ser humano ha conllevado de manera paralela un desarrollo de las Obras Públicas. Por tres motivos: por las necesidades, por los conocimientos y por los medios y capacidades técnicas.

Las Obras Públicas han servido desde la antigüedad para mejorar la vida de los habitantes del planeta. Al principio las obras respondían a un criterio funcional y a veces propagandístico, sin tener en cuenta el tema económico en muchas ocasiones, ya que los grandes imperios/reinos/repúblicas disponían de mano de obra esclava. Este es el caso de los grandes templos y pirámides egipcias, los templos griegos, los acueductos y teatros romanos, etc. Las obras públicas y las construcciones en general han sido siempre reflejo del desarrollo humano y de los retos técnicos que se ha ido poniendo día tras día para mejorar. Empezó con la talla de la piedra en las construcciones prehistóricas, las grúas egipcias y griegas, la invención del hormigón y el arco por los romanos y las cimbras, el uso de los contrafuertes y vidrieras en las catedrales góticas, la innovación del hierro en la Revolución Industrial, el hormigón armado de finales del siglo XIX, las grandes construcciones de acero del siglo XX y los nuevos materiales del siglo XXI. Todo ello ha contribuido a superar los límites de altura, luz, longitud, etc. En esta tesis se aborda el tema del "desafío humano" con relación a las obras públicas. Un desafío que actualmente se está viendo reflejado en China con su ritmo muy elevado de construcción.

Como ejemplo claro se pueden poner los puentes. En la prehistoria un puente podría ser un tronco de un árbol que cruzara un río o losas de piedra apoyadas en dos piedras asentadas en el lecho, dejando pasar la corriente por debajo. Los griegos para resolver el reto de cruzar un cauce con una estructura de piedra lo hacían con un falso arco por aproximación, como se puede ver en el puente micénico de Arkadiko del siglo XIII a.C. (Figura 24). Los romanos descubrieron el 
arco como elemento resistente que permitía salvar luces mayores a una sola viga o dintel, gracias a la construcción de cimbras. Con los siglos, las cimbras eran mayores y los arcos de piedra crecían. Llegaron nuevos materiales (hierro, hormigón y acero) y ya no hacían falta arcos para salvar grandes luces porque se crearon las celosías, vigas de hormigón, puentes colgantes, atirantados, etc.

Es decir, los puentes han ido evolucionando porque las necesidades de la población cada vez son más exigentes (queremos puentes más rectos y a mayor altura, que eviten carreteras con fuertes pendientes y que acorten más distancia), cada vez se van conociendo nuevos materiales y se tienen más medios, más maquinaria, más tecnología.
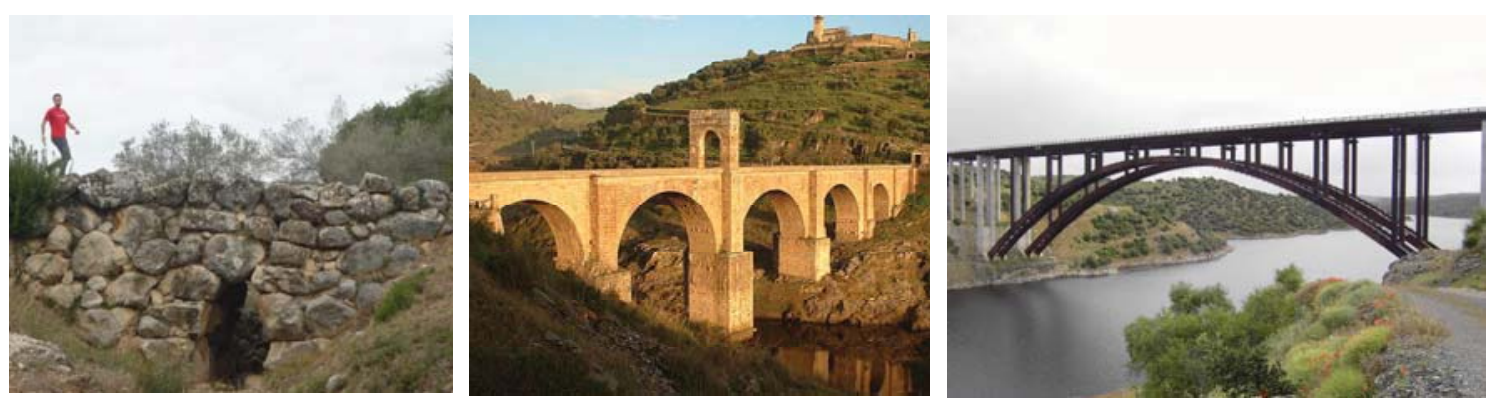

Figura 24: Evolución de los puentes. Puente micénico de Arkadiko (Grecia, S. XIII a.C.), Puente Romano de Alcántara (Cáceres, s. II), Arcos de Alconétar de la A-66 sobre el río Tajo (Cáceres, s. XXI) (Fotos Mario Martín Antón)

La palabra ingeniería proviene de "ingenio". Por lo tanto, esta disciplina también ha sido la que se ha cuestionado cómo resolver problemas que no tenían una fácil solución. Este es el caso de los canales para atravesar istmos, como el de Corinto en Grecia, por ejemplo (Figura 25). Hay que recordar que la palabra istmo proviene del griego "isthmós" (cuello) y que la ciudad situada al este de esa franja estrecha de tierra se llama en la actualidad Istmia. Los antiguos griegos tenían la necesidad de unir el mar Egeo con el Golfo de Corinto pero no tenían ni los conocimientos ni los medios para hacerlo mediante una excavación como la actual. Aquí surge el ingenio que bien define nuestra profesión, creando el Diolkos ("transporte al otro lado" en griego) en el siglo VI a.C. Era una calzada de piedra que salvaba los $6 \mathrm{~km}$ de istmo y tenía curvas para suavizar las pendientes. En esa calzada estaban cortados unos surcos a una misma distancia para que por ellos circulara una especie de vagón o carro con ruedas, tirado por animales. Encima de esos carros estaban situadas las embarcaciones y era la única manera de cruzar de un mar a otro sin tener que rodear todo el Peloponeso. En el siglo XIX seguía existiendo esa necesidad pero ya los medios permitieron excavar el actual Canal de Corinto. Y ahora también se pueden encontrar canales que crucen ríos o megaobras de este siglo o del pasado como el Canal de Panamá. En este último caso se ha visto cómo las necesidades crecientes de la población requieren obras con características mejoradas, como ha sido el caso de la ampliación de hace unos años.
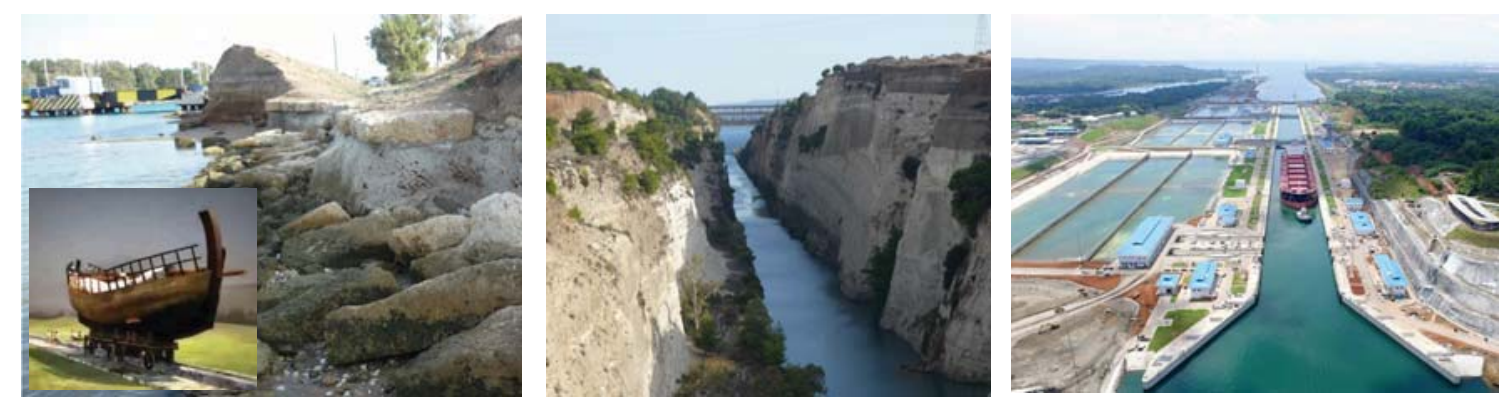

Figura 25: Evolución de los canales. Diolkos (Grecia, S. VI a.C.), Canal de Corinto (Grecia, s. XIX), Canal de Panamá (s. XXI) (Fotos Mario Martín Antón y skyscrapercity.com) 
Este concepto de la evolución se puede observar en todas y cada una de las Obras Públicas: ferrocarriles con trazados sinuosos y de lentos que son sustituidos por una red mejor que soporte mayores velocidades, depuradoras que tienen que ampliarse para tratar un mayor caudal diario de agua residual; diques que tienen que ampliarse para el crecimiento de un puerto; túneles que tienen que alargarse por los requerimientos de la alta velocidad; presas que tienen que recrecerse porque la población aumenta y, con ella, la demanda de agua; carreteras de una calzada que tienen que desdoblarse, aeropuertos que necesitan otra pista más para operar más tráfico aéreo, etc.

Y, a veces, como se ha comentado antes, el ingenio del ser humano y la creatividad del ingeniero crean soluciones sorprendentes, muchas de ellas difícilmente imaginables hace siglos o hace décadas. Ejemplos de ello son los puentes flotantes (Figura 26), como los que hay en Noruega; bus guiado en vías de ferrocarril para evitar atascos, como el que había en Mannheim; barcos que portan trenes, como el del estrecho del Bósforo o el de Messina, el antiguo del Canal de la Mancha, etc; diques y barreras móviles para frenar los temporales, como el Maeslant en Rotterdam o el Plan Delta en Países Bajos; incluso un túnel para barcos, como el que hay proyectado en Noruega (Stad Ship Tunnel) (Figura 26). También se encuentran ascensores o grandes norias en los canales que sustituyen a las antiguas esclusas o incluso se están desarrollando medios de transporte con levitación magnética, que supone un paso más allá en el transporte por ferrocarril (Figura 27). Todo esto refleja cómo han ido mejorando las Obras Públicas, y lo seguirán haciendo en un futuro de maneras que ahora no podemos imaginar.
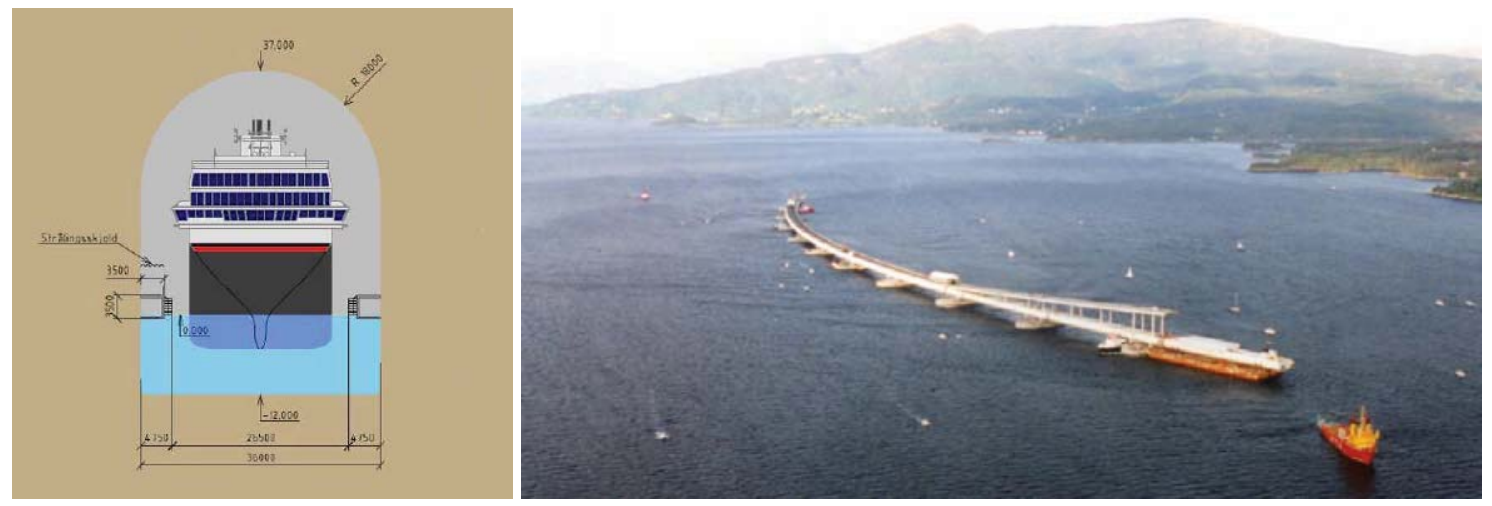

Figura 26: Proyecto del Stad Ship Tunnel y Puente Flotante de Nordhordland (Noruega)

(Fotos: Asociación Cultural Caminos, 2015)
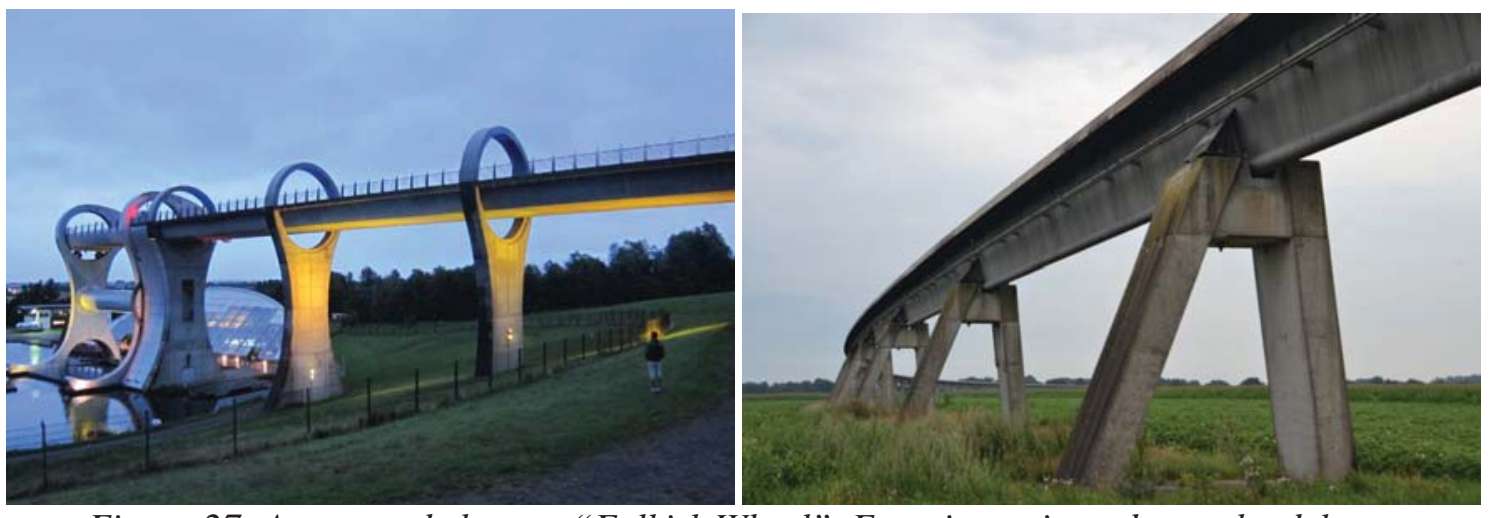

Figura 27: Ascensor de barcos "Falkirk Wheel”, Escocia; y pistas de prueba del tren magnético Transrapid, Alemania (Fotos: Mario Martín Antón) 


\subsection{Objetivos de la tesis doctoral}

Como se comentó en la introducción de esta investigación, el objetivo fundamental de la tesis doctoral es una reflexión sobre el paisaje y el arte de construir, cómo "ser en el mundo" distinto a "estar en el mundo".

Por todo ello, se han planteado una serie de objetivos definidos por las distintas etapas de percepción de la ingeniería/naturaleza/individuo/actuación. Para dar estos pasos, ha servido como reflexión el gigantismo asiático. Se ha introducido en la escala temporal para comprender al ser humano y sus actuaciones en el territorio.

Gigantismo $\longrightarrow$ (hacia atrás $) \longrightarrow$ Paisaje (etapas del ser humano)

Los pasos planteados que permiten concretar las metas, fines y propósitos de esta investigación son los siguientes:

- El arte de construir como la respuesta a la necesidad de mejora de las condiciones de vida del ser humano. Puente (vecindad), castillo (defensa), monasterio (percibir el silencio), puerto (refugio e intercambio modal), playa y paseo marítimo (disfrute y esparcimiento), embalse (acumulación de agua) como ejemplos de esta reflexión.

- Concretar los conceptos de paisaje natural, construido y destruido sobre la base de los criterios funcionales, estéticos, ambientales, socioeconómicos y de sostenibilidad.

- Concretar las etapas evolutivas del ser humano en el arte de construir: sumisión, adaptación, conquista y respeto.

- Analizar la preocupación ambiental y los conceptos de equilibrio del medio físico y marco territorial tras los enormes "simulacros de obras sin sentido", el gigantismo tanto en edificios, como en puentes, en dragados y rellenos, obras hidráulicas, entre otras tipologías de elementos de la ingeniería civil.

Finalmente, como objetivo final, poner ejemplos de las distintas fases de actuaciones humanas simbólicas que convierten al ser humano en "trabajador", en desvertebrador y desmantelador del territorio, en generador de ventas e impulsor de la economía, en lugar de reflexionar sobre el concepto subjetivo u objetivo del paisaje, el espíritu de lugar y las distintas manifestaciones del mismo.

Ejemplos de gigantismo se encuentran en Oriente, preferentemente en China y Emiratos Árabes, desde presas a edificios singulares, dragados, rellenos, islas artificiales y aeropuertos en el mar.

Ejemplos de estética, en las coronaciones de los espaldones de los diques de abrigo, en sus formas, armonías y esbelteces. En los mantos, en bloques con memoria, tanto en pintura, dibujo y cromatura como en formas y tipos. En los puentes, tanto por su esbeltez como su conexión, enlace y vertebración territorial.

El caso de la megápolis de Sydney facilita los ejemplos en una ciudad costera, con emblemas de paisaje construido (Opera House y Harbour Bridge), paisaje destruido (Botany Bay, pistas del aeropuerto y terminal de contenedores) y paisaje natural (Dee Why Beach y Palm Beach).

El objetivo de esta Tesis Doctoral no es el análisis del paisaje como "recurso", como elemento destinado a satisfacer necesidades, como "elemento" que se puede utilizar. 
Tampoco se plantea su gestión ambiental, su protección y su componente territorial o visual. Tampoco se analiza desde la postura de "patrimonio". Ello conduce a la ecuación "gestión + patrimonio = protección", implicando economía, explotación y consumo, con ello, sus instrumentos de aplicación.

Es una reflexión profunda e íntima de "estar en el mundo", construir y afectar el territorio mediante simulacros de obras cuya finalidad es dudosa y demuestran el "poder" y la "conquista" en este siglo XXI. La dualidad percepción - recurso, natural - artificial, demuestran "fragilidad".

Podría haberse planteado el caso español, donde se instrumentaliza, gestiona y legisla mediante los siguientes mecanismos:

- Mecanismos de Evaluación del Impacto Ambiental.

- Mecanismo de Urbanismo y Ordenación del Territorio. Concepto de ciudad.

- Mecanismos de Ordenación de Recursos Naturales.

- Mecanismos legislativos incluidos en normativas sobre paisaje.

Del mismo modo, podría haberse seguido el "método de proyectar el paisaje" de Castañeda (2009 - 2017), con las fases siguientes:

- Conocimiento del territorio a gran y media escala.

- Elementos característicos del paisaje. Identificación y reconocimiento.

- Búsqueda de los puntos de vista.

- Recogida de información sobre los puntos de vista.

- Determinar, buscar y "encontrar" el espíritu del lugar (genius loci).

- Encontrar un mensaje a transmitir.

- Realizar una propuesta plástica.

- Definir los detalles finales.

- Pasar a paisaje construido con la componente social, territorial, cultural y subjetiva.

El paisaje presenta una componente tridimensional; la realidad física, la percepción y la gestión. Ello no implica la protección, más bien, la formación del individuo. Ello no provocará la necesidad de actuación e incluirá la componente de percepción al territorio.

Este es el verdadero objetivo de la Tesis "formar en la percepción" para incorporar el resultado al medio y convertirlo en paisaje independiente de los lugares de mayor singularidad. 


\section{CAPÍTULO 2: ESTADO DEL ARTE Y METODOLOGÍA DE LA INVESTIGACIÓN}

\subsection{Estado del arte del paisaje}

¿Es el paisaje el resultado de las experiencias sensoriales del ser humano? ¿Hace este hecho que sea difícil conceptualizar, consensuar o lograr criterios "objetivos" sobre el paisaje? ¿Existe un marco tan separado entre el concepto "rural" y "urbano" en la concreción de términos?

Como puede observarse, estas preguntas complican el tratamiento y la metodología de la investigación. De la misma manera, el estado del arte es diferente visto desde los ojos de un arqueólogo, un sociólogo, un ambientalista, o, en nuestro caso, desde la sensibilidad de un ingeniero donde los arduos estudios científicos, técnicos y tecnológicos han reducido el humanismo, coartado la sensibilidad y laminado la reflexión interior. Ni que decir tiene la notable diferencia entre un arquitecto y un ingeniero de caminos, canales y puertos en el lenguaje y la percepción.

Empleando los criterios de Criado (1993), Vicent (1991) y Veyne (1988), el paisaje puede pertenecer a cualquiera de las tres categorías expuestas siguiendo las ideas y criterios de sociólogos y arqueólogos:

- Forma empirista: en la que el paisaje aparece como una realidad dada y que se niega a sí misma, por diferentes razones.

- Forma sociológica: explica el paisaje como medio y producto de procesos sociales (Vicent, 1991).

- Forma sociocultural: lo interpreta como la objetivación de las prácticas sociales, tanto de carácter material (estructura) como imaginario (superestructura) (Veyne, 1988)

Otra de las ideas que aparecen en esta revisión bibliográfica es el análisis del término en otros idiomas. Por citar un ejemplo, en inglés se habla de "landscape", y uno se pregunta, ¿por qué no se utiliza el término "earthscape"?, implicando así el concepto natural, el urbano, el territorial o el metropolitano. Incluso, podría plantearse, el concepto "artscape" ó "cityscape".

Empleando raíces germánicas, el vocablo alemán y holandés es "landschap", que identifica horizontes o escenarios rurales.

Otros autores identifican el concepto con la finalidad o el uso. Entre ellos, Busquets (2009) aprecia las siguientes modalidades:

- Paisaje Contemporáneo: Paisaje resultado de las actividades productivas y de las formas de vida actuales. También se utiliza este concepto para designar al paisaje proyectado de acuerdo con los valores y gustos artísticos y estéticos contemporáneos.

- Paisaje Cultural: Obras combinadas de la naturaleza y el hombre que ilustran la evolución del ambiente natural ante fuerzas sociales y culturales, según UNESCO (Tabla 1).

- Paisaje Industrial: Paisaje generado por el desarrollo de actividades industriales en un determinado territorio.

- Paisaje Protegido: Categoría legal establecida en numerosos países para la defensa de lugares excepcionales, dentro de una concepción que contempla el paisaje básicamente en su dimensión objetiva. 


\begin{tabular}{|c|c|c|}
\hline \multicolumn{3}{|c|}{ - Tabla 3. Clasificación de paisaje cultural según UNESCO. } \\
\hline \multicolumn{2}{|c|}{ TIPO DE PAISAJE CULTURAL } & PRINCIPAL DESCRIPTOR \\
\hline \multicolumn{2}{|l|}{ Paisaje diseñado } & $\begin{array}{l}\text { Incluye jardines y parques construidos por motivos estéticos, que están a } \\
\text { menudo (pero no siempre) asociados a edificios o conjuntos monumentales. }\end{array}$ \\
\hline \multirow[t]{2}{*}{$\begin{array}{l}\text { Paisaje que ha } \\
\text { evolucionado } \\
\text { orgánicamente }\end{array}$} & $\begin{array}{l}\text { Paisaje } \\
\text { en evolución } \\
\text {-vivo- }\end{array}$ & $\begin{array}{l}\text { Paisaje evolucionado orgánicamente debido a un imperativo inicial de } \\
\text { carácter social, económico, administrativo y/o religioso. Se desarrolló en y } \\
\text { en respuesta al entorno natural y conserva un papel activo en la sociedad } \\
\text { actual, relacionado directamente con modos de vida tradicionales y con pro- } \\
\text { cesos de desarrollo continuo. }\end{array}$ \\
\hline & $\begin{array}{l}\text { Paisaje } \\
\text { en evolución } \\
\text {-fósil- }\end{array}$ & $\begin{array}{l}\text { Paisaje evolucionado orgánicamente debido a un imperativo inicial de } \\
\text { carácter social, económico, administrativo y/o religioso, cuyo proceso de } \\
\text { evolución finalizó en el pasado, ya sea de forma abrupta o no, pero aún es } \\
\text { distinguible de forma material. }\end{array}$ \\
\hline \multicolumn{2}{|l|}{ Paisaje asociativo } & $\begin{array}{l}\text { Asociaciones culturales, religiosas o artísticas en sus componentes } \\
\text { naturales }\end{array}$ \\
\hline
\end{tabular}

Tabla 1: Clasificación del paisaje cultural (Fuente: UNESCO)

Otra de las grandes especialistas en paisaje, María de Bolós, sobre la base de sistemas dinámicos, organizados, abiertos, armonizados con relación y flujo de energía y materia (geosistema) especifica las siguientes categorías del paisaje.

- Clasificación de los paisajes como naturales y antrópicos en función de los elementos dominantes.

- Clasificación de los paisajes en relación con el espacio geográfico.

- Clasificación de los paisajes en función de las escalas temporales.

- Clasificación de los paisajes según su función.

- Clasificación de los paisajes en función de su estado.

En esta introspección que representa la presente Tesis Doctoral y dentro del marco del urbanismo litoral y paisaje costero, este último apartado es verdaderamente notable.

El mar y sus acciones ejercen sobre la frontera simbólica de la costa, una tensión. Es un territorio en disputa, un contraste. El agua frente a la tierra; lo llano y seco frente a húmedo; lo blando frente a lo duro; lo arraigado frente a lo desarraigado; el encuentro con la incertidumbre; la nostalgia; el anhelo, el ancla y la vela; la sensatez frente al sueño; lo fijo y el vuelo. Es contacto y lejanía.

En este sentido, el paisaje puede ser Paisaje en equilibrio (biostasia), cuando las entradas y salidas de energía y materia son parecidas o estables, y la erosión es mínima. Es difícil que la costa esté en equilibrio tanto estático como dinámico, e incluso, morfodinámico.

Paisajes en regresión: gran presencia de erosión física a causa de modificaciones climáticas (oleaje, marea, corriente y viento), impactos antrópicos (regulación de cauces, embalses, diques de abrigo, edificación masiva en primera línea de orilla en zona activa, desforestación, sequía), entre otros. La estrecha y sensible franja se encuentra en un estado de retroceso iniciado, a veces, imperceptible, pero paulatino.

Paisajes en rexistasia o progresión: son aquellos que tienden a la estabilidad gracias a las entradas y salidas de energía y materia.

El paisaje costero es una plataforma de privilegio y exhibición. Visto desde el mar configura la costa; desde tierra, constituye el litoral.

La visión ofrecida por el profesor Aguiló (2014) con relación a los puertos y la costa permite enlazar con un nuevo concepto de paisaje. Comenta de manera certera y sabia, que fueron los puertos los que causaron el nacimiento de las ciudades. Hoy se ven expulsados de ellas, por su 
crecimiento, especialización y devenir economicista del valor de la estrecha y poblada franja que es la línea fronteriza con el océano.

El puerto se convierte en centro comercial, en lugar lúdico en el nacimiento del "puerto- ciudad" en un nuevo concepto de paisaje. Dominan las megatiendas, los centros comerciales, la restauración y los "espacios basura".

Otro elemento del mar es el faro, verdadero centinela de la bandeja de plata, guía de la navegación. Hoy se ve reducido a residencia de verano o alojamiento turístico, por su enclave privilegiado.

Es la muestra del paisaje cultural (Busquets); paisaje en equilibrio (Bolós), o, tal vez, la forma sociocultural de Veyne a la hora de definir el paisaje.

La tabla adjunta (Tabla 2) ofrece la dificultad de conjugar el concepto de paisaje urbano con los grandes puertos y su especialización, dificultando conceptos como "smart ports" o "green ports" alejando al intercambiador modal de las polis. Esto se ve claramente en ciudades como Sídney donde Botany Bay ha sido "desnaturalizada" por las nuevas pistas del aeropuerto o la nueva terminal de contenedores monolítica con cajones realizados en tierra en forma de vela para hacer ciudad y territorio en Port Jackson.

\begin{tabular}{|c|c|c|c|c|c|}
\hline USO & \multicolumn{2}{|c|}{ TIPO DE MERCANCÍA } & \multicolumn{2}{|c|}{ ÍNDICE IRE ${ }^{4}$} & $\begin{array}{l}\text { VIDA ÚTIL MÍNIMA }\left(V_{\text {MIN }}\right)^{4} \\
\text { (AÑNOS) }\end{array}$ \\
\hline \multirow{5}{*}{ COMERCIAL } & \multicolumn{2}{|c|}{ Graneles líquidos } & $r_{3}\left(r_{2}\right)^{l}$ & Alto (Medio) ${ }^{1}$ & $50(25)^{1}$ \\
\hline & \multicolumn{2}{|c|}{ Graneles sólidos } & $r_{3}\left(r_{2}\right)^{1}$ & Alto (Medio) ${ }^{1}$ & $50(25)^{1}$ \\
\hline & \multicolumn{2}{|c|}{ Mercancía general } & $r_{2}$ & Medio & 25 \\
\hline & \multirow{2}{*}{ Pasajeros } & Ferris & $r_{3}\left(r_{2}\right)^{2}$ & Alto (Medio) ${ }^{2}$ & $50(25)^{2}$ \\
\hline & & Cruceros & $r_{2}$ & Medio & 25 \\
\hline \multicolumn{3}{|l|}{ PESQUERO } & $r_{1}$ & Bajo & 15 \\
\hline \multicolumn{3}{|c|}{ NAÚTICO-DEPORTIVO } & $r_{1}$ & Bajo & 15 \\
\hline \multicolumn{3}{|l|}{ INDUSTRIAL } & $r_{2}\left(r_{3}\right)^{3}$ & Medio (Alto) ${ }^{3}$ & $25(50)^{3}$ \\
\hline \multicolumn{3}{|l|}{ MILITAR } & $r_{3}$ & Alto & 50 \\
\hline \multicolumn{6}{|c|}{$\begin{array}{l}\text { (I) El índice IRE podrá reducirse a } r_{2} \text { cuando el granel sólido ó líquido no esté relacionado con el suministro energético o con mate- } \\
\text { rias primas minerales estratégicas y no se pueda disponer de sistemas alternativos para su manipulación y almacenamiento. } \\
\text { (2) El indice IRE podrá reducirse a } r_{2} \text { cuando se pueda disponer de instalaciones alternativas. } \\
\text { (3) El índice IRE se elevará a } r_{3} \text { cuando la industria a la que sirve la obra de atraque esté asociada con la producción energética } \\
\text { o con la transformación de materias primas minerales estratégicas. } \\
\text { (4) Los indices } r_{1} \text { y } r_{2} \text { de la tabla se elevarán un grado por cada } 25 \mathrm{M} € \text { de inversión inicial de la obra de atraque. }\end{array}$} \\
\hline
\end{tabular}

Tabla 2: Vidas útiles mínimas, naturaleza de las mercancías y usos portuarios (Puertos del Estado, 2012)

Aparece tras esta revisión del estado del arte un nuevo concepto que usualmente se llama paisaje urbano, pero que el autor define como ciudad - paisaje y territorio. Es el paisaje del siglo XXI, pero no es neutral, porque depende de los árbitros y sus jugadores (distintas filosofías, religiones, tendencias políticas, culturas) o incluso modas o tendencias (movilidad, ecoturismo, ecodriving).

Queda bastante lejana la postura de García (2009), pese a ser muy reciente en el ámbito temporal su conceptualización.

- Ciudad tradicional, en la que el lugar de reunión (ágora), el mercado y el tránsito continúan coexistiendo en mayor o menor equilibrio.

- Ciudad invadida, en la que un uso único, generalmente el tráfico rodado (automóviles), ha usurpado el territorio a costa de otras funciones del espacio urbano. 
- Ciudad abandonada, en la que han desaparecido el espacio público y la vida en la calle.

- Ciudad reconquistada, en la que se están llevando a cabo grandes esfuerzos para encontrar un nuevo y posible equilibrio entre los usos de la ciudad como lugar de reunión, mercado y espacio de transito.

Hoy la ciudad es heterogénea, la cultura urbana divergente, no uniforme, y el control del paisaje, imposible.

En este sentido, la complejidad de las sociedades actuales neoliberales afecta al concepto de paisaje.

¿Quién usa la ciudad? ¿Es el transeúnte? ¿Quién articula la ciudad? ¿Cómo se controlan las redes del transporte para combinar aspectos culturales, sociales, ambientales y de patrimonio que configuran el paisaje? ¿Cómo se gestiona el paisaje de la ciudad? ¿Es el nuevo concepto el del centro comercial o el centro de ocio el que provoca una ciudad invadida o abandonada?

Por eso, esta tesis es una introspección y una reflexión profunda sobre "estar en el mundo". Más bien, la investigación ha buscado ejemplos donde se sacrifica el medio ambiente costero para proteger el paisaje construido y conservar el natural, volviendo a reincidir en el caso de Sídney con sus tres grandes bahías, la ensenada de Botany Bay (sacrificada); Port Jackson (antropizada y emblemática) y Palm Beach (natural - protegida pero amenazada).

Este hecho hace que se proponga una nueva clasificación del paisaje.

- Paisaje natural. Consiste en la defensa de lugares excepcionales, dentro de una concepción y dimensión objetiva. En ciertas fuentes bibliográficas responde al concepto de "protegido".

- Paisaje construido. Obras combinadas de la naturaleza y el hombre que ilustran la evolución del ambiente natural ante fuerzas sociales y culturales. En ciertas fuentes bibliográficas responde al concepto de "cultural".

- Paisaje destruido. Consiste en la desaparición del espacio natural y territorial, de la ciudad y la naturaleza en todos sus aspectos, desde social al ambiental, desde sostenible al de comunicaciones, "abandonado".

- Paisaje reconstruido. Consiste en rehabilitar, desmantelar, devolver el "lugar" a su escenario y horizonte excepcional y objetivo, "reconquistado".

Esto hace que numerosos investigadores y teóricos del paisaje discutan sobre la subjetividad o la objetividad en la valoración. Eso sí, su conceptualización difiere de acuerdo a la disciplina que lo estudie: arquitectura, geografía, historia, arqueología, sociología, antropología o ingeniería. Sin embargo, todas ellas concuerdan en que es el ser humano quien lo crea, lo valoriza y lo destruye.

Los seres humanos son, en última instancia, los llamados a tomarse en serio el paisaje, apropiarse de él, hacerlo suyo, sentirlo y cobijarse.

Hoy, después de años de estudio y trabajo, el paisaje se considera como la expresión perceptual del medio físico. Es el resultado de la vivencia y la experiencia humana. Es el patrimonio que se deja a las generaciones siguientes en todas sus disciplinas del humanismo, la técnica y la ciencia.

Sin embargo, siempre se debe proceder con respeto y cuidado, pues estos paisajes serán heredados por ellos. Pensando en ellos se debe proteger el paisaje y analizar sus diferentes 
variables, para preservar de mejor manera la memoria histórica de nuestras sociedades contemporáneas.

De la misma manera, el paisaje puede ser identificado, estructurado y sentido. El primer término se asocia, se equipara, se asemeja o corresponde con el objeto; el segundo, se plantea en magnitudes espacio y tiempo; para, finalmente, él mismo cobra sentido desde la perspectiva subjetiva de la percepción.

La primera etapa de identificación es un reconocimiento. La segunda de estructura es la recepción sensorial. La tercera es la conciencia interna de comunicación de y entre sentimientos.

Por estas circunstancias, identidad - estructura - sentido; enlazadas con las etapas del ser humano en relación con el territorio (sumisión, adaptación, conquista y respeto), se plantea una relación con el paisaje, introduciendo cuatro conceptos: percepción, asimilación, manipulación y búsqueda (Tabla 3).

La percepción es la recepción por alguno de nuestros sentidos del medio físico y el individuo.

La asimilación es la comprensión de lo percibido, incorporando lo nuevo a los conocimientos previos del ser humano.

La manipulación es consecuencia de la percepción (primera fase), tamizada por las experiencias del individuo mediante la asimilación (segunda fase) pudiendo ser manipulados por el entorno, sus cánones y filtros.

La belleza se juzga sobre estos principios, que no es otra idea que la manipulación del paisaje.

Finalmente, aparece el concepto de búsqueda. Verdaderamente complejo, porque el paisaje es dinámico y ambiguo, social y cultural, responde a modelos estéticos, puede estar preconcebido. Por ello, ¿cómo es posible que se busque?

\begin{tabular}{|l|l|l|l|}
\hline Finalidad y uso & Estado & Paisaje urbano & Subjetivismo \\
\hline Paisaje contemporáneo & En equilibrio & Ciudad tradicional & Natural \\
\hline Paisaje cultural & En regresión & Ciudad invadida & Construido \\
\hline Paisaje industrial & En progresión & Ciudad abandonada & Destruido \\
\hline Paisaje protegido & En equilibrio & Ciudad reconquistada & Reconstruido \\
\hline
\end{tabular}

Tabla 3: Formas de analizar el concepto de paisaje (Fuente: elaboración propia)

D. Eduardo Torroja comentaba en su "Razón y ser de los tipos estructurales", que "en lo estético, es mucho más difícil que en lo técnico, dar reglas generales que no queden en las nubes de la filosofía general del arte, sin aplicación y contactos directos con el problema que nos ocupa".

Por ello, el concepto de buscar el paisaje es fascinante, pero como el agua entre los dedos de las manos, escurridizo, cambiante y fugaz. Aquí se muestran las relaciones entre los conceptos del paisaje (Tabla 4).

\begin{tabular}{|l|l|l|}
\hline Subjetivismo & Etapas & Sentido \\
\hline Natural & Sumisión & Percepción \\
\hline Construido & Adaptación & Asimilación \\
\hline Destruido & Conquista & Manipulación \\
\hline Reconstruido & Respeto & Búsqueda \\
\hline
\end{tabular}

Tabla 4: Relaciones entre los conceptos de paisaje (Fuente: elaboración propia) 
Por todo ello, el concepto de paisaje y de lugar se representa a partir del diagrama de flujo del profesor Aguiló, relacionando el medio físico con el individuo; el entorno con la obra, las actividades y su evolución (Figura 28).

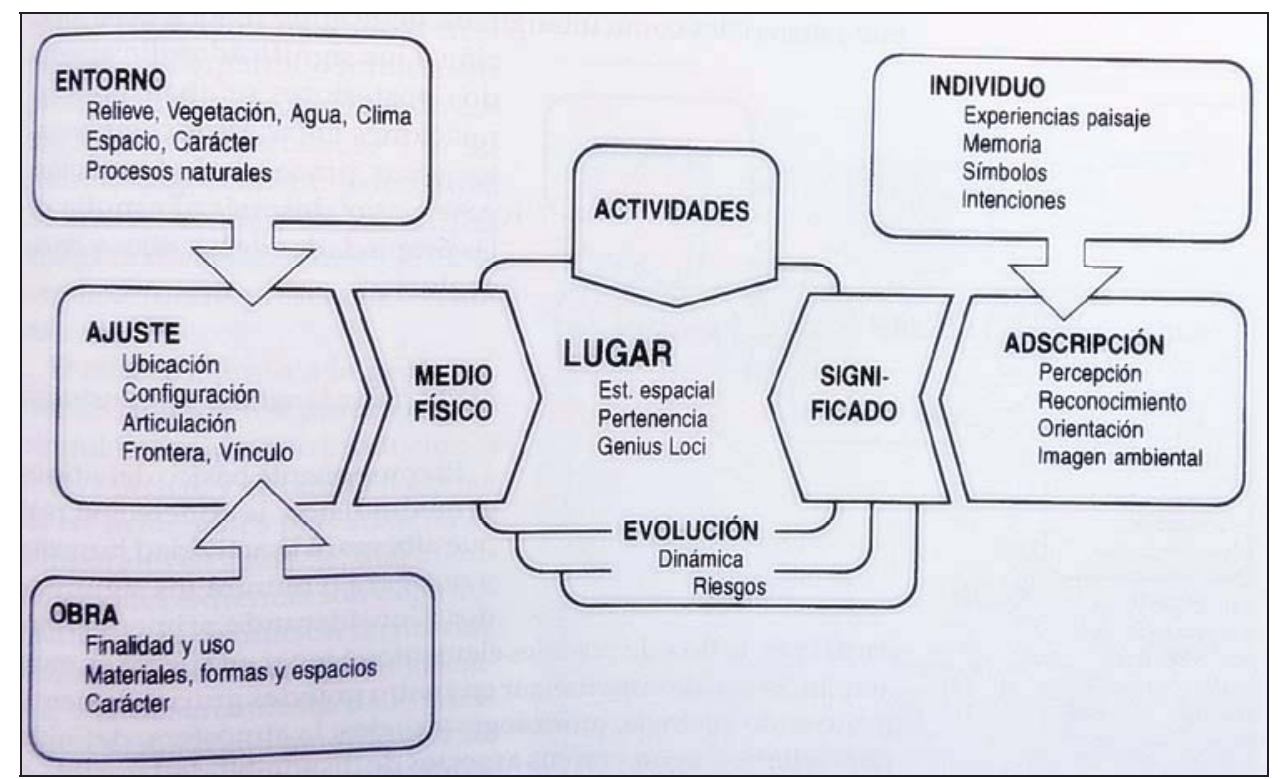

Figura 28: Concepto de lugar (Fuente: Aguiló, 1999)

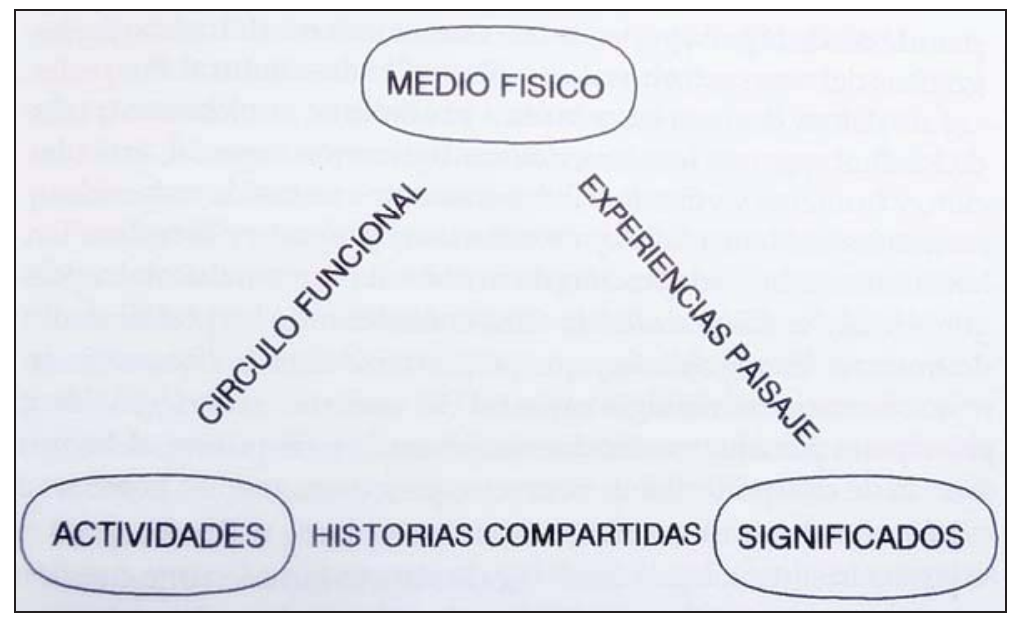

Figura 29: Componentes del lugar (Fuente: Aguiló, 1999)

Igualmente, el triángulo equilátero cuyos vértices responden al medio físico, la actividad y el significado permite dilucidar las experiencias relativas al paisaje (Figura 29).

La naturaleza tiene una respuesta lenta; el "territorio intervenido" presenta una modificación casi instantánea. Sobre este, el nuevo orden es una variable temporal indefinida, una integral "impropia", basada en la realidad física; en territorio y percepción; en territorio - percepción paisaje en función de las distintas teorías de análisis (Zubelzu y Allende, 2015).

Ahora el ser humano se preocupa de la subida del nivel del mar, del cambio climático, del protocolo de Kyoto que finaliza en 2020, de los acuerdos de París de diciembre de 2015, de las decisiones del Gobierno de Estados Unidos de 1 de junio de 2017, tras décadas de especulaciones y robos del medio físico a su dueño, el océano.

Tras el proceso de "sumisión" y "adaptación", el hombre dominó, guerreó, destrozó y conquistó. Tal vez esta reflexión de paisaje debería ser una introspección en el comportamiento humano en su historia y su relación con el territorio. 


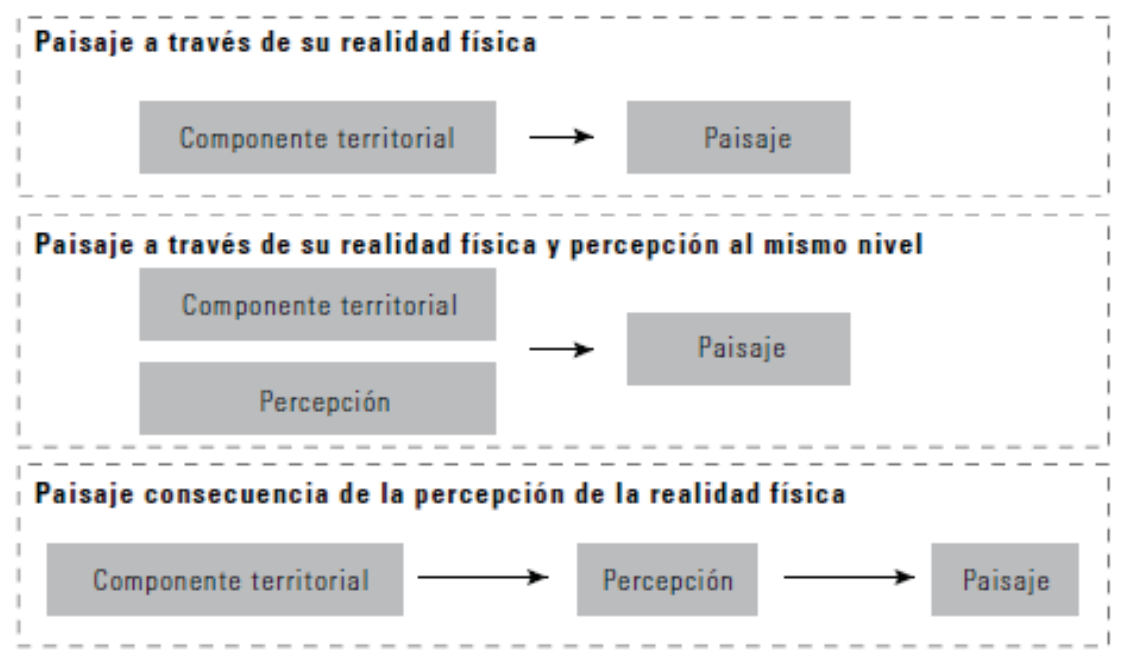

Figura 30: Paisaje: componente territorial y de percepción (Zubelzu y Allende, 2015)

La existencia de la "percepción" conlleva el "juicio de valor", por tanto, una preferencia subjetiva o una escala de gustos (Figura 30). Esta situación condiciona el concepto de "paisaje natural" y de "paisaje cultural", cuya línea fronteriza, simbólica resulta difícil de quebrantar.

Esta investigación desea analizar el concepto de subjetividad como elemento constituyente del paisaje, dejando en un segundo nivel, el "paisaje - recurso". Las siguientes tablas desarrolladas por los autores muestran la evolución de las ideas sobre el paisaje (Tabla 5 y Tabla 6).

\begin{tabular}{|c|c|c|}
\hline Componente & Denominación & Autor \\
\hline Territorial & $\begin{array}{l}\text { Fisiográfica } \\
\text { Sistema natural }\end{array}$ & $\begin{array}{l}\text { Duun (1974) } \\
\text { Bolós (1992) }\end{array}$ \\
\hline Territorial & $\begin{array}{l}\text { Jerárquico } \\
\text { Paisaje Total } \\
\text { Paisaje Visual }\end{array}$ & $\begin{array}{l}\text { Sanz Herranz (2000) } \\
\text { Kessler (2000) } \\
\text { Martínez Pisón (2002) } \\
\text { Mata Olmo (2008) } \\
\text { Otero (2009) } \\
\text { Cazorla (2009) }\end{array}$ \\
\hline Territorial & Perceptual & $\begin{array}{l}\text { Gómez Orea (1992) } \\
\text { García Moruno (1998) } \\
\text { Busquets y Castro (2003) }\end{array}$ \\
\hline Sistémica & $\begin{array}{l}\text { Poder } \\
\text { Imaginación }\end{array}$ & Cosgrove (2002) \\
\hline Cultural & $\begin{array}{l}\text { No natural } \\
\text { Dinámico } \\
\text { Social }\end{array}$ & Tello et al (2007) \\
\hline $\begin{array}{l}\text { Territorial } \\
\text { Social } \\
\text { Cultural } \\
\text { Subjetiva }\end{array}$ & $\begin{array}{l}\text { Paisaje natural } \\
\text { Paisaje construido } \\
\text { Paisaje destruido } \\
\text { Paisaje } \\
\text { reconstruido }\end{array}$ & $\begin{array}{l}\text { Aguiló (1999) } \\
\text { Negro (2008) } \\
\text { Martín Antón (2016) } \\
\text { (2017) }\end{array}$ \\
\hline
\end{tabular}

Tabla 5: Criterios de análisis del paisaje (componente, denominación y autores) (Elaboración propia)

Se puede concluir que la percepción es subjetividad, impregnando de este concepto al paisaje. Sin ella, no existiría paisaje, por lo que se hace imprescindible en su existencia. Como se comentó con anterioridad, la evolución del ser humano en el "arte de construir y estar en el mundo" ha ido pasando por cuatro etapas con el devenir de los tiempos. La búsqueda de sitios 
elevados para defenderse ante el ataque de los enemigos; la desembocadura de los ríos para tener agua y refugiarse antes de salir al violento océano; los caminos y los puentes para garantizar la comunicación y la movilidad, hizo que la especie tuviera una primera fase de "sumisión", e incluso temor, a la naturaleza.

\begin{tabular}{|l|l|l|}
\hline Tipos de percepción & Naturaleza & Autor \\
\hline Subjetiva & Experiencia personal & Bolós (1992) \\
\hline Subjetiva & Personalidad individual & $\begin{array}{l}\text { Bosque (1997) } \\
\text { Gómez Alzate (2010) }\end{array}$ \\
\hline Subjetiva & Cultura e historia & $\begin{array}{l}\text { Martínez Pisón (2006) } \\
\text { Santos y Ganges (2002) }\end{array}$ \\
\hline Subjetiva & Edad & $\begin{array}{l}\text { Maciá (1980) } \\
\text { Tassinari (2006) }\end{array}$ \\
\hline Subjetiva & $\begin{array}{l}\text { Social - simbólica } \\
\text { Trascendente }\end{array}$ & Martín Antón (2017) \\
\hline
\end{tabular}

Tabla 6: Criterios de percepción y su origen (Elaboración propia)

La agricultura, la ganadería y el comercio, así como el aumento de la población, condujo a la "adaptación", al sedentarismo y al nacimiento y crecimiento de las urbes. Los pueblos viven y conviven en el marco de la ciudad.

Tanto la "sumisión" como la "adaptación" se prolongaron durante miles de años. El ser humano, con el tiempo, se apropió del territorio. Con sus obras demostró el poder, dominó y llegó a una tercera etapa, la "conquista", en este caso, de la naturaleza. Desde el acueducto de Segovia, al Dique Torres en Gijón; desde el Teatro de Mérida al Puente sobre el estrecho de Golden Gate; desde la Presa de las Tres Gargantas a las islas artificiales o los notables edificios de Emiratos Árabes o los rellenos portuarios de Shanghái, estas obras son también una demostración de "poder".

En las últimas décadas, motivado por el crecimiento masivo, la explotación discrecional de los recursos naturales, las desigualdades sociales y poblacionales, la desafección con el medio físico, la falta de sensibilidad ambiental, la ingeniería descubre y promociona el "respeto", la colaboración con el entorno, el "lugar" de emoción de donde hemos salido y donde volveremos, si bien es cierto que algunas obras realizadas en la antigüedad lo asumían. El paisaje se hizo percepción sobre el territorio, social, cultural, patrimonio y gestión. Se planteó con una componente subjetiva por encima de la simple respuesta del medio o la incorporación de las magnitudes poblacionales que lo diagnostican.

Qué complicado es el futuro y qué obtuso el pasado, si no se conservan las raíces y se disputa el territorio sin percepción. Se destruye, en vez de construir, alejándose del "genius loci", "sense of place" del espíritu protector del lugar, de la trascendencia de la obra.

El paisaje natural no existe. Sin embargo, se dice que el paisaje natural se transforma por el arte de construir, por la relación de la obra con la naturaleza, creando un paisaje nuevo emocional, viviente y, sobre todo, trascendente, el paisaje construido. Cualquier otra acción humana que altera, ataca y agrede al medio físico se enmarca en el concepto de paisaje destruido. El siglo XXI todavía tiene el reto del paisaje reconstruido.

De este modo, la forma no se fragmenta, se integra, se hace auténtica y se convierte en monumento. Domina el espacio y elimina el vacío, se hace sueño, y, con ella, paisaje construido trascendente. Si no se integra rompe el equilibrio con la naturaleza y enferma el territorio, perdiendo su armonía y vertebración. La naturaleza se ve agredida, atacada, pasa a ser defectuosa, esperando que el tiempo enderece sus pasos. El nuevo arte puede ser su desmantelamiento, retornando al escenario natural, que solo es recuperado plenamente en la mayoría de los casos con el paso de largos lapsos de tiempo. 
El paisaje objetivo se divide en dos categorías: necesario (construido) y superfluo (destruido); trascendente (construido) e irreflexivo (destruido); espiritual y simbólico (construido) e ineficaz y frío (destruido); utopía, belleza y sueño (construido) frente a inútil, feo y real (destruido). Un diseño debe enamorar, en caso contrario, hay que seguir ensayando.

Por todos estos motivos, se realizó la presente investigación basada en el concepto de territorio - paisaje y memoria.

Como se comentó con anterioridad, al redactarse en la modalidad de artículos, los resultados y la discusión se presentan sobre la base de los retos e hitos alcanzados durante estos tres años de dedicación completa.

No se desea terminar esta reflexión sin la definición del Convenio Europeo del Paisaje (CEP) que lo entiende como "cualquier parte del territorio tal como lo percibe la población, cuyo carácter sea el resultado de la acción y la interacción de factores naturales y/o humanos". Esta definición junto con otras se expone en el siguiente apartado. 


\subsection{Definiciones de paisaje}

¿Qué es el paisaje? La Real Academia Española de la Lengua lo define en su diccionario:

Paisaje (Del fr. paysage, der. de pays 'territorio rural', 'país'.)

1. m. Parte de un territorio que puede ser observada desde un determinado lugar.

2. m. Espacio natural admirable por su aspecto artístico.

3. m. Pintura o dibujo que representa un paisaje (espacio natural admirable).

Paisaje protegido.

m. Espacio natural que, por sus valores estéticos y culturales, es objeto de protección legal para garantizar su conservación.

El Convenio Europeo del Paisaje, firmado en Florencia el 20 de octubre del 2000 y que entró en vigor en España en 2008 tiene las siguientes definiciones (Figura 31):

Artículo $10^{\circ}$ Definiciones.-A los efectos del presente Convenio:

a) por "paisaje» se entenderá cualquier parte del territorio tal como la percibe la población, cuyo carácter sea el resultado de la acción y la interacción de factores naturales y/o humanos;

b) por «política en materia de paisajes» se entenderá la formulación, por parte de las autoridades públicas competentes, de los principios generales, estrategias y directrices que permitan la adopción de medidas especificas con vistas a la protección, gestión y ordenación del paisaje;

c) por «objetivo de calidad paisajístíca» se entenderá, para un paisaje especifico, la formulación, por parte de las autoridades públicas competentes, de las aspiraciones de las poblaciones en lo que concierne a las características paisajísticas de su entorno;

d) por «protección de los paisajes» se entenderán las acciones encaminadas a conservar y mantener los aspectos significativos o característicos de un paisaje, justificados por su valor patrimonial derivado de su configuración natural y/o la acción del hombre;

e) por "gestión de los paisajes» se entenderán las acciones encaminadas, desde una perspectiva de desarrollo sostenible, a garantizar el mantenimiento regular de un paisaje, con el fin de guiar y armonizar las transformaciones inducidas por los procesos sociales, económicos y medioambientales;

f) por «ordenación paisajística» se entenderá las acciones que presenten un carácter prospectivo particularmente acentuado con vistas a mejorar, restaurar o crear paisajes.

\section{Artículo 2 - Ámbito de aplicación}

Con sujeción a las disposiciones contenidas en el artículo 15, el presente Convenio se aplicará a todo el territorio de las Partes y abarcará las áreas naturales, rurales, urbanas y periurbanas. Comprenderá asimismo las zonas terrestre, marítima y las aguas interiores. Se refiere tanto a los paisajes que puedan considerarse excepcionales como a los paisajes cotidianos o degradados.

Figura 31: Definiciones del Convenio Europeo del Paisaje (Fuente: Consejo de Europa, 2000) 
En este epígrafe, resumen del abundante estado del arte existente en el concepto de "paisaje", se van a enumerar y relacionar distintas definiciones, muchas de ellas de profesionales de otros campos de la ciencia, la cultura, el estudio y la investigación, para, pasar posteriormente, a dar una visión de paisaje - ingeniería con ingenieros - humanistas ilustres como pueden ser: Eduardo Torroja, José Antonio Fernández Ordóñez, Miguel Aguiló, Carlos Nárdiz, Ignacio Español, Juan José Arenas, o Javier Manterola, como ejemplos representativos del "nuevo concepto de paisaje" de percepción, geometría, territorio, estética y evolución.

Destacan como representativas, las siguientes dentro del amplio abanico de las recopiladas:

- El paisaje es más difícil en lo estético que en lo técnico, dar reglas generales que no queden en las nubes de la filosofía general del arte, sin aplicación y contactos directos con el problema que nos ocupa. (Eduardo Torroja, 1960).

- La obra debe reunir el valor científico, el estético, el histórico, el simbólico y el de uso. Son conceptos amplios que incluyen la calidad y singularidad técnico-constructiva y artística, el carácter histórico o historiográfico, la monumentalidad, la implantación en el territorio y su encaje en el paisaje, sus significados cultural, etnográfico, arqueológico, conmemorativo, etc., y algo muy característico de las obras públicas que es el valor de uso. (Fernández Ordóñez, 1984).

- La idea de paisaje, como las ideas sobre la historia y sobre la tradición, evoluciona con el tiempo. (Conan, 1994).

- El paisaje está imbricado en la vida social (y recíprocamente), está condicionado permanentemente por las relaciones sociales. En resumen, el paisaje es una entidad relativa y dinámica, en la que naturaleza y sociedad, aspecto y entorno están en constante interacción. (Berqué, 1994).

- El paisaje es una entidad relativa y dinámica, donde naturaleza y sociedad, la visión y el entorno se encuentran en constante interacción. (Berqué, 1994).

- Las obras públicas son el testimonio de una época, manifestación de las sensibilidades que han podido aflorar en el proceso de concepción, proyecto y construcción de la misma. (Rui-Wamba, 1995).

- El paisaje es como un objeto de percepción estética que irá evolucionando con los modelos de valoración. (Roger, 1997).

- El paisaje compete a un análisis esencialmente estético. (Roger, 1997).

- Un paisaje no puede reducirse nunca a un ecosistema menos aun puede reducirse a un geosistema. El paisaje no es un concepto científico. (Roger, 1997 - 2008).

- El ingeniero debe actuar con la conciencia y con la responsabilidad de estar contribuyendo a la construcción de un territorio, de una segunda naturaleza, en definitiva, de un paisaje. (Fernández Ordóñez, 1998).

- La belleza y la calidad resistente son conceptos prácticamente paralelos, nunca independientes y, menos aún, divorciados. (Arenas, 2000).

- El paisaje mejora con la geometría. (Manterola, 2003).

- El paisaje con el que nos relacionamos es todo territorio, artificio cultural. (Nárdiz, 2007). 
- El paisaje puede interpretarse como un producto social, como el resultado de una transformación colectiva de la naturaleza y la proyección cultural de una sociedad en un espacio determinado. (Nogué, 2007).

- El paisaje es un concepto escurridizo, pero fascinante. (Minca, 2008).

- La historia del paisaje no puede ser entendida más que como un capítulo de la historia de la sociedad, consagrados al examen de las transformaciones de las relaciones de dominio sobre la naturaleza, de la evolución de las ideas y la formación de rituales. (Minca, 2008).

- El paisaje es el resultado de una transformación colectiva de la naturaleza y como la proyección cultural de una sociedad en un espacio determinado. (Nogué, 2008).

- El paisaje es, a la vez, una realidad física y la representación que culturalmente nos hacemos de ella; la fisionomía externa y visible de una determinada porción de la superficie terrestre y la percepción individual y social que genera. (Nogué, 2008).

- La percepción es el peculiar filtro de esa especial relación del individuo con el mundo, que es el paisaje. (Aguiló, 2010).

- El paisaje aparece como un argumento renovado de reclamación de un planteamiento ético de la gestión de los recursos naturales y el territorio. (Español, 2012).

- El arte del paisaje ha trabajado desde siempre en ese campo doble de la ética y la estética y aparece ahora como un argumento sólido de reclamación social contra las actuaciones abusivas en el territorio. (Español, 2012).

- Si el siglo XIX fue el siglo de descubrimientos y conquistas de la naturaleza; el XX fue el gran siglo de las cuestiones sociales y económicas. Pienso que en el siglo XXI hay un redescubrimiento de la naturaleza, esta vez no para conquistarla, sino para tutelarla. (Calatrava, 2012).

- Este concepto de tutela de la naturaleza es uno de los conceptos fundamentales que lleva al planteamiento de sostenibilidad, ecología y respeto del paisaje y planteamientos restitutivos. Ya no solo se trata de conservar sino de restituir las áreas paisajísticas. (Calatrava, 2012).

- El paisaje es el territorio donde convive sueño y realidad. (Negro, 2017) (Figura 32).
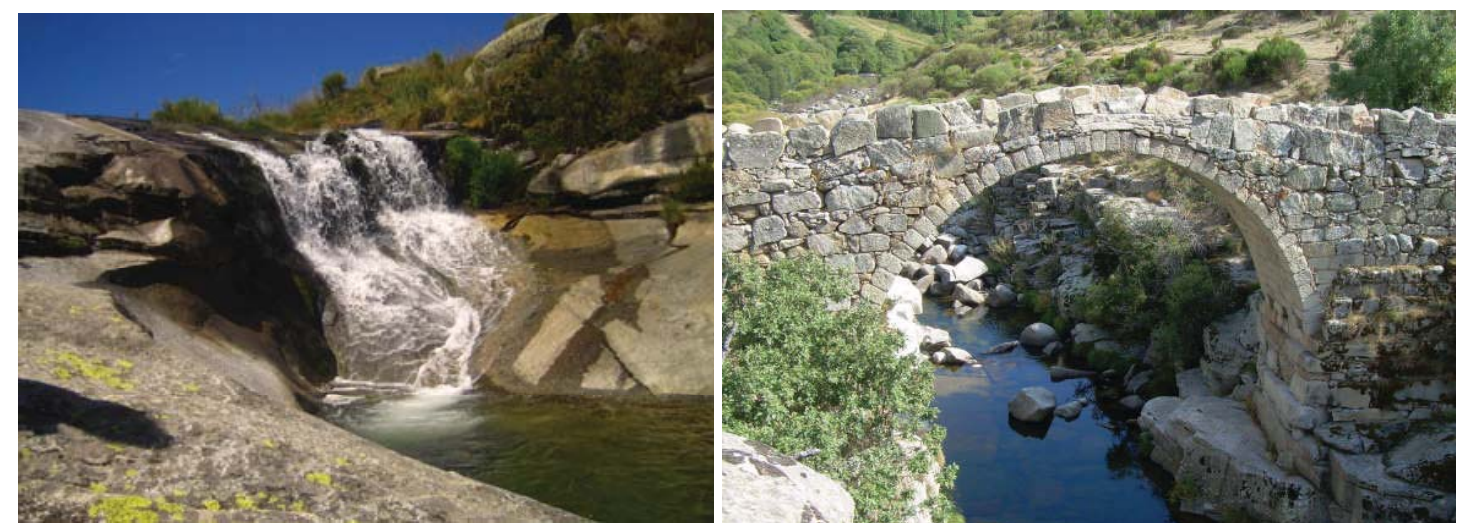

Figura 32. Paisaje natural (garganta del Jabalí, Valdeascas, Navarredonda de Gredos) (izquierda) y paisaje construido (Pozo de las Paredes, Navacepeda de Tormes) (derecha)

(Fotos: Vicente Negro Valdecantos) 


\subsection{Ejemplos de Paisaje y Obras Públicas}

En la introducción se ha hablado de la motivación de las Obras Públicas y su evolución. Pero un tema importante es la percepción de la Obra Pública por parte de la ciudadanía. Y ahí es donde entra el concepto de paisaje. Es un concepto que va teniendo cada vez más importancia en este mundo tan antropizado. En la antigüedad, los puentes se hacían donde y como se hacían por razones funcionales o propagandístico. No había motivos que excluyeran proyectos por ser visualmente impactantes o que afectaran a zonas naturales. Hoy en día, en cambio, es una de las cosas que más se tiene en cuenta, con el tema medioambiental a veces incluso más que el aspecto económico.

La Ingeniería de Caminos no ha inventado muchas cosas nuevas. Lo que ha hecho es construir artificialmente y "a medida" formaciones que nos podemos encontrar en la naturaleza que llevan miles o millones de años existiendo (puentes, diques, presas, túneles, etc). Aquí hay algún ejemplo de estas formaciones naturales en España, lo que supone un paso más allá en el paisaje natural. Esto nos lleva a la siguiente conclusión: El ser humano ha nacido rodeado de naturaleza, y es ella la que ha sido referencia para su actividad en el Mundo y sus realizaciones, por lo que se puede considerar como paisaje copiado.

\subsubsection{Paisaje natural}

Aquí se tienen algunos ejemplos de formaciones geológicas y naturales que son el antecedente a nuestras Obras Públicas. Son ejemplos de España (Figuras 33 a 38).

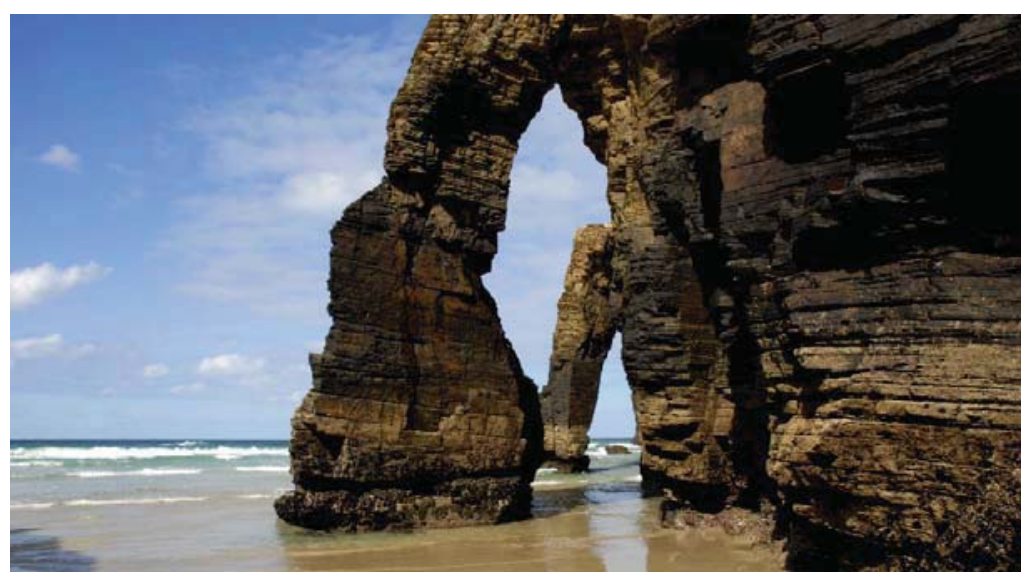

Figura 33: "Contrafuertes" de la Playa de las Catedrales, Lugo (Foto: playadecatedrales.com)

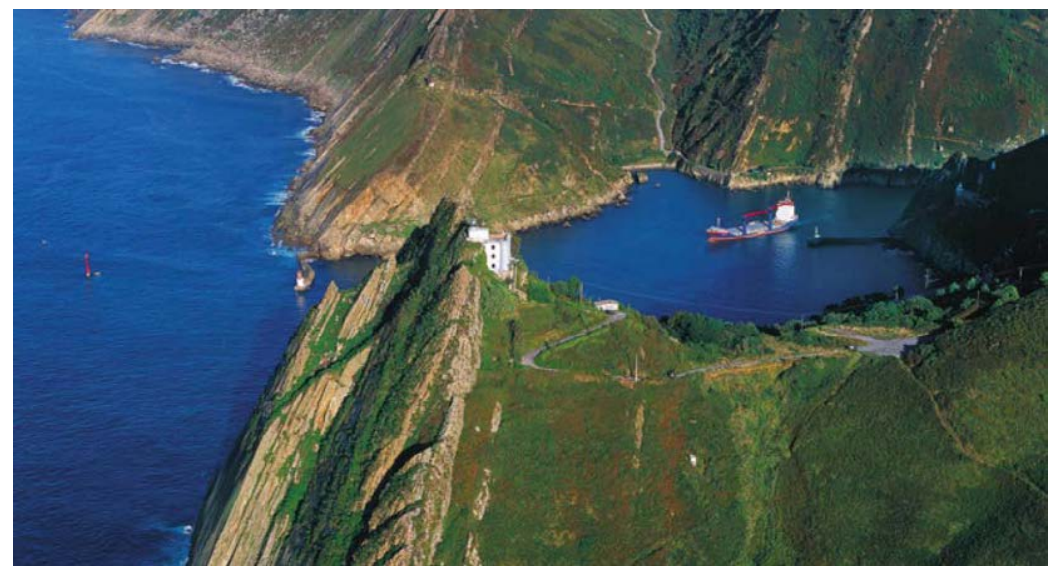

Figura 34: "Dique" (acantilados del faro de la Plata) y "puerto natural abrigado" de Pasaia, Gipuzkoa (Foto: caminosantiagogipuzkoa.com) 


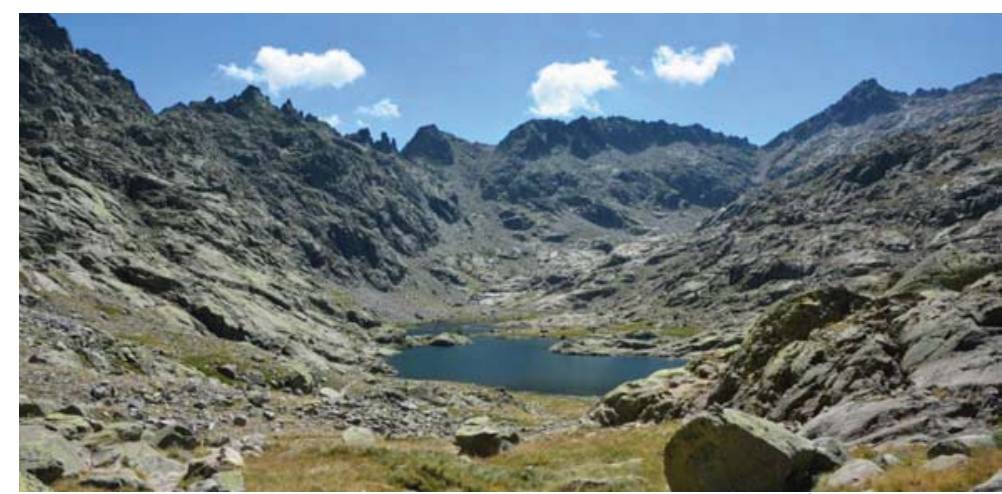

Figura 35: "Presa y embalse" de la Laguna Grande de Gredos, Ávila (Foto: Vicente Negro)

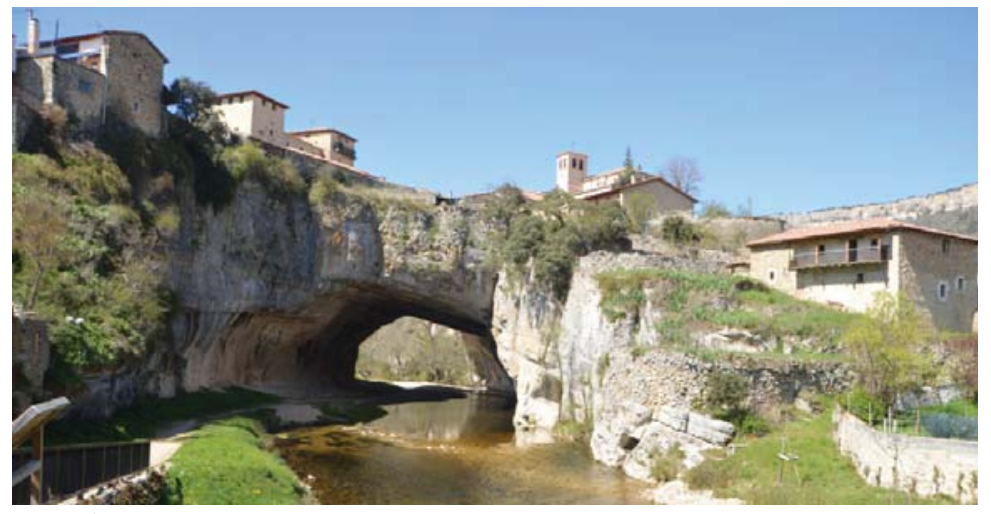

Figura 36: "Puente" de Puentedey, Burgos (Foto: Mario Martín Antón)

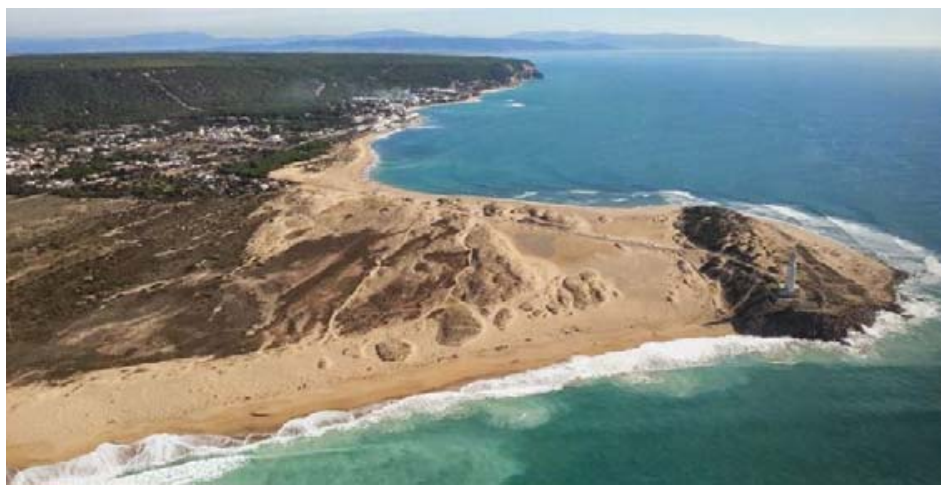

Figura 37: "Terrenos ganados al mar (land reclamation)" en el tómbolo de Trafalgar, Cádiz (Foto: Luis Gómez, vecinosdezahora.blogspot.com)

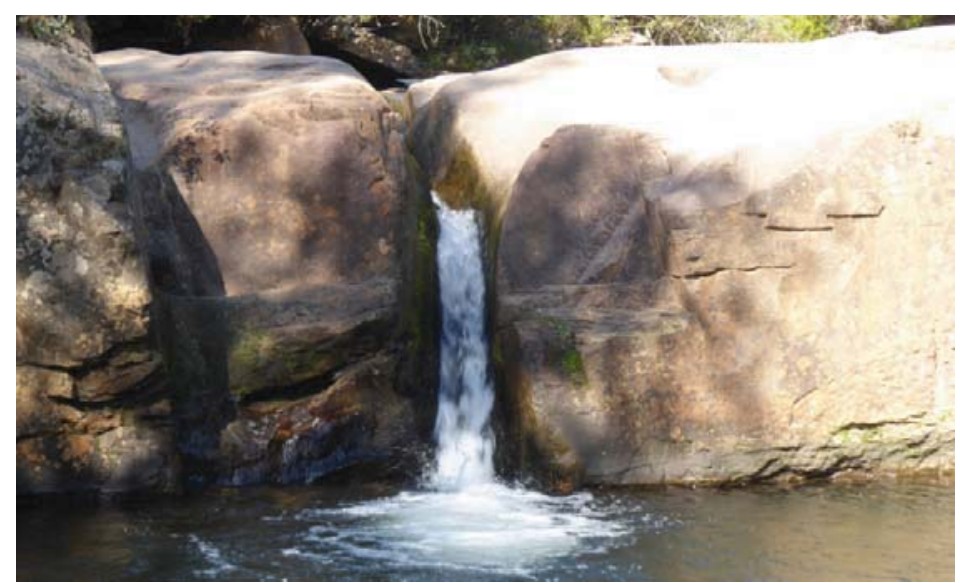

Figura 38: "Salto de agua para aprovechamiento hidráulico" en el Chorrón del Río Razón, Soria (Foto: picosysendas.files.wordpress.com) 
Además, los animales han conseguido tener relaciones con las plantas, el agua y la tierra que también representan la misma idea que muchas construcciones humanas (Figuras 39 a 42).

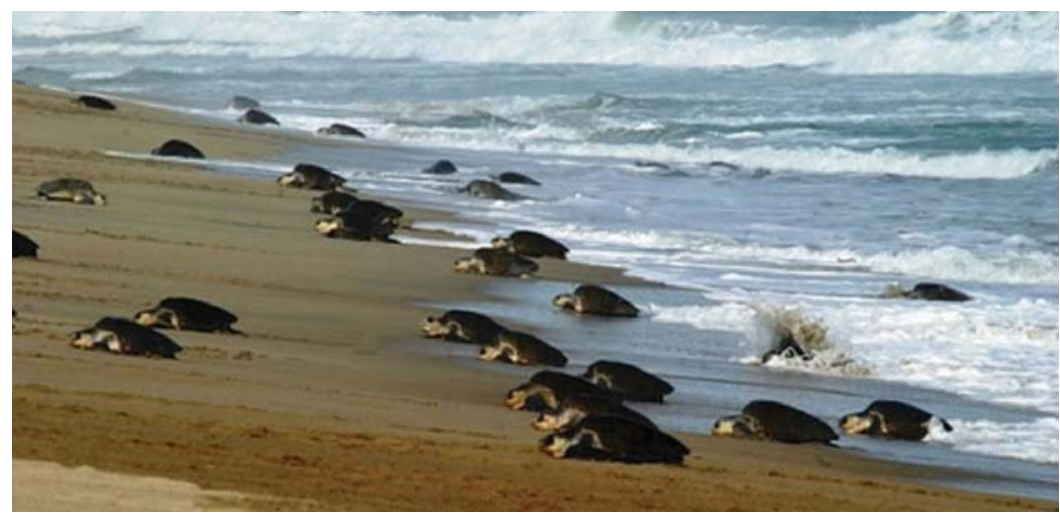

Figura 39: "Puerto de mercancías" con la puesta de huevos de las tortugas (Foto: pagina3.mx)

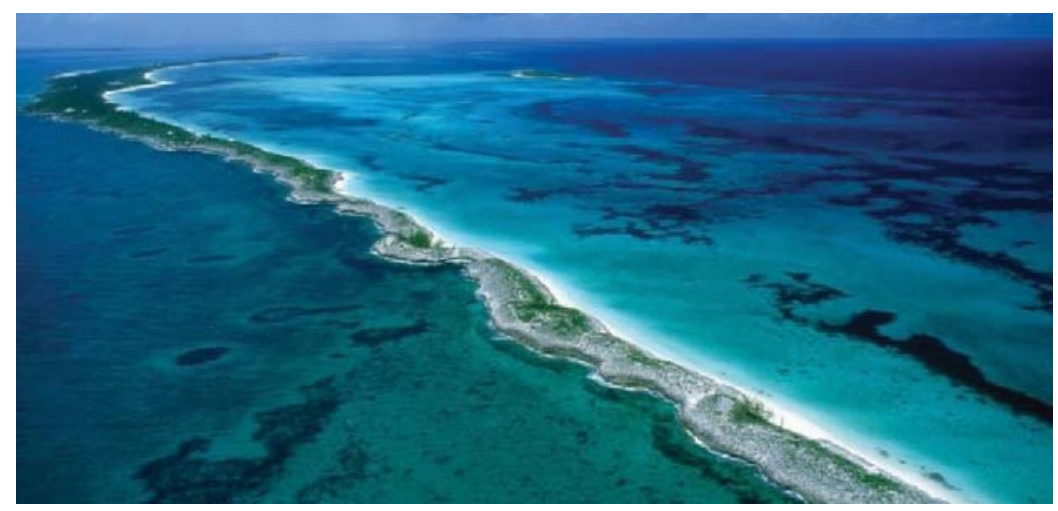

Figura 40: "Dique" vivo de la Gran Barrera de Coral (Foto: explora.cl)

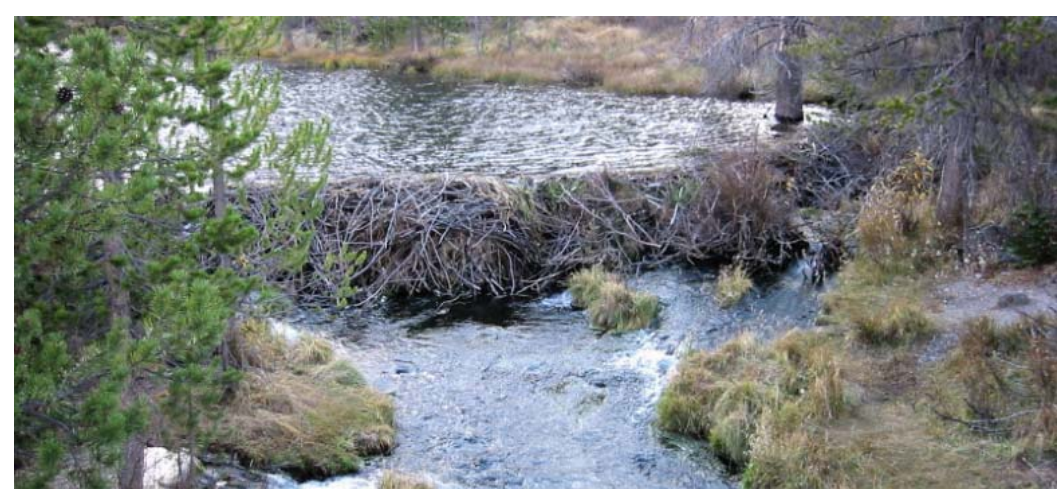

Figura 41: "Presa" realizada por castores (Foto: Wikipedia)

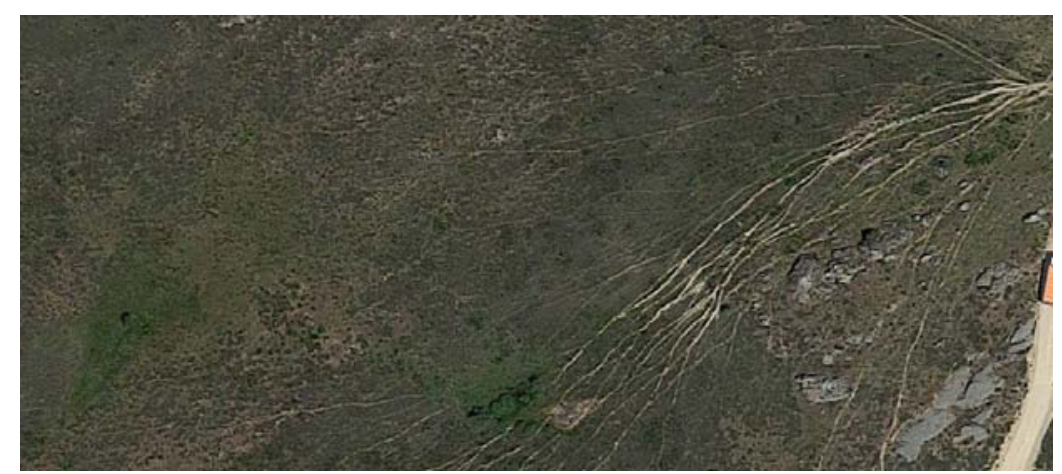

Figura 42: "Caminos" en las veredas realizadas por el ganado en la Cañada Real Soriana Occidental, Trescasas, Segovia (Foto: Google Maps) 


\subsubsection{Paisaje construido en España}

Hay rincones de nuestra geografía que no se podrían entender de la misma manera sin las obras públicas que un día se construyeron. Que han adquirido un espíritu de lugar (genius loci) gracias a ellas. Es el paisaje construido. Aquí hay algunos ejemplos de España (Figuras 43 a 53).

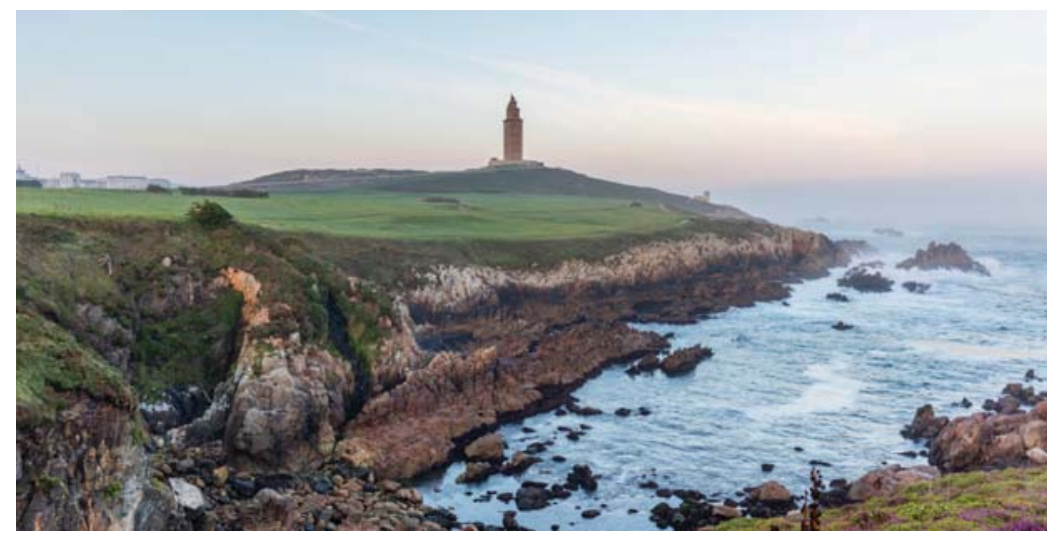

Figura 43: Torre de Hércules, A Coruña. (Diego Delso, Wikipedia)

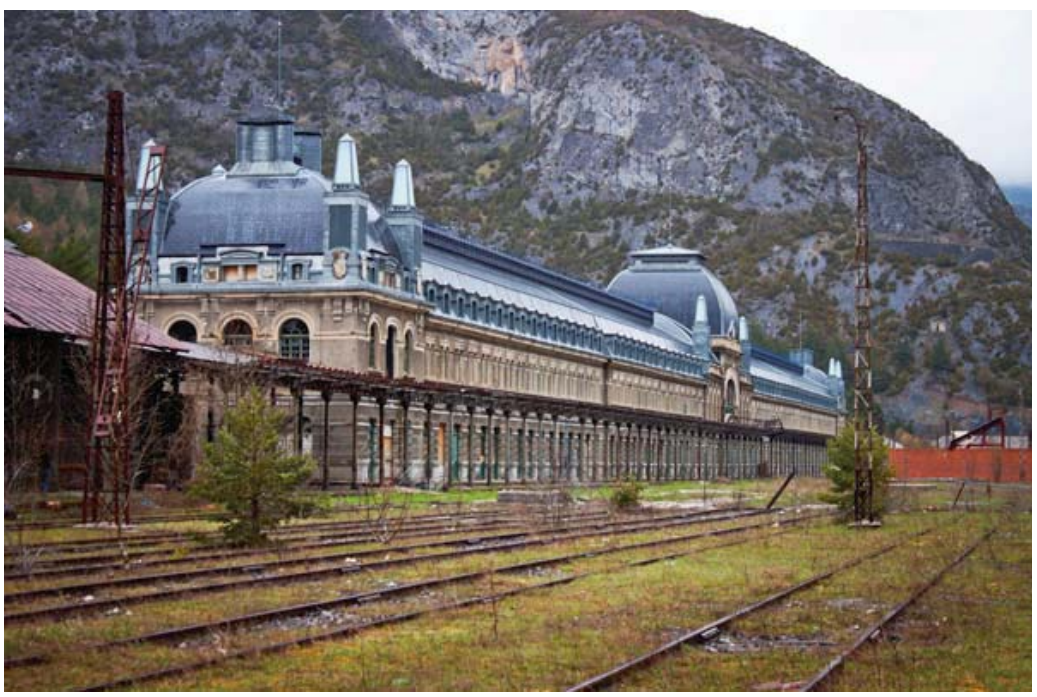

Figura 44: Estación de tren de Somport, Huesca (Foto: viajediario.com)

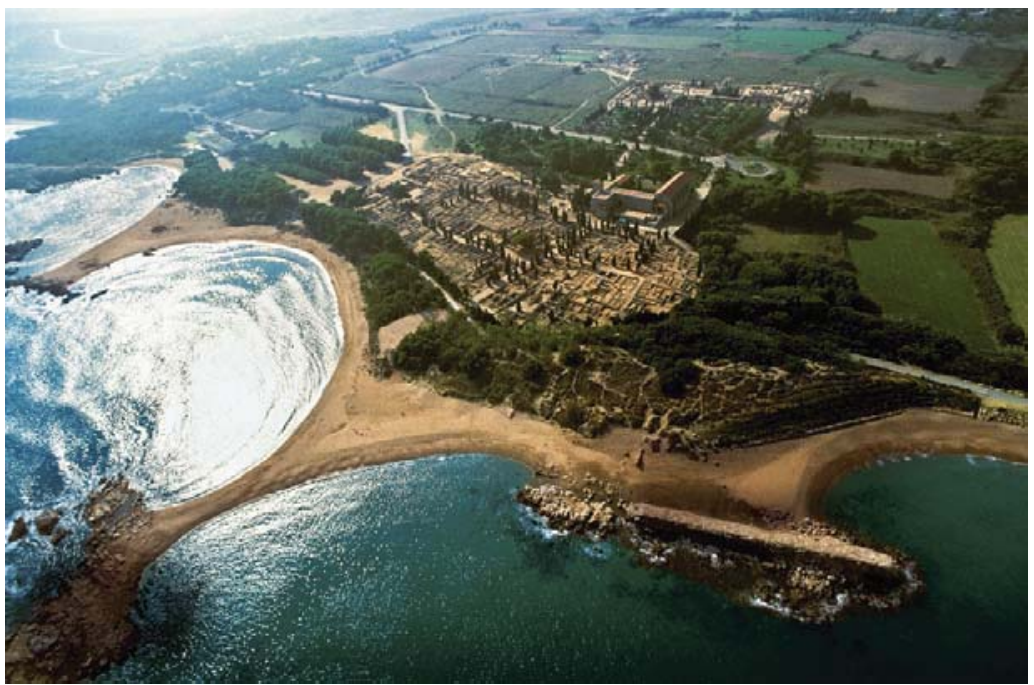

Figura 45: Dique romano de Ampurias, Girona (Foto: National Geographic) 


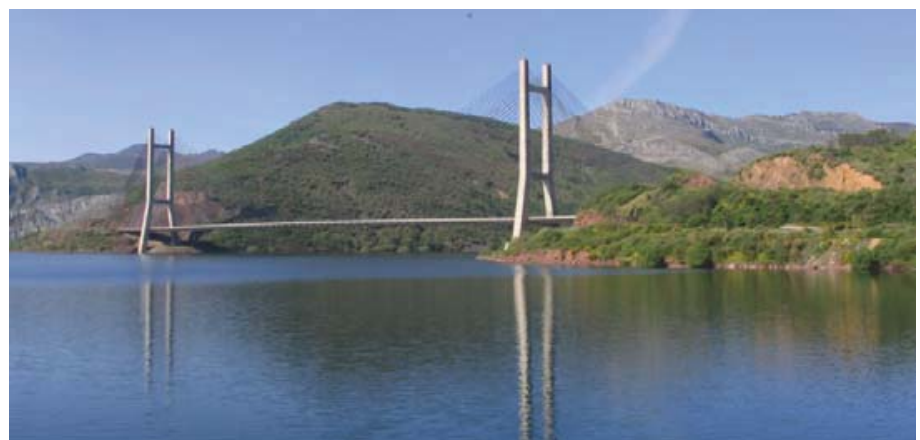

Figura 46: Puente Carlos Fernández Casado en Barrios de Luna, León (Foto: asturlinux.org)

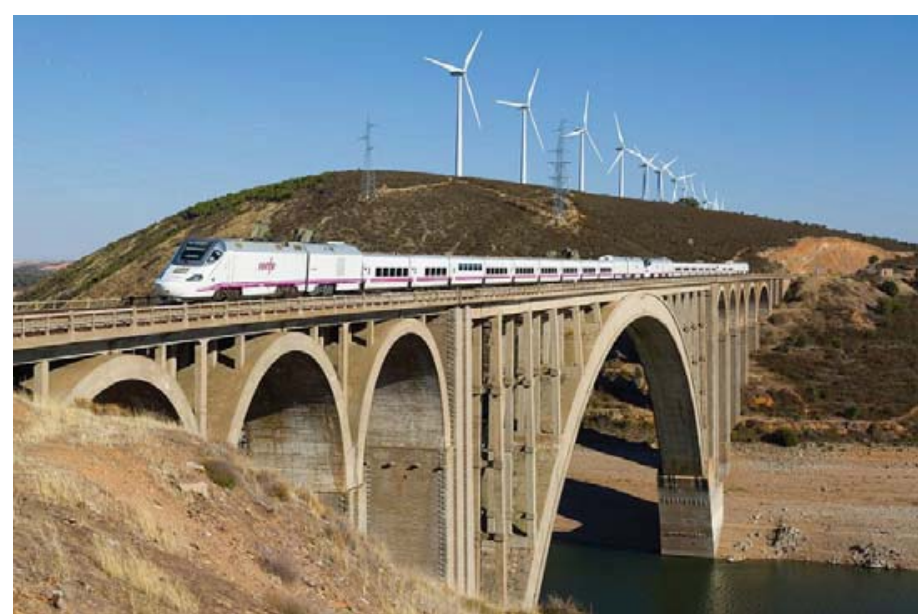

Figura 47: Viaducto Martín Gil, Zamora (Foto: David Gubler)

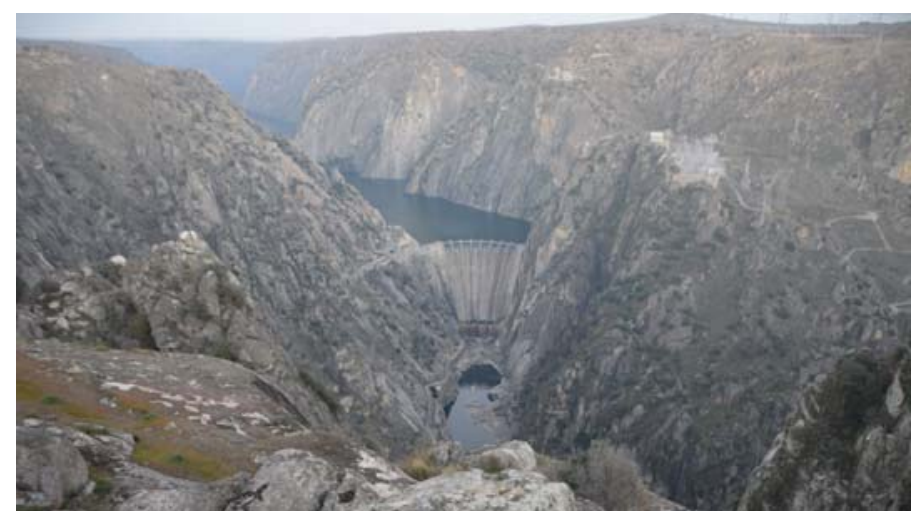

Figura 48: Presa de Aldeadávila, Salamanca (Foto: Mario Martín Antón)

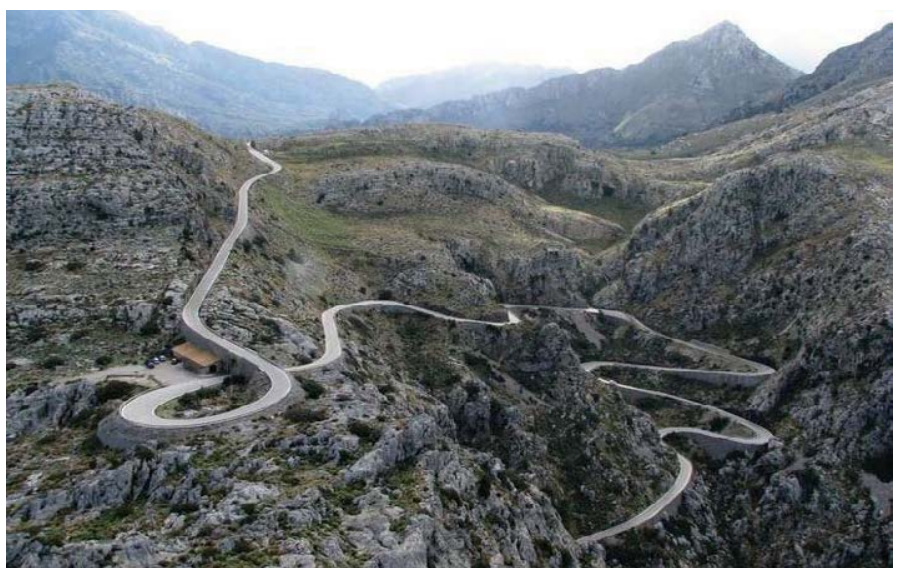

Figura 49: Carretera de Sa Calobra, Mallorca, Baleares (Foto: es.pinterest.com/fhshernandez) 


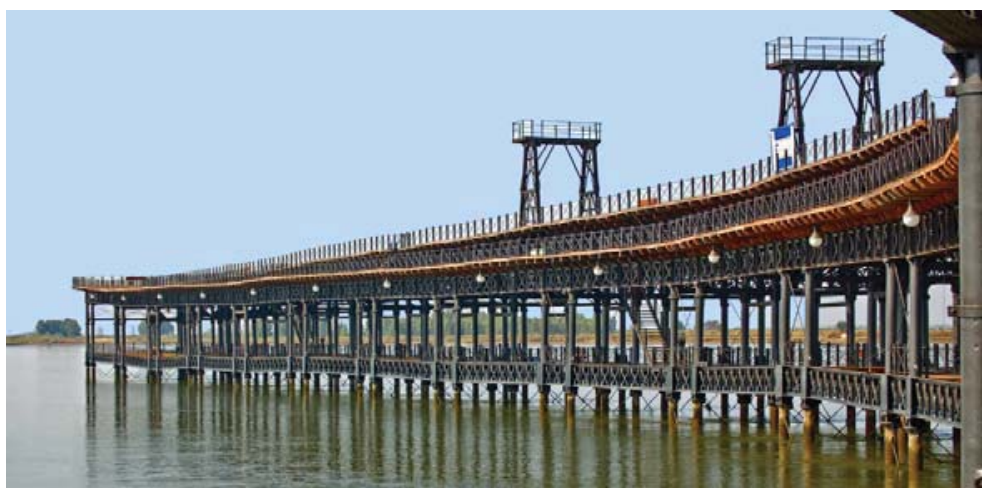

Figura 50: Muelle de Riotinto, Huelva (Foto: Juan Martín, muelleriotinto.blogspot.com)

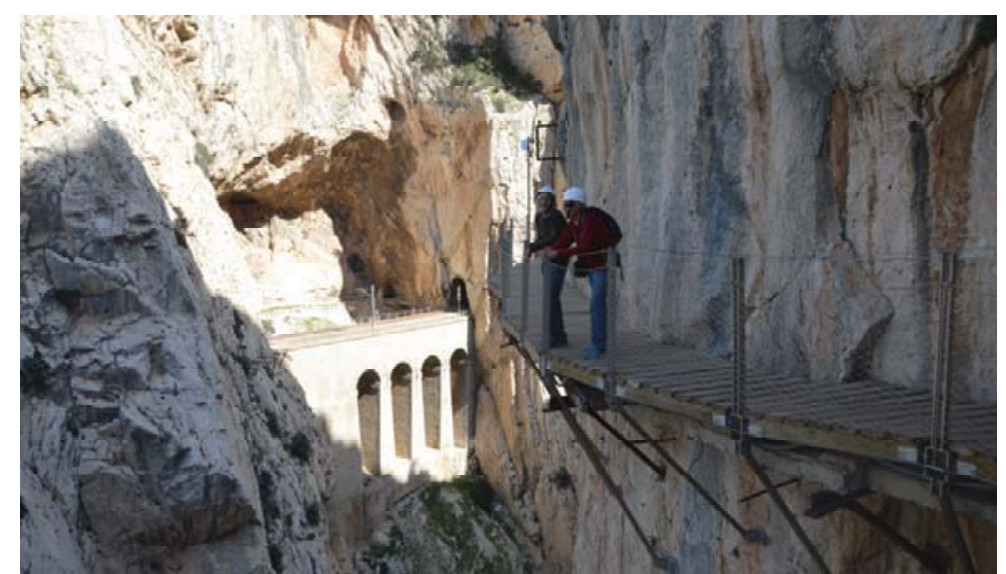

Figura 51: Caminito del Rey, Málaga (Foto: Mario Martín Antón)

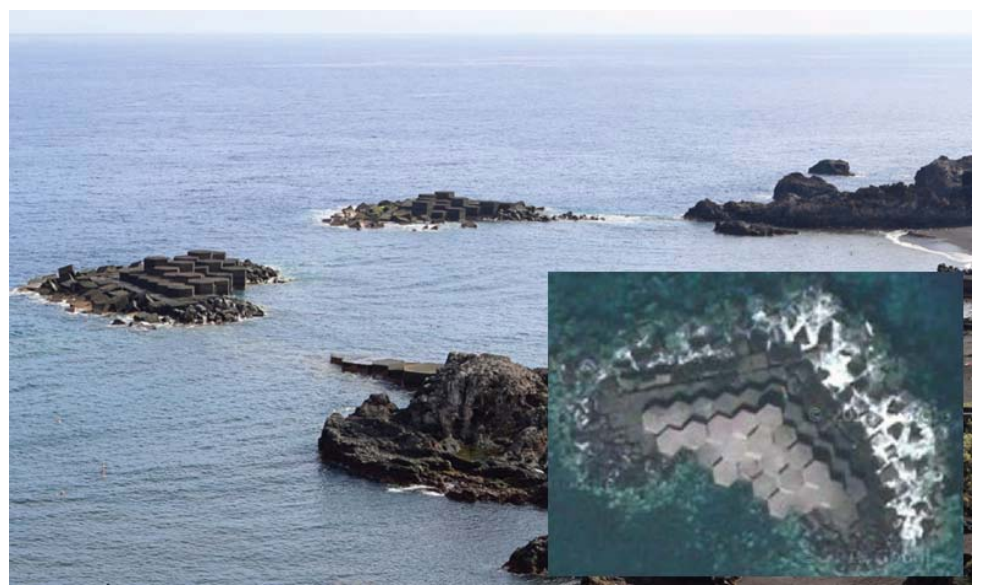

Figura 52: Playa de Los Cancajos, La Palma, Canarias (Foto: Wikipedia)

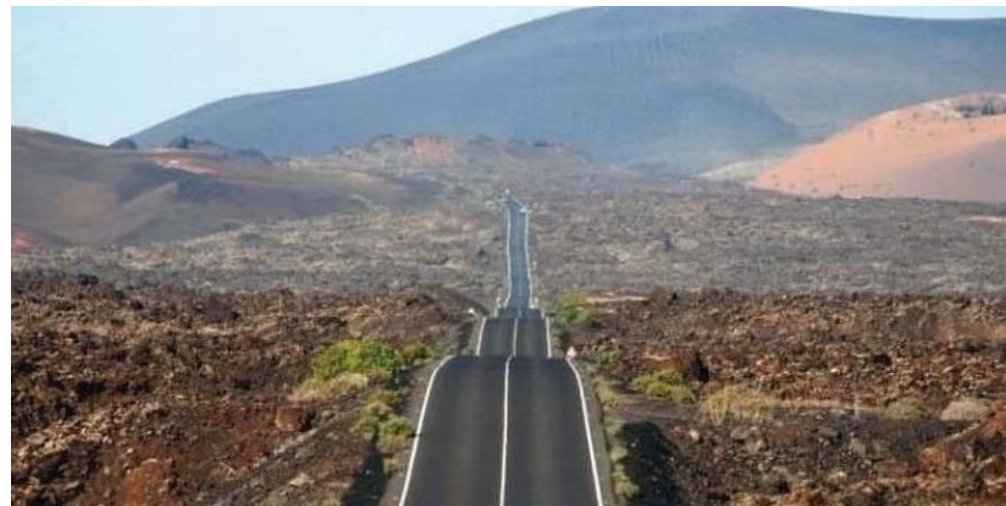

Figura 53: Carretera LZ-67 hacia Timanfaya, Lanzarote (Foto: vacacionesenlanzarote.es) 


\subsubsection{Paisaje costero destruido en España}

Anteriormente se han mostrado ejemplos de paisaje construido en España que, expresado de otra manera, son paisajes que pierden su razón de ser sin la obra de ingeniería, su esencia, su significado. En cambio, hay muchos más ejemplos donde la construcción ha superado el "límite elástico" del paisaje, destruyéndolo sin remedio. En este caso solo se van a mostrar ejemplos de paisaje costero (Figuras 54 a 59): El paisaje litoral destruido.

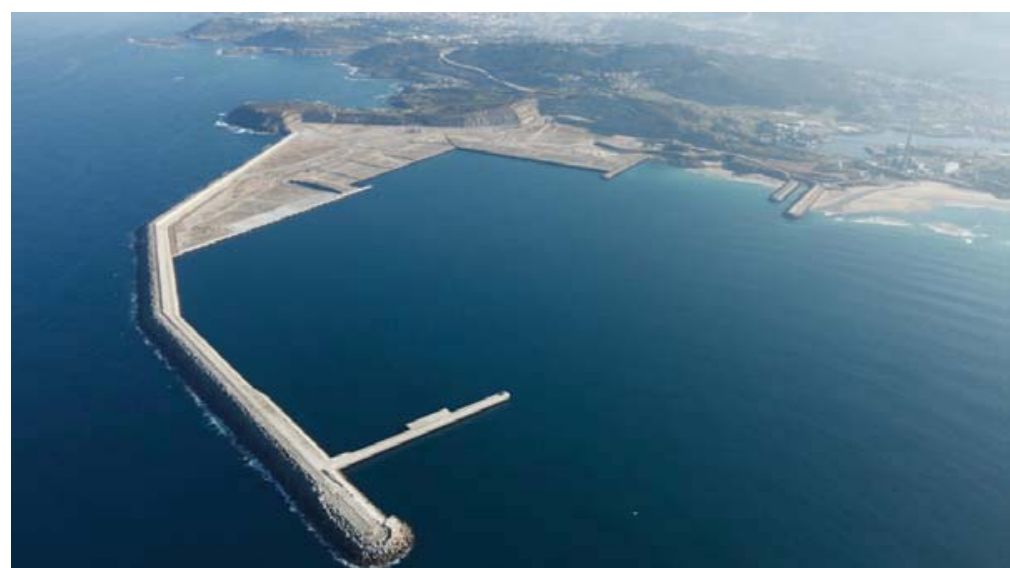

Figura 54: Puerto de Langosteira, A Coruña (Foto: El Confidencial)

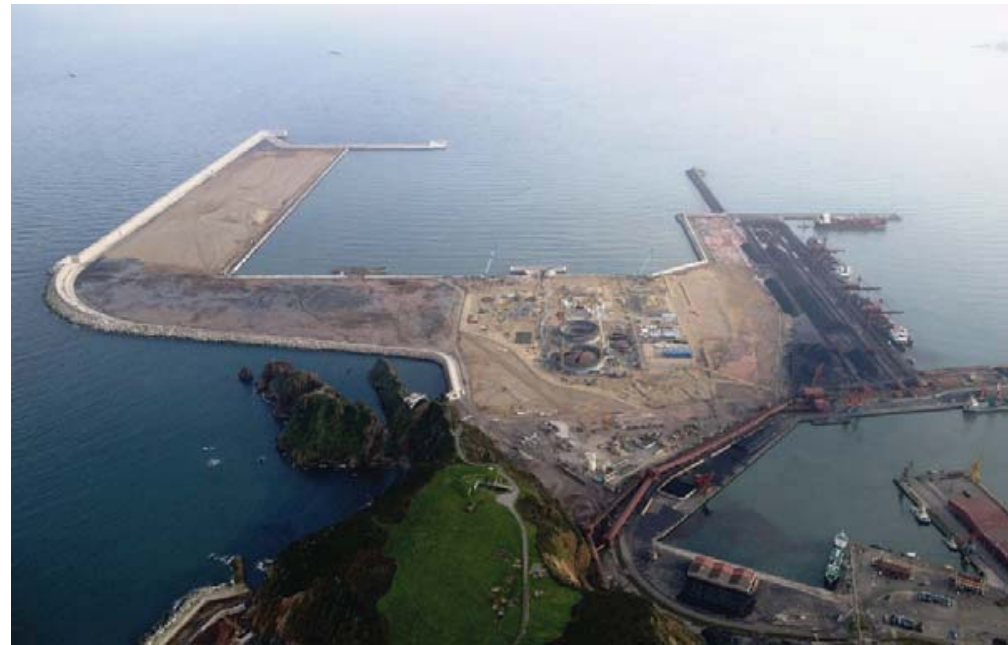

Figura 55: Dique Cabo Torres, Gijón, Asturias (Foto: FCC)

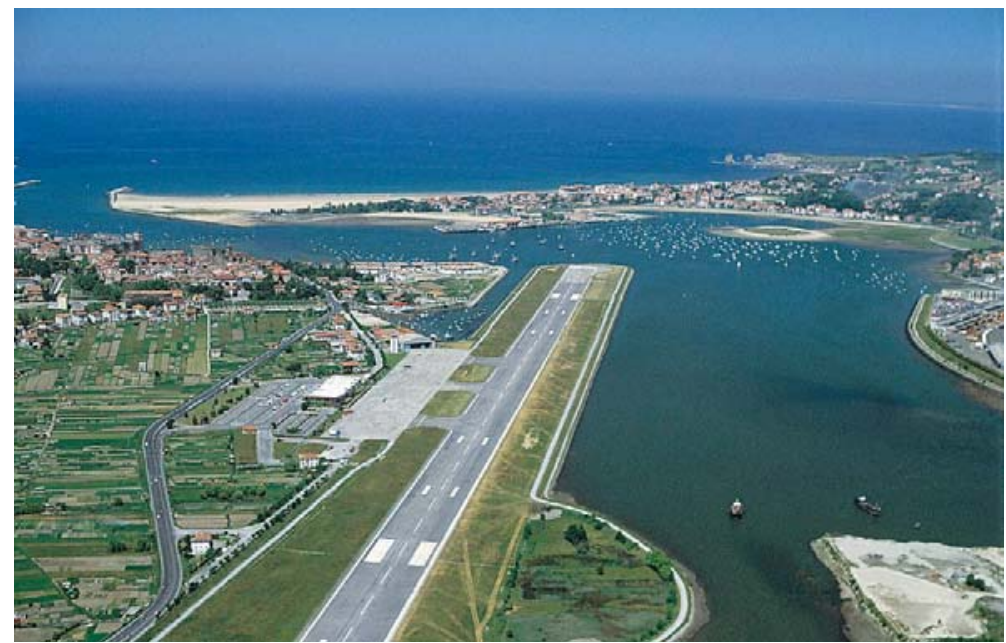

Figura 56: Aeropuerto de San Sebastián (Foto: Wikipedia) 


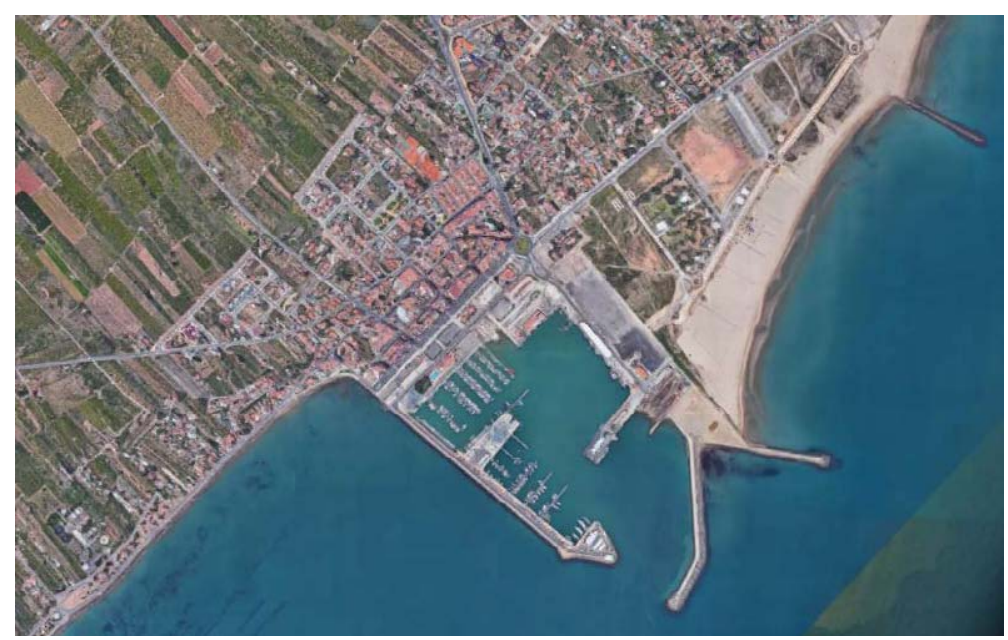

Figura 57: Puerto de Burriana, Castellón (Foto: Google Maps)

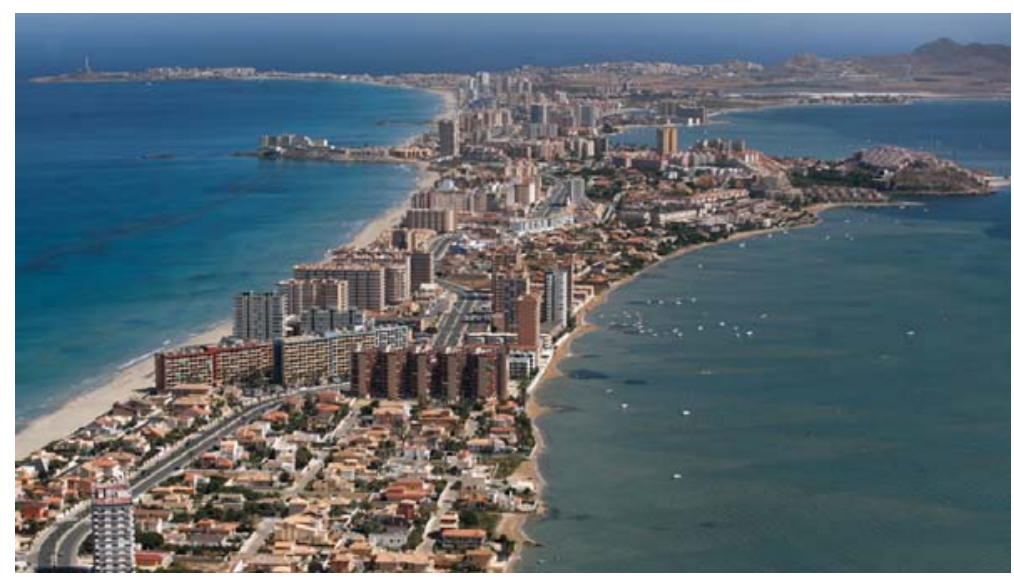

Figura 58: La Manga del Mar Menor, Murcia (Foto: blacknuba.wordpress.com)

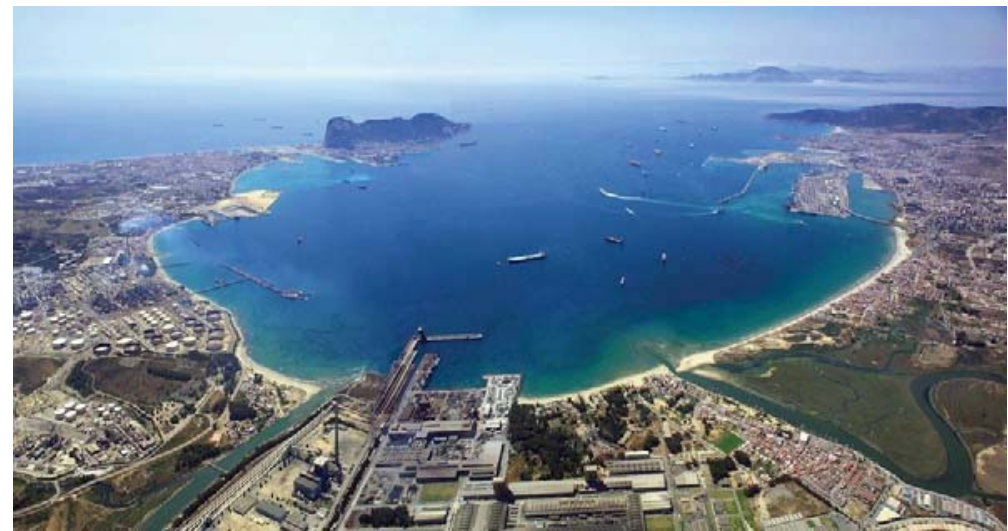

Figura 59: Bahía de Algeciras (Foto: El Estrecho Digital)

\subsubsection{Paisaje oculto}

La construcción de obras civiles supone siempre un impacto en el paisaje. Muchas de ellas, además, tienen efectos secundarios sobre el entorno. Es el caso de las presas, que, una vez construidas, sirven para formar un volumen de agua que va a "invadir" el paisaje. Muchas veces esa invasión se produce anegando pueblos enteros (caso de Riaño) y otras Obras Públicas existentes. La magia de la sequía, que a efectos prácticos es negativa por la escasez y restricciones en el uso del agua, deja al descubierto verdaderos paisajes ocultos, muchos de ellos antiguos paisajes construidos. Aquí se tiene algún ejemplo de España (Figuras 60 y 61): 


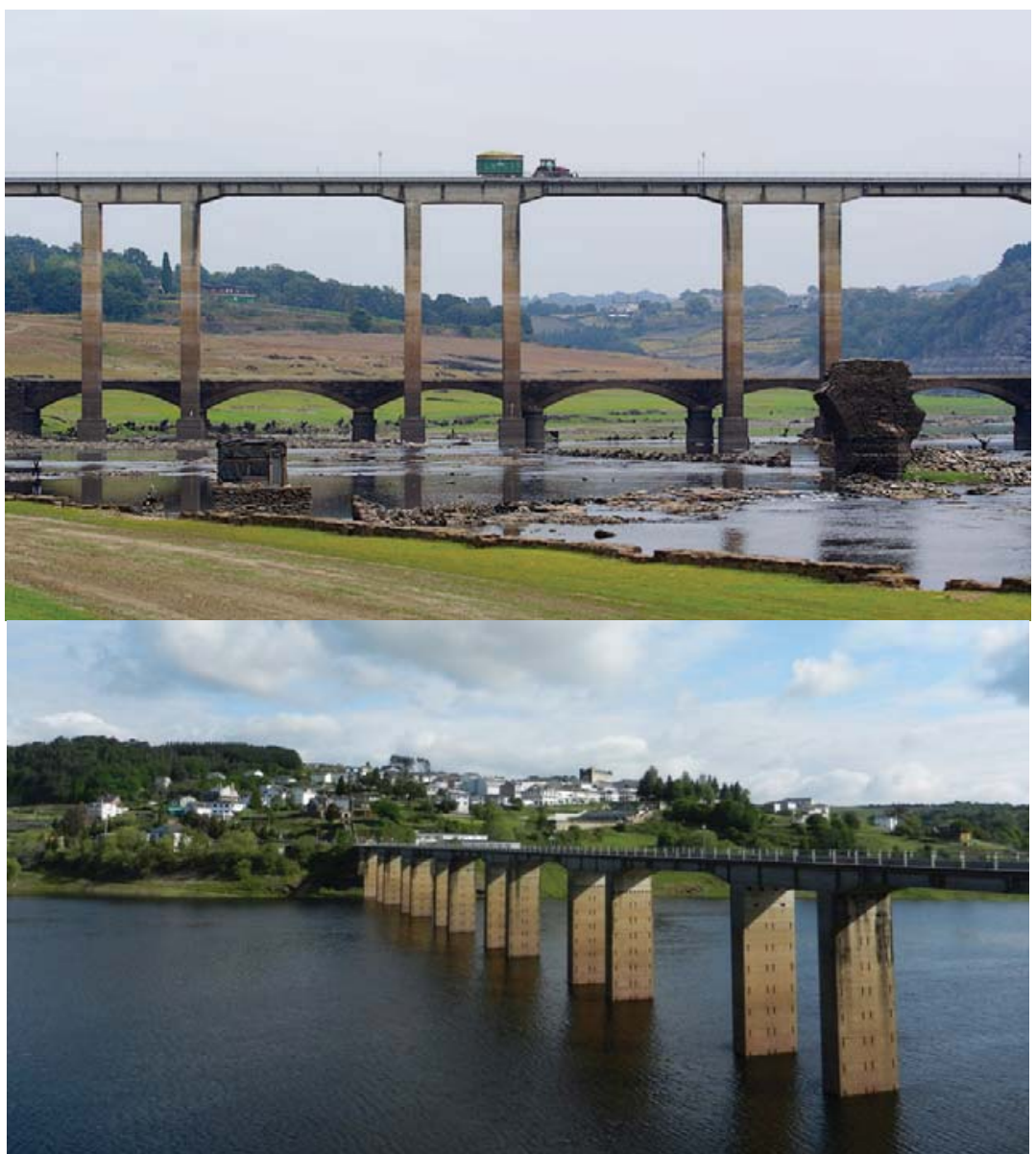

Figura 60: Puentes de Portomarín, Lugo: embalse vacío (Foto: galiciaenfotos.com) y embalse lleno (Foto: Pixabay.com)

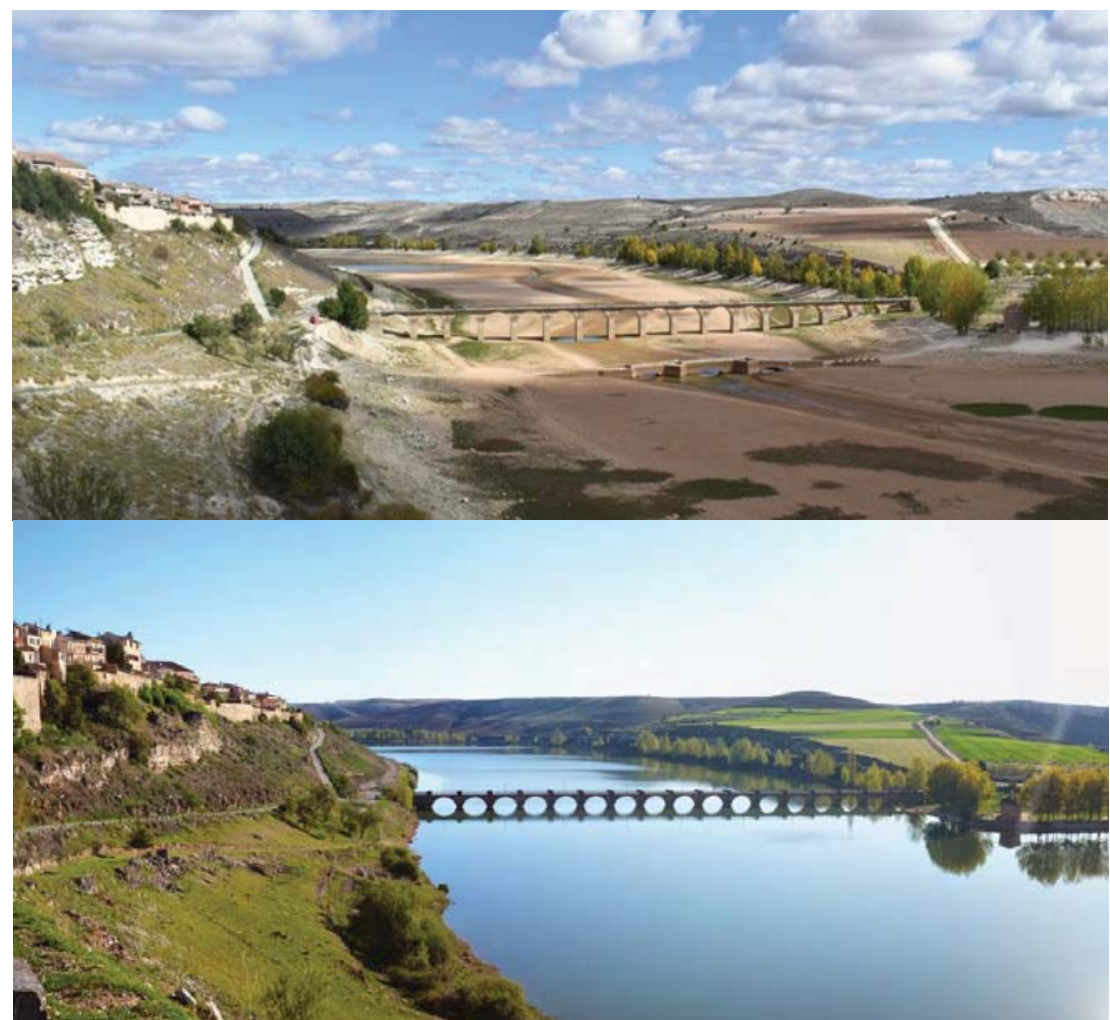

Figura 61: Puentes de Maderuelo, Segovia: Embalse vacío (Foto: Adrián Escobar) y embalse lleno (Foto: rutaspitufasmtb.blogspot.com) 


\subsubsection{Paisaje aéreo}

Las obras de ingeniería se suelen realizar por criterios funcionales o estéticos a nivel de suelo, pero hay algunos ejemplos realmente fascinantes que se pueden visualizar gracias a las imágenes aéreas o de satélite, hace algún siglo algo impensable. La simetría, la ornamentación, la sinuosidad, las formas, los colores, etc., hacen posible contemplar el mundo terrenal desde los cielos con otro enfoque. Como ejemplo en la antigüedad tenemos los geoglifos de Nazca (Perú). Aquí se habla simplemente de paisaje visual en sentido vertical que solo abarca las fotografías de los ejemplos, obtenidas con Google Earth. Hace falta bajar a tierra firme y observar la Obra Pública para poder valorar su impacto en el paisaje en su conjunto (Figuras 62 a 72).

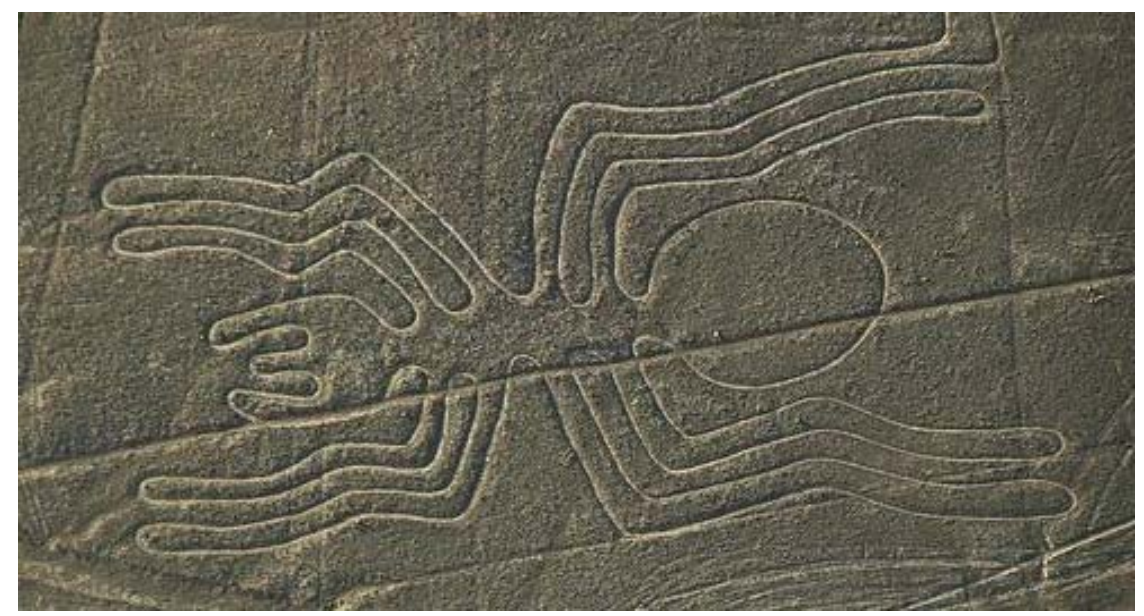

Figura 62: Líneas de Nazca (Perú)

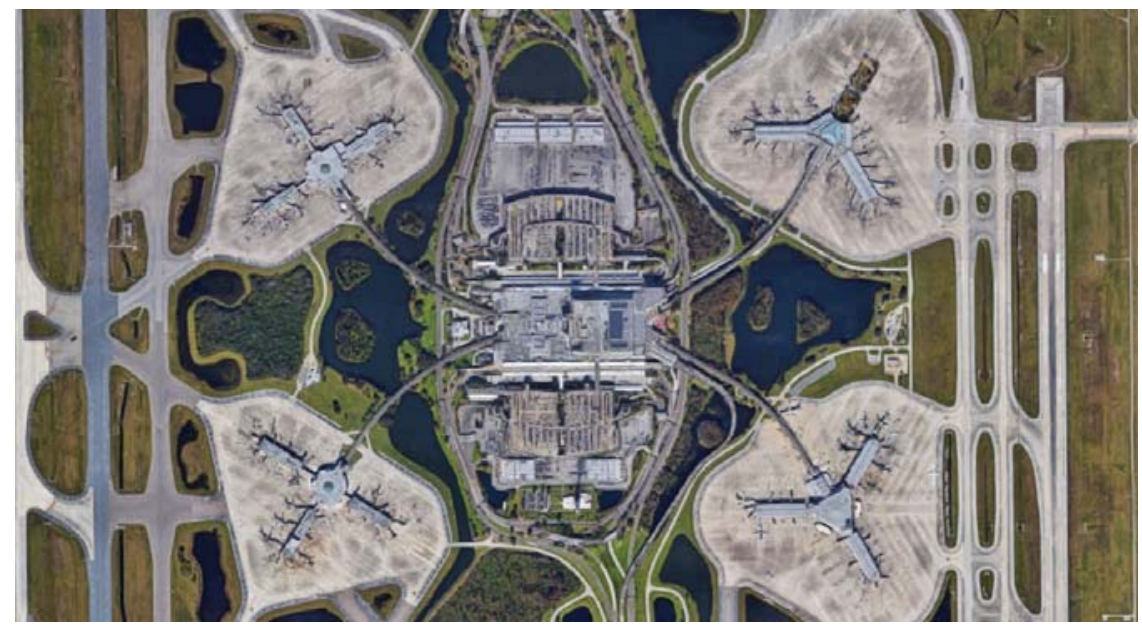

Figura 63: Aeropuerto de Orlando (EEUU)

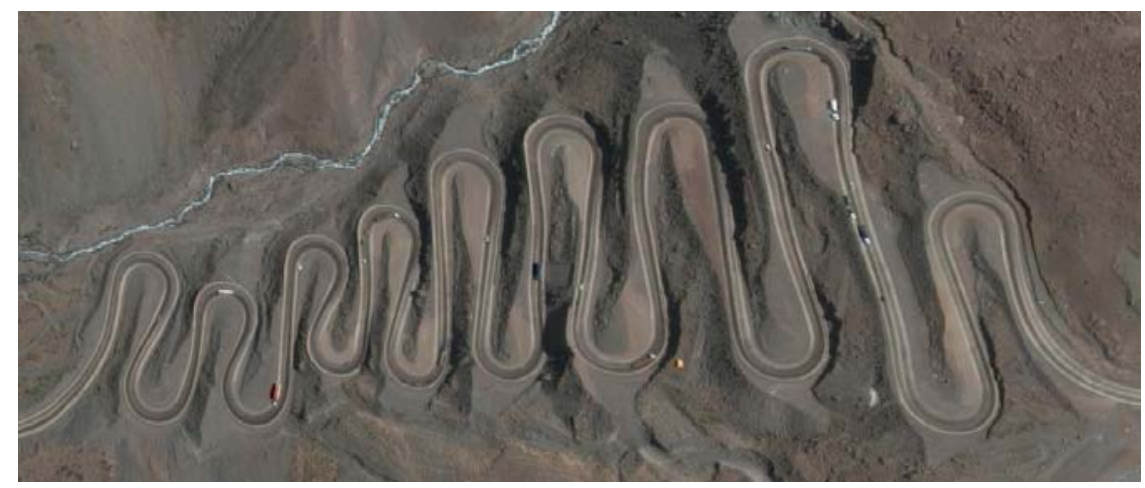

Figura 64: Paso del Cristo Redentor (Chile) 


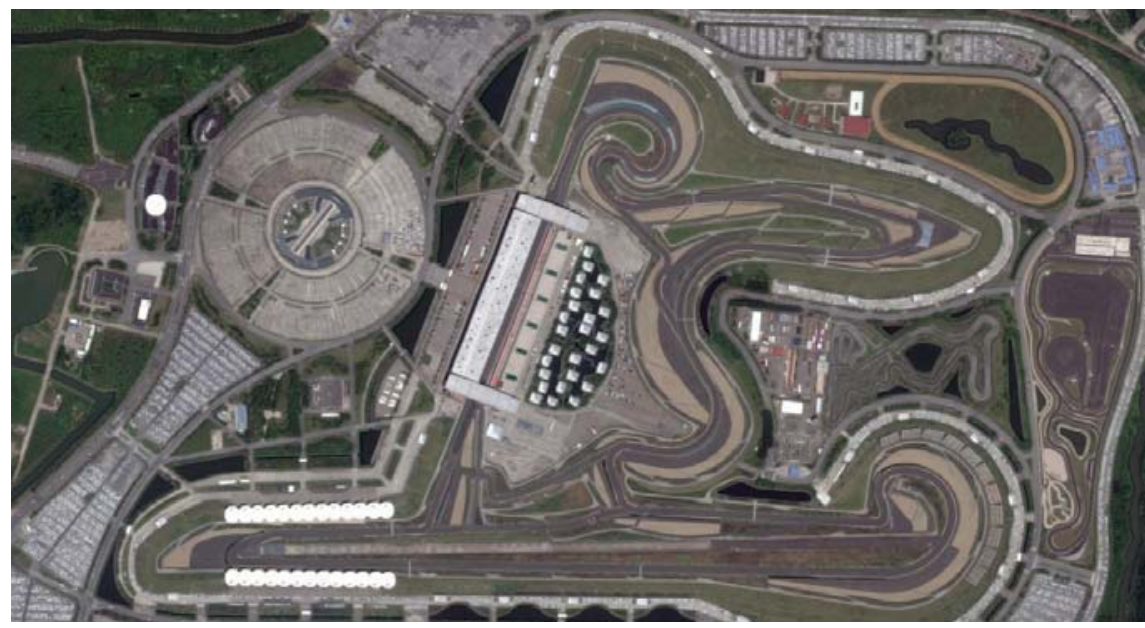

Figura 65: Circuito de Fórmula 1 de Shanghai

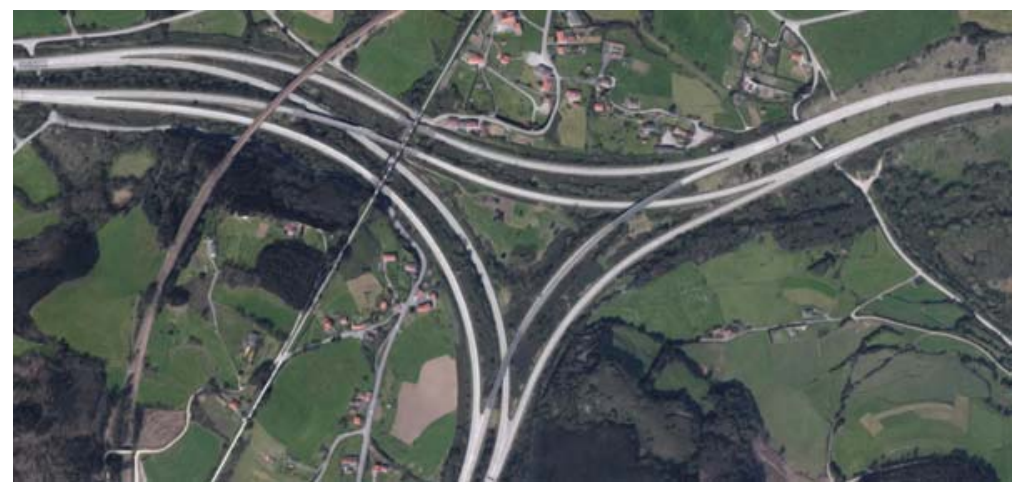

Figura 66: Enlace de la "Y asturiana" (A66-A8) (Asturias)

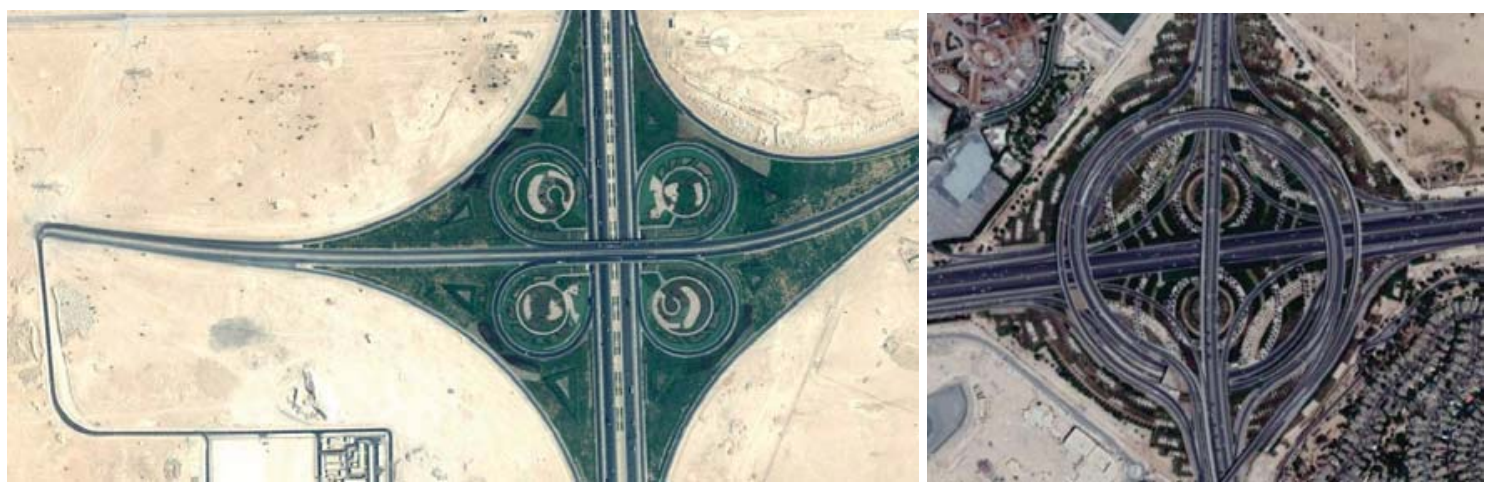

Figura 67: Enlace de carreteras en Doha (Qatar) y Dubai (EAU)

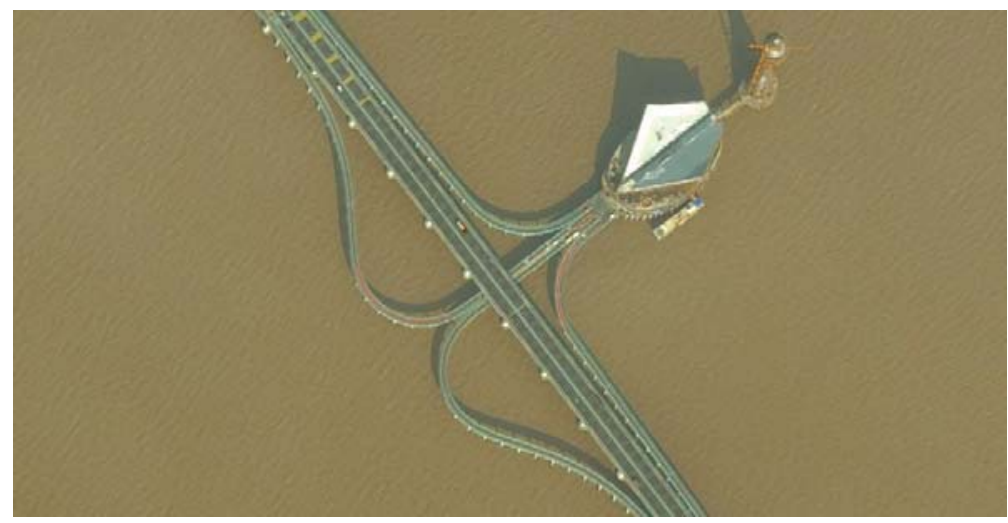

Figura 68: Enlace en el puente de la bahía de Hangzhou, China 

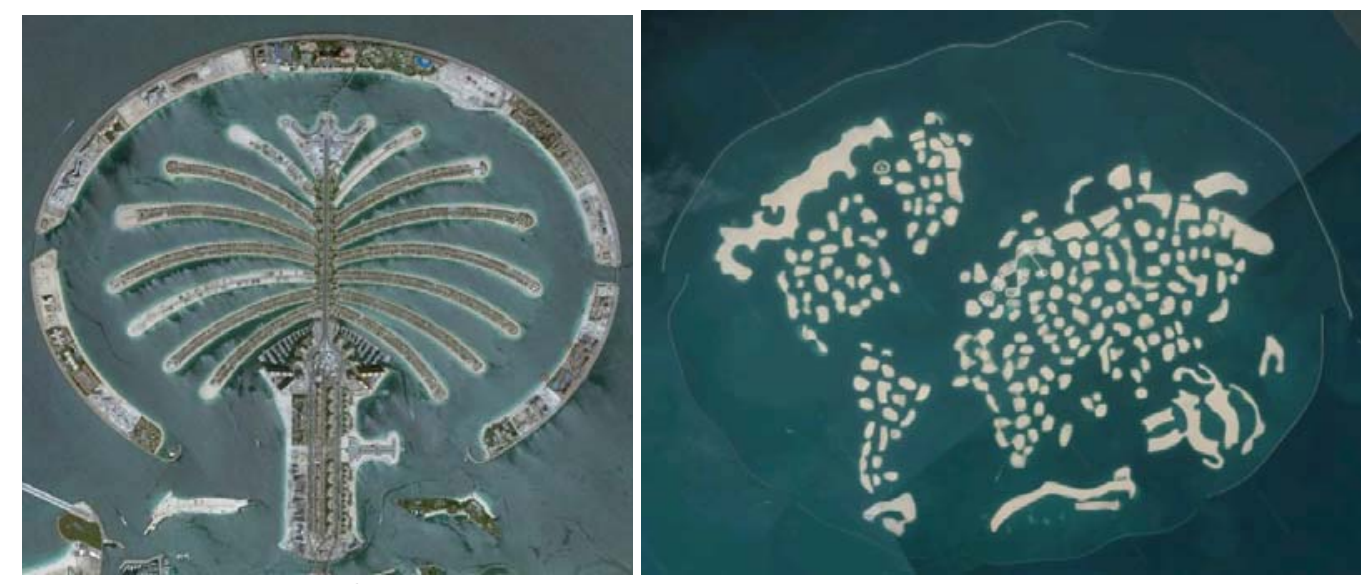

Figura 69: "Palm Jumeirah" y "The World" de Dubai, EAU

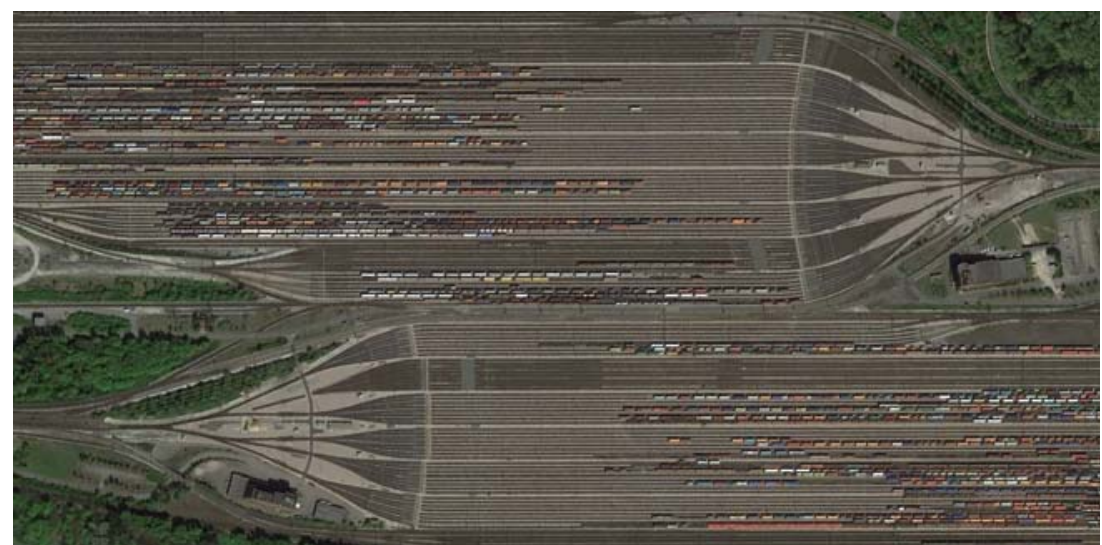

Figura 70: Puerto seco de Hamburgo, Alemania

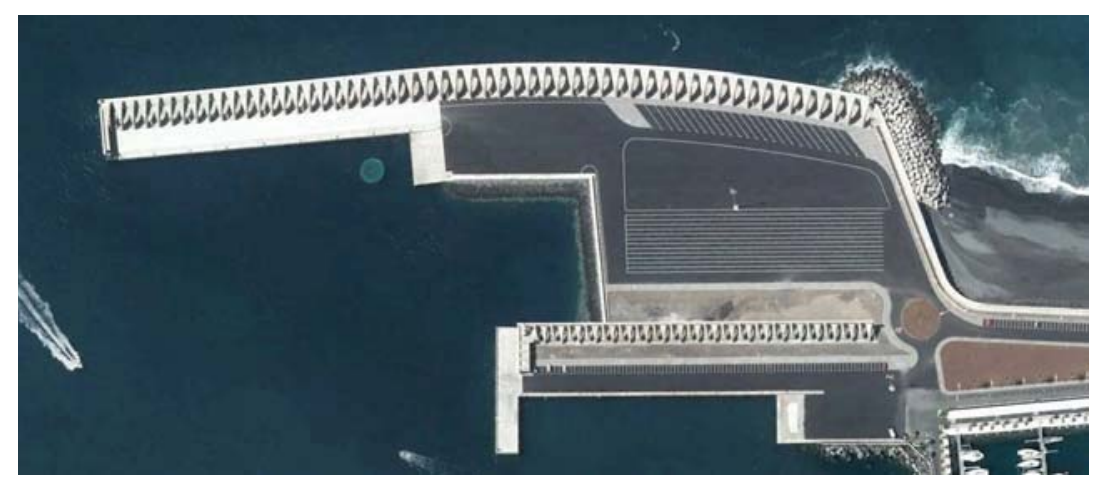

Figura 71: Puerto de Tazacorte, Isla de la Palma, Canarias

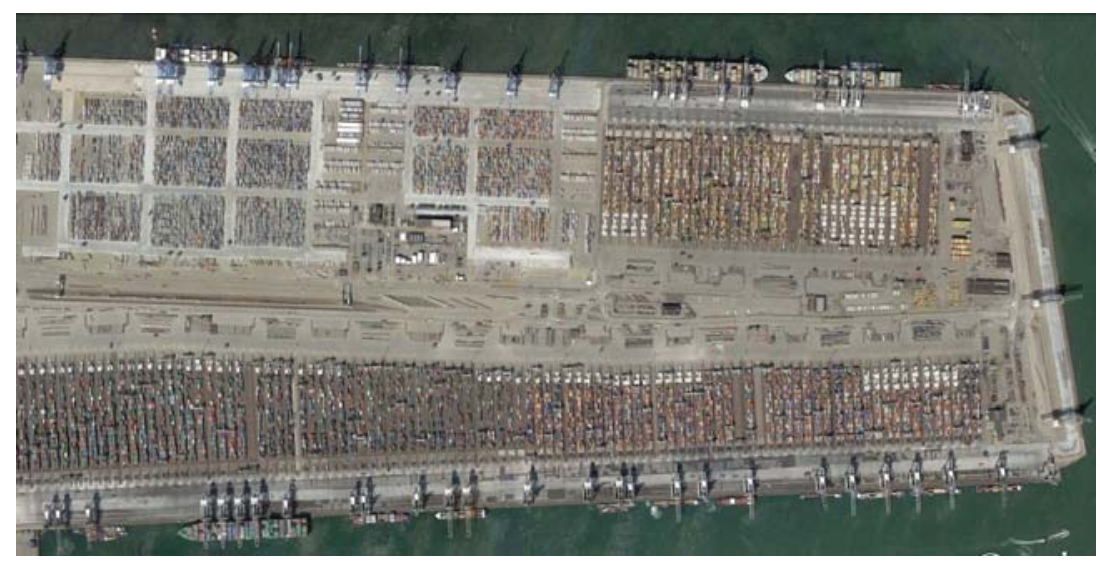

Figura 72: Puerto de Rotterdam, Países Bajos 


\subsubsection{Paisaje aéreo urbano: el urbanismo}

Sin duda, el mejor contexto para admirar desde el aire la acción del hombre sobre el entorno son las ciudades. De esta manera, muchas veces es posible catalogar esas poblaciones según los criterios que se comentan en el estado del arte: ciudad tradicional, invadida, abandonada y reconquistada. El urbanismo está estrechamente ligado al paisaje urbano y en los siguientes ejemplos se verán grandes realizaciones en las que los dos van de la mano (Figuras 73 a 79).
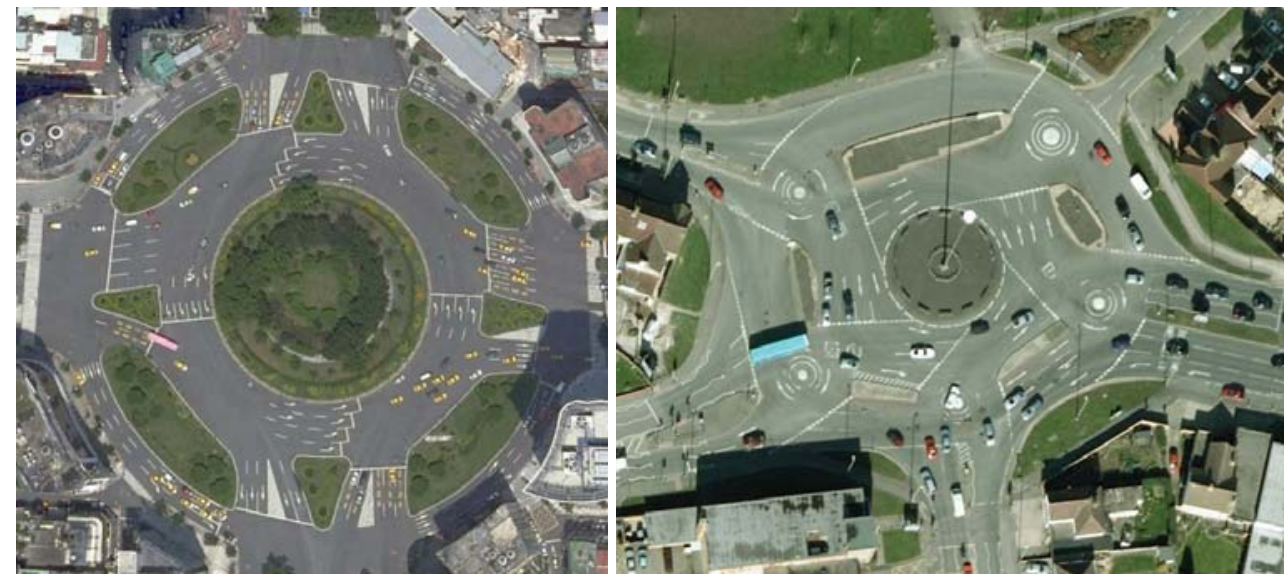

Figura 73: Rotonda en Taipei (Taiwan) y "Magic Roundabout" en Swindon (UK)
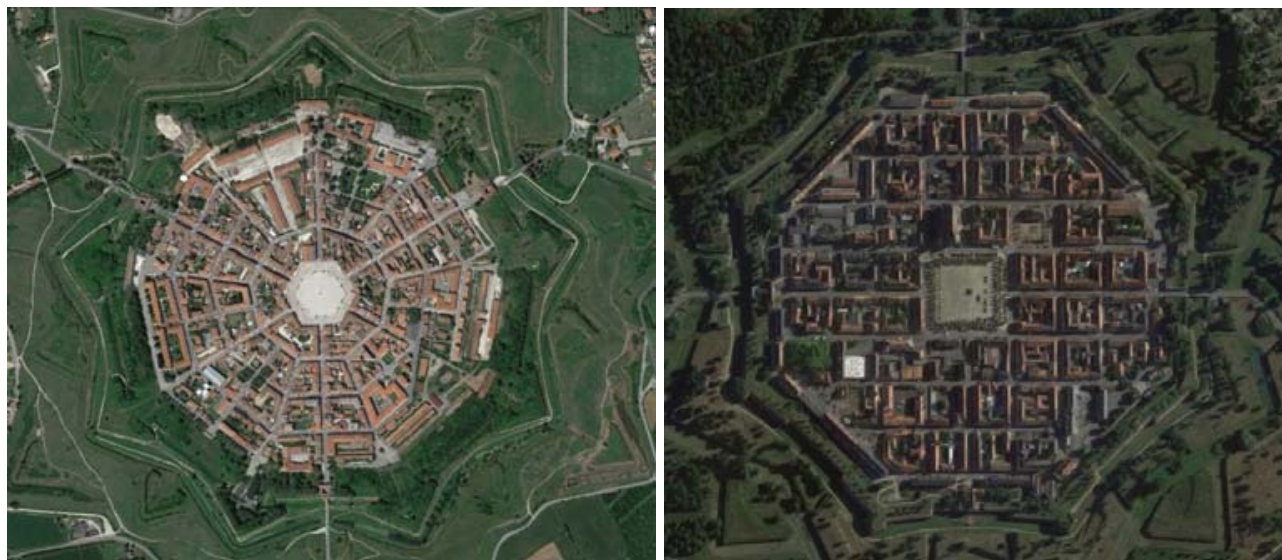

Figura 74: Urbanismo en Palmanova (Italia) y Neuf-Brisach (Francia)

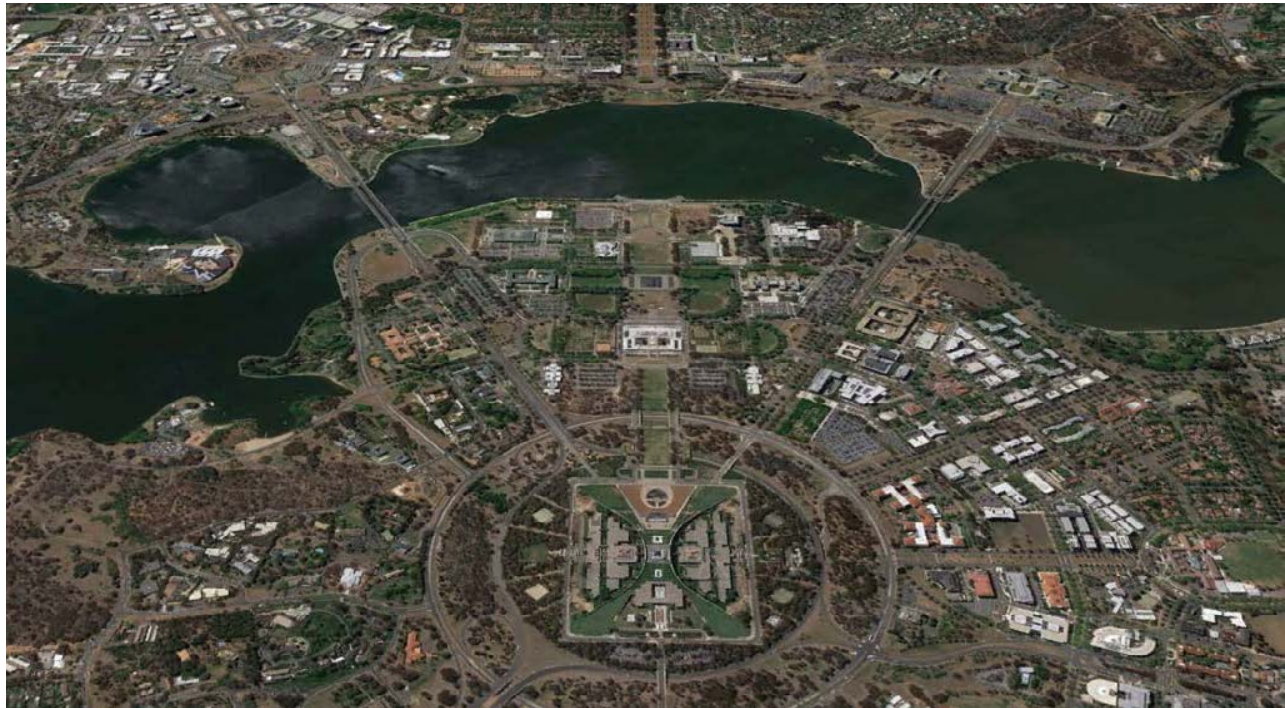

Figura 75: Urbanismo de Canberra, Australia 


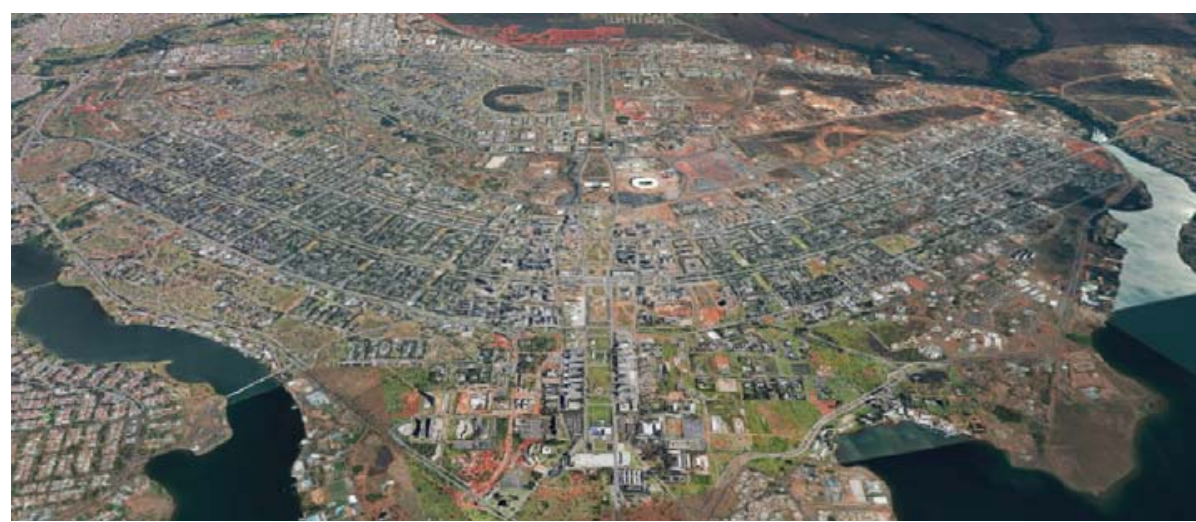

Figura 76: Urbanismo en Brasilia, Brasil

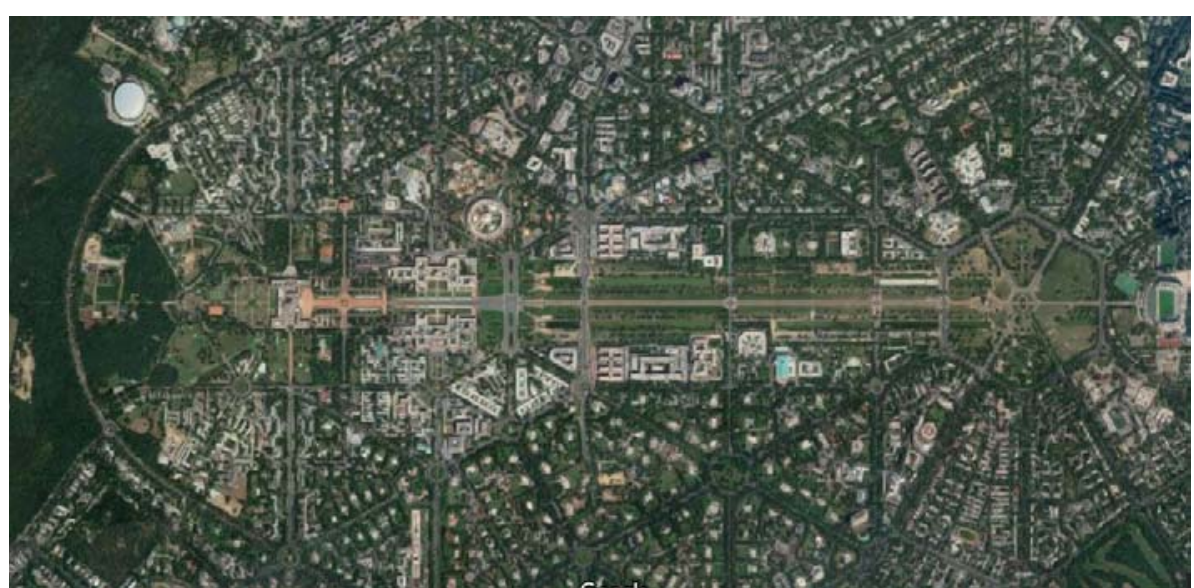

Figura 77: Urbanismo en Nueva Delhi, India

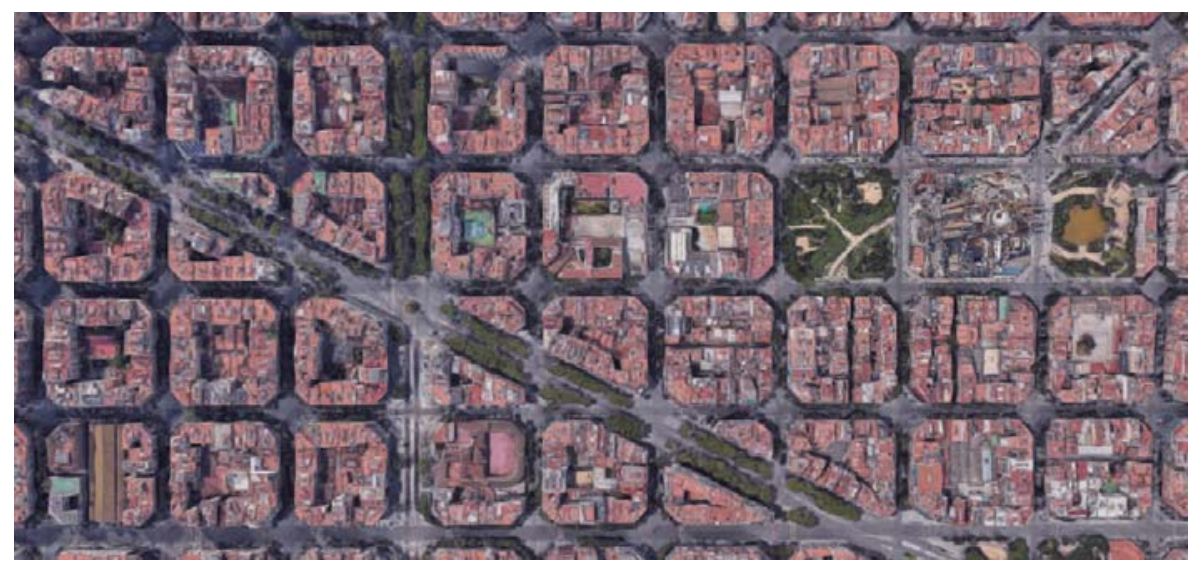

Figura 78: Plan Cerdá de Barcelona, España

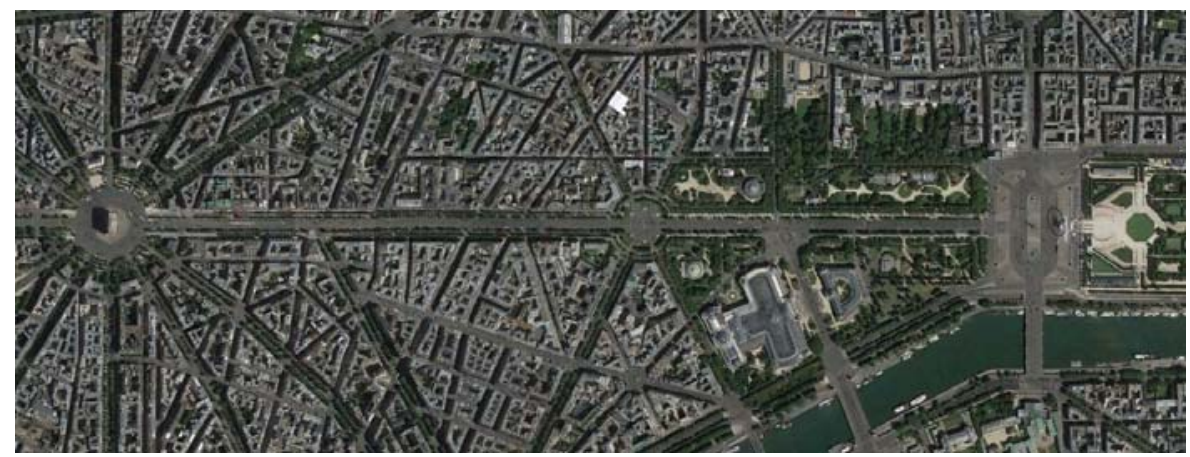

Figura 79: Urbanismo de París, Francia. Avenida de los Campos Elíseos 


\subsubsection{Paisaje evolutivo}

El ser humano siempre ha intentado mejorar su calidad de vida y eso se refleja en la construcción. Hace muchos siglos, los caminos se empleaban para pasar con carros tirados por animales, por lo que las pendientes y las curvas no eran muy importantes. Con los años y la aparición del automóvil, los puentes, por ejemplo, tenían que cumplir una serie de requisitos de comodidad: anchura, alineación y regularidad. Todo esto se ha comentado en la introducción, pero solo desde el punto de vista técnico y de utilidad, no con su relación con el paisaje.

Los puentes se construyen en el tramo de río más favorable ya sea por la orografía o por la ubicación geográfica más propensa. Y cuando se hacen puentes nuevos para nuevas carreteras, muchas veces se realizan en las inmediaciones del anterior. Esto produce a veces una imagen curiosa, de un tramo corto de río o valle cruzado por un gran número de pasos, ya sean de carretera, ferrocarril e incluso acueductos, cables eléctricos o presas... Cada uno más moderno que el anterior y más alto, de otros materiales y, en la mayoría de los casos, teniendo menos en cuenta el paisaje.

Aquí se tienen algunos ejemplos (Figuras 80 a 85):

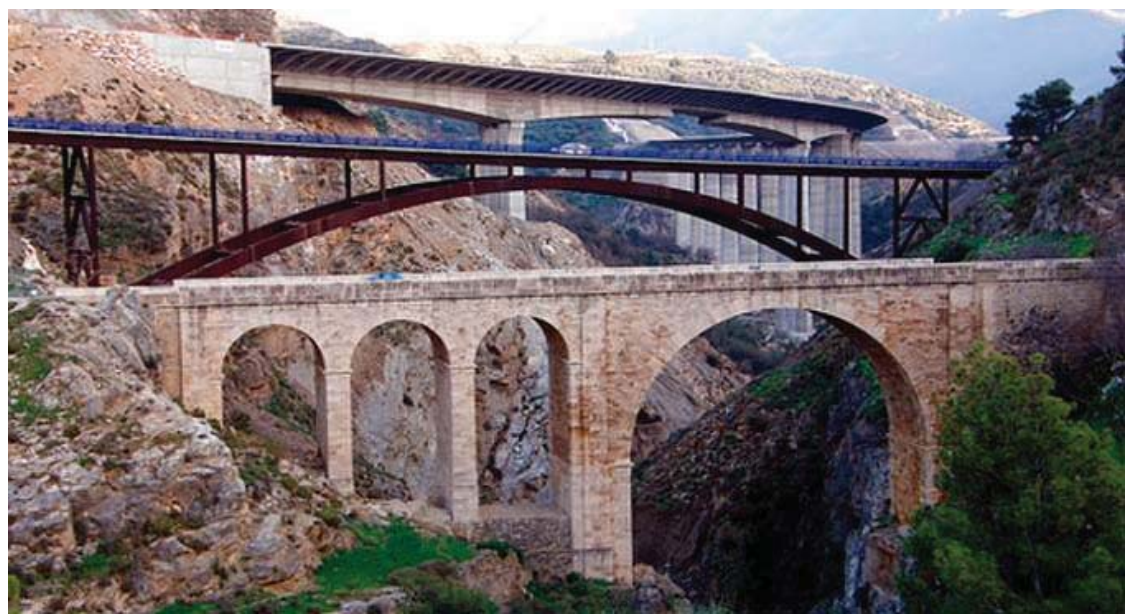

Figura 80: Puentes sobre el río Ízbor en Acebuches, Granada (Foto: turismovalledelecrin.com)

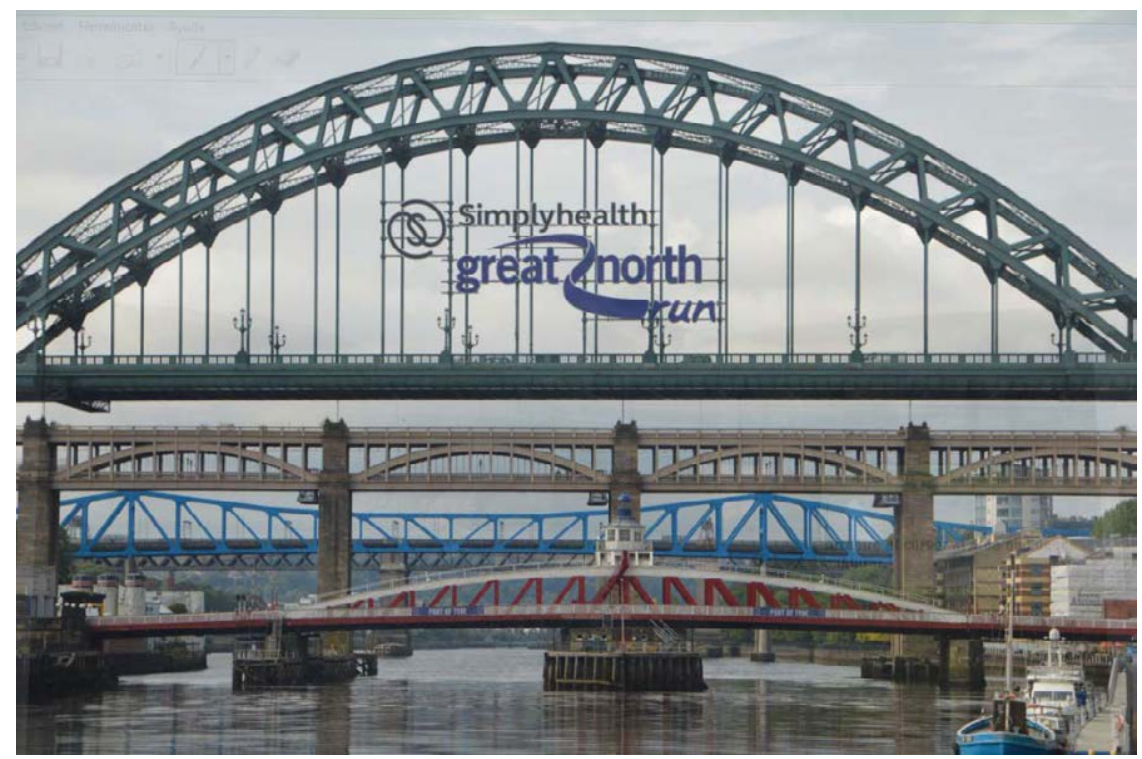

Figura 81: Puentes de Newcastle, Inglaterra: High Level (1849, marrón), Swing (1876, rojo), King Edward VII (1906, gris), Tyne (1928, verde), Queen Elizabeth II (1981, azul). (Foto: Mario Martín Antón) 


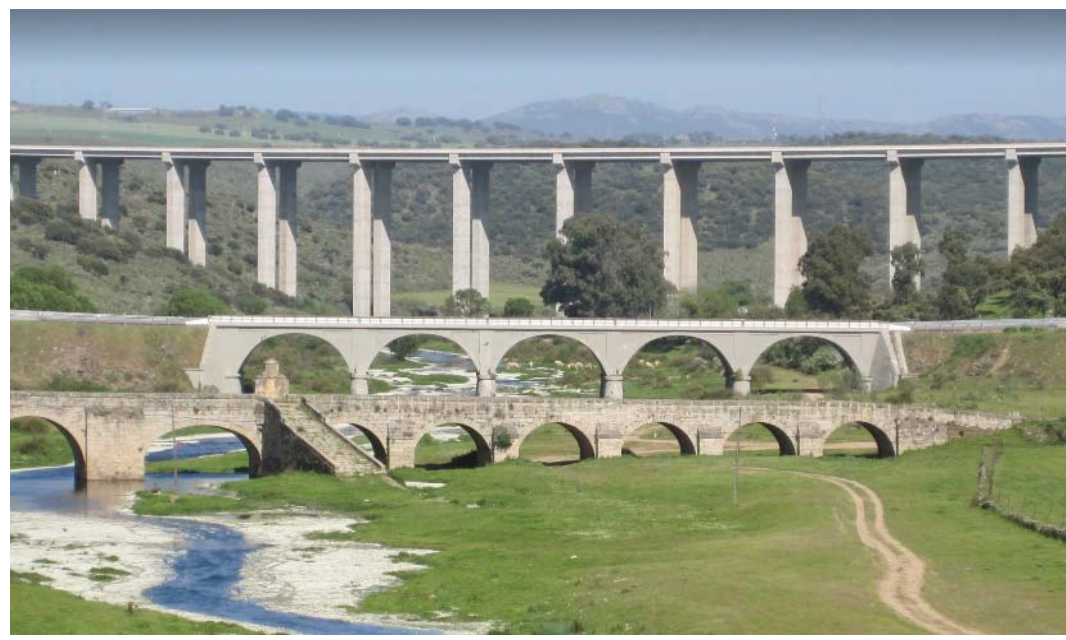

Figura 82: Puentes de Jaraicejo (A-5 con río Almonte), Cáceres (Foto: panoramio.com)

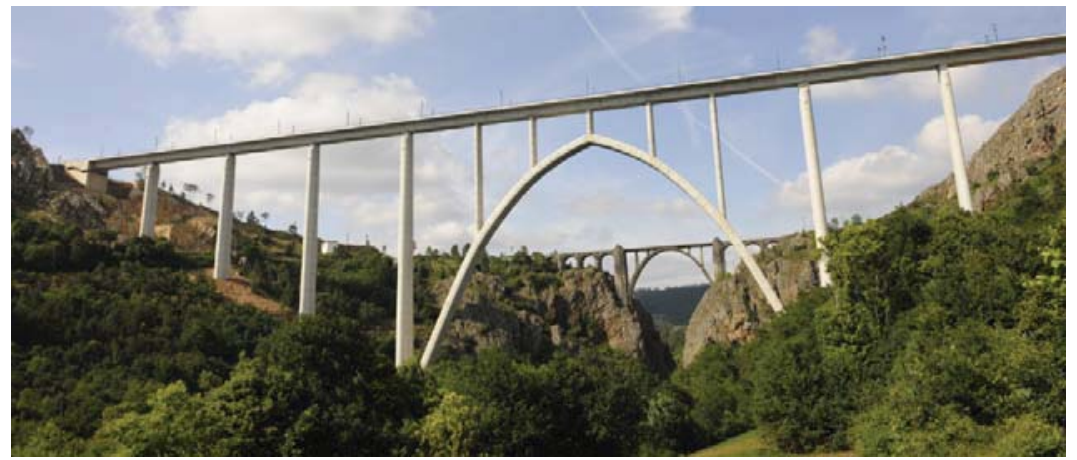

Figura 83: Puentes ferroviarios del Río Ulla, A Coruña-Pontevedra (Foto: faltadeingenieria.wordpress.com)

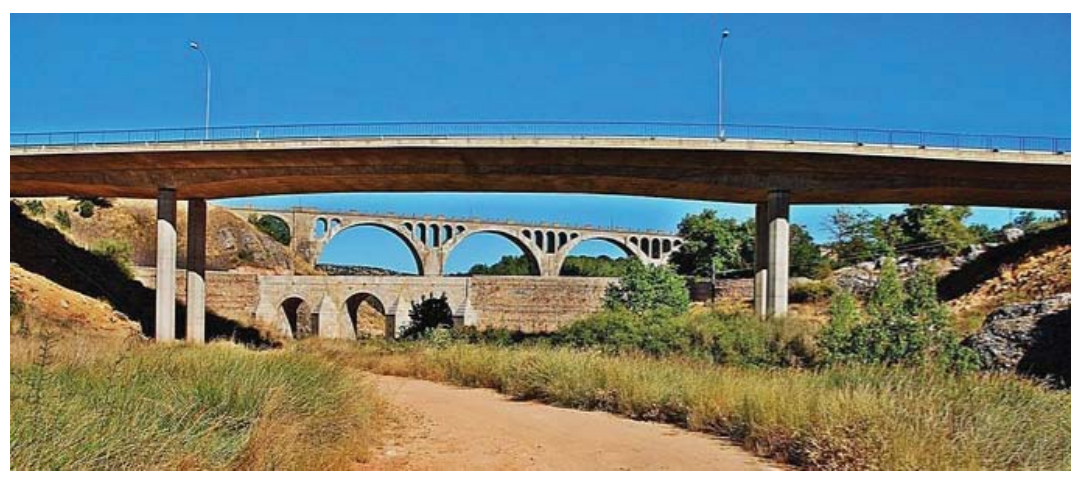

Figura 84: Puentes del río Golmayo en Soria (Foto: AmerBik, eltiempo.es)

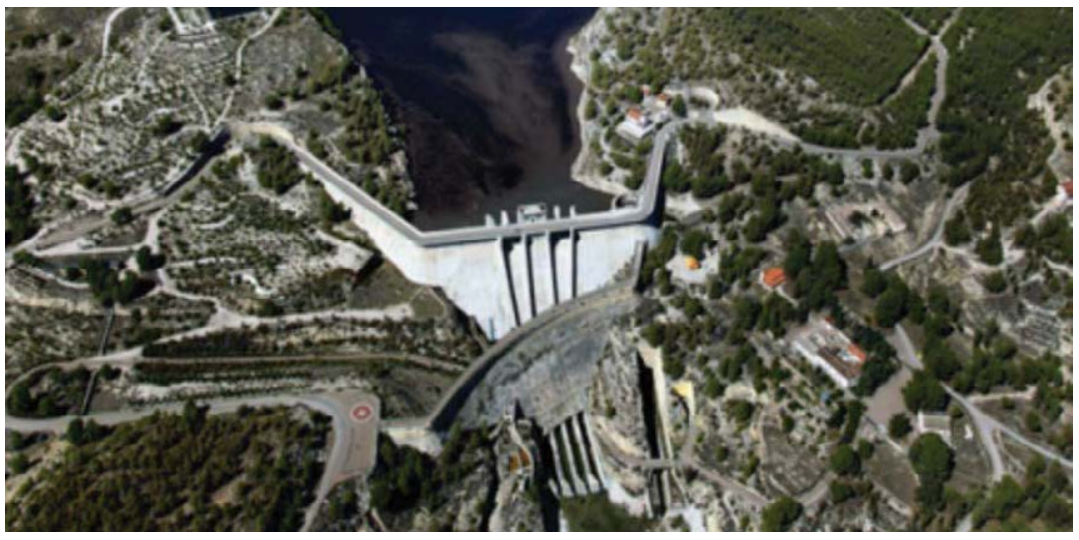

Figura 85: Presa de Puentes 3 y 4, Murcia (Foto: chsegura.es) 


\subsubsection{Paisaje construido en Reino Unido}

Uno de los artículos de esta tesis es relativo a la estética de las Obras Marítimas en España y Reino Unido. Ese artículo fue presentado en un congreso en Liverpool en septiembre de 2017. Aprovechando el viaje, se pudo contemplar la gran cantidad de Obras Públicas. Y además es pionero en muchas de ellas y en tipologías y materiales nuevos. Por ejemplo, los puentes de hierro empezaron allí (Ironbridge, 1779), el ferrocarril de vapor (Liverpool-Manchester, 1830), los túneles por debajo de ciudades (Wapping Tunnel, Liverpool, 1830) y subacuáticos (Thames Tunnel, Londres, 1843), la tipología de puentes colgantes (Union Bridge, Río Tweed, 1820), etc.

Reino Unido es un país con una estética antigua, con poco hormigón en general: casas de piedra, puentes de piedra y hierro, presas de sillería o materiales sueltos, etc. Una estética que se camufla muy bien con el paisaje (Figuras 86 a 92).

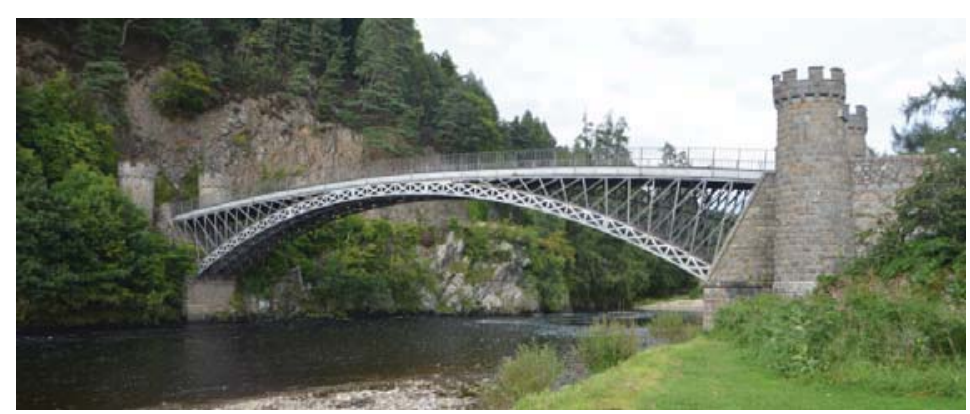

Figura 86: Puente Craigellachie (Thomas Telford, 1814), Craigellachie, Escocia (Foto: Mario Martín Antón)

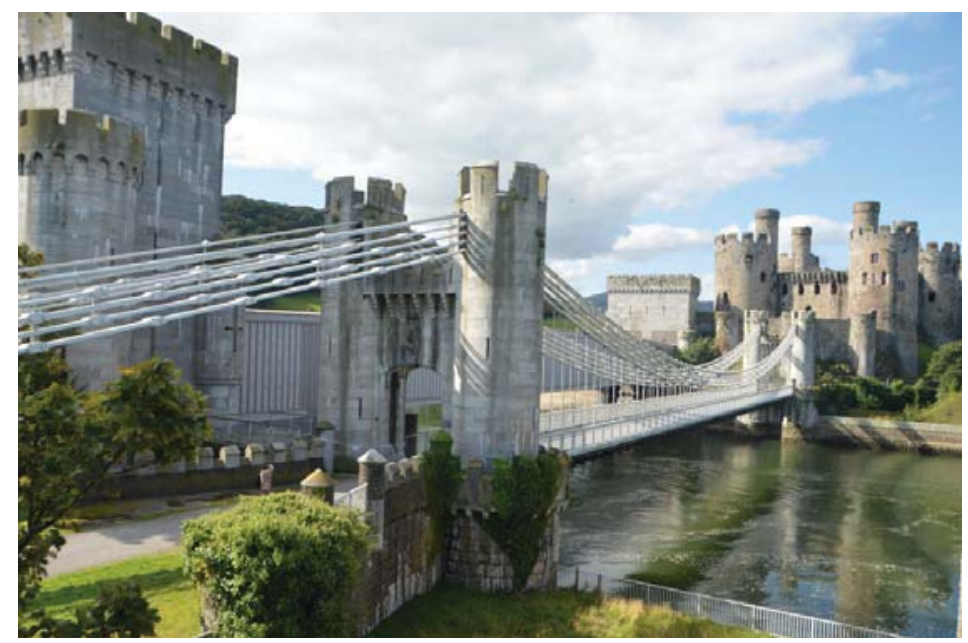

Figura 87: Puente colgante de Conwy (Thomas Telford, 1826), Conwy, Gales (Foto: Mario Martín Antón)

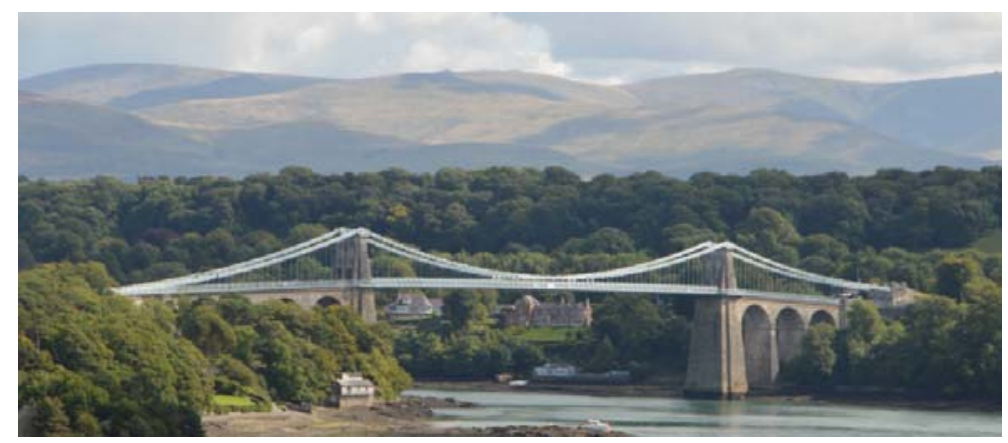

Figura 88: Puente colgante de Menai (Thomas Telford, 1826), Menai Bridge, Gales (Foto: Mario Martín Antón) 


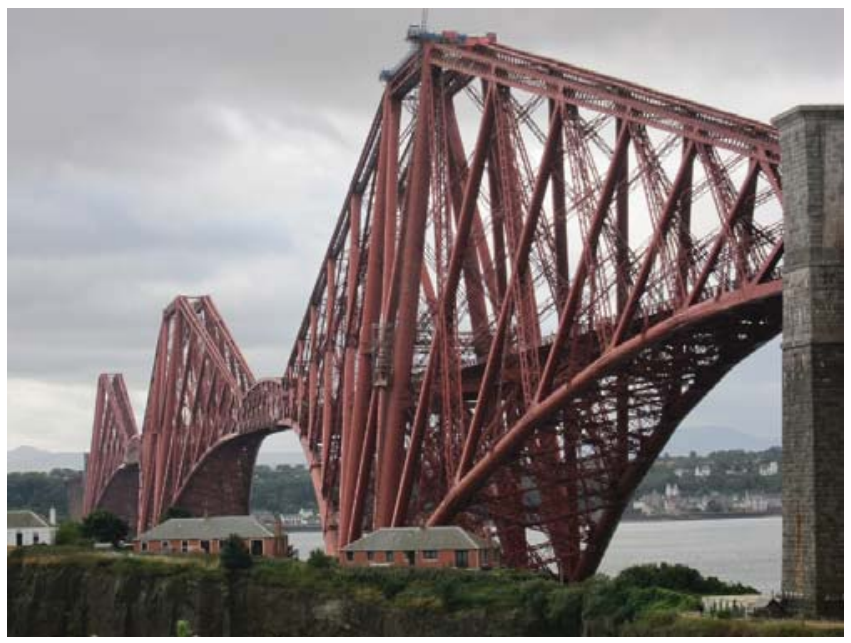

Figura 89: Puente de Forth (Fowler \& Baker, 1890), Escocia (Foto: Mario Martín Antón)

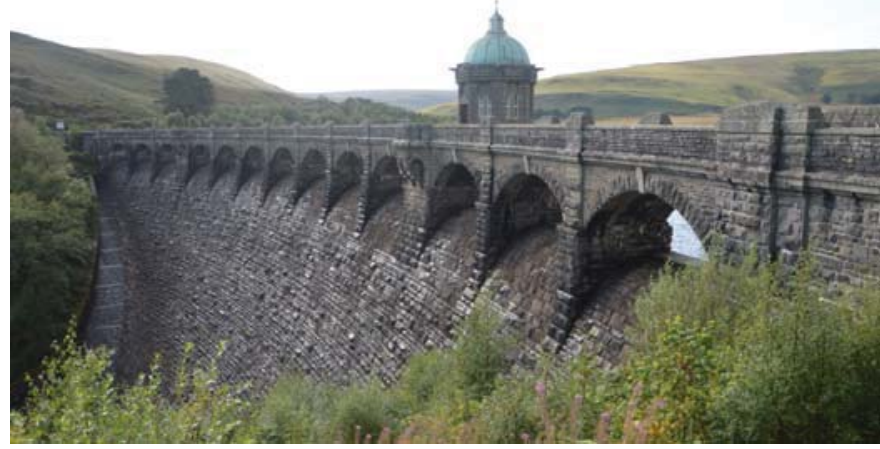

Figura 90: Presa Craig-Goch (1904), Elan Valley, Gales (Foto: Mario Martín Antón)

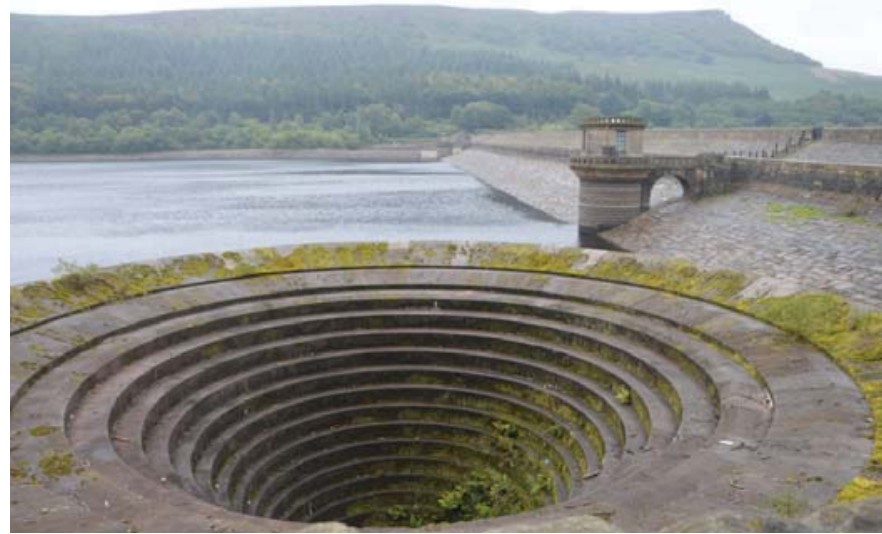

Figura 91: Presa Ladybower (1943), Peak District, Inglaterra (Foto: Rubén Rodríguez Parga)

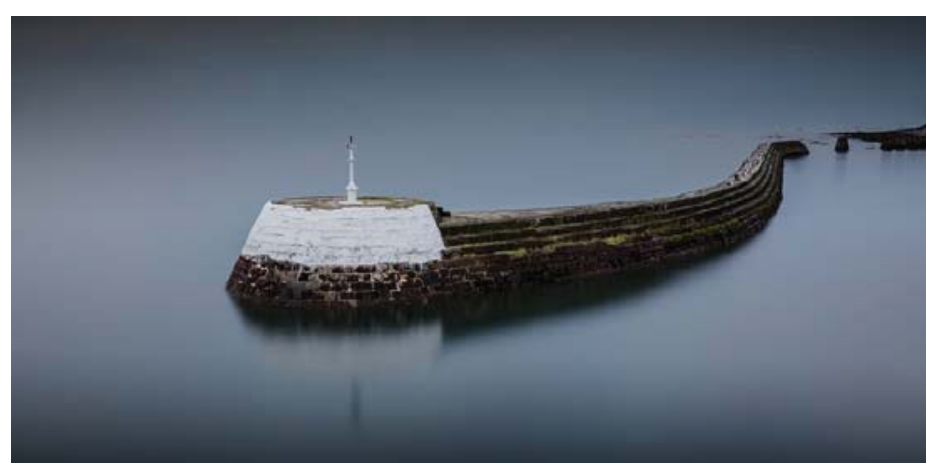

Figura 92: Dique de Arbroath, Escocia (Foto: flickr.com) 


\subsubsection{Paisaje destruido en Asia}

En Asia se ha producido un crecimiento gigantesco de la construcción en los últimos años, que es lo que llamamos gigantismo. En la mayoría de los casos, ese desarrollo se ha realizado sin tener en cuenta aspectos medioambientales y de paisaje, por lo que se considera paisaje destruido. Es una de las conclusiones de esta tesis (Figuras 93 a 99).

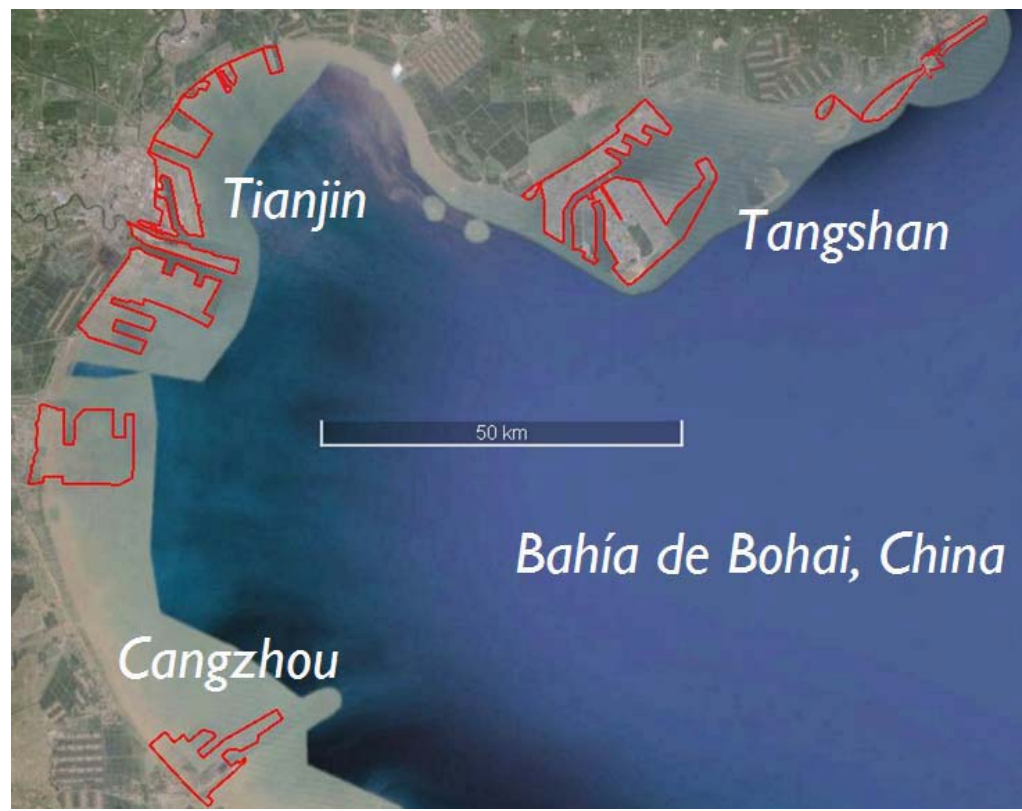

Figura 93: Rellenos portuarios en la Bahía de Bohai, China (Foto: Google Earth)

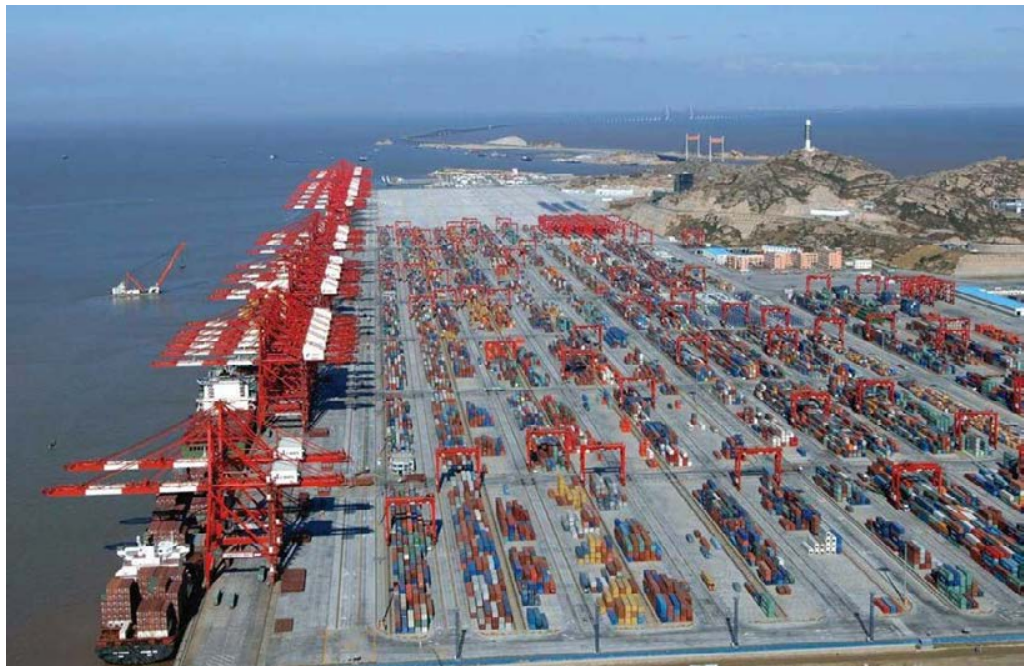

Figura 94: Puerto de Shanghai, China (Foto: shine.cn)

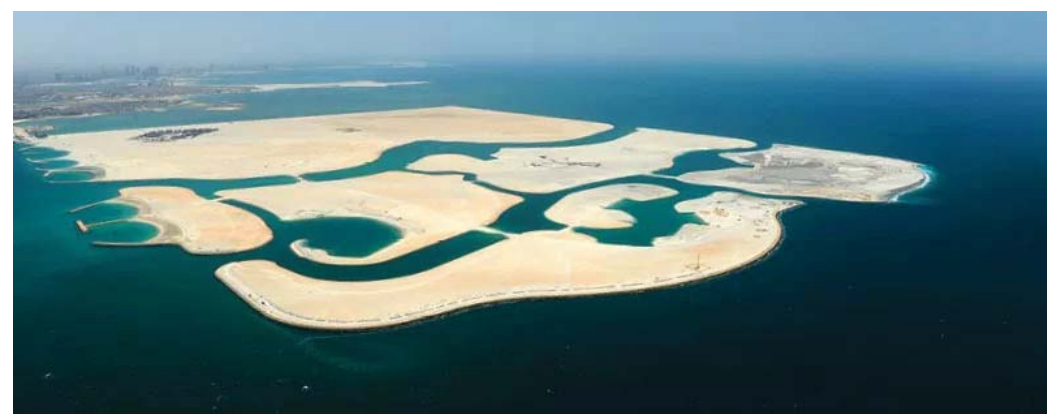

Figura 95: Proyecto de ciudad ganada al mar de Diyar Al Muharraq, Bahrein (Foto: gldd.com) 


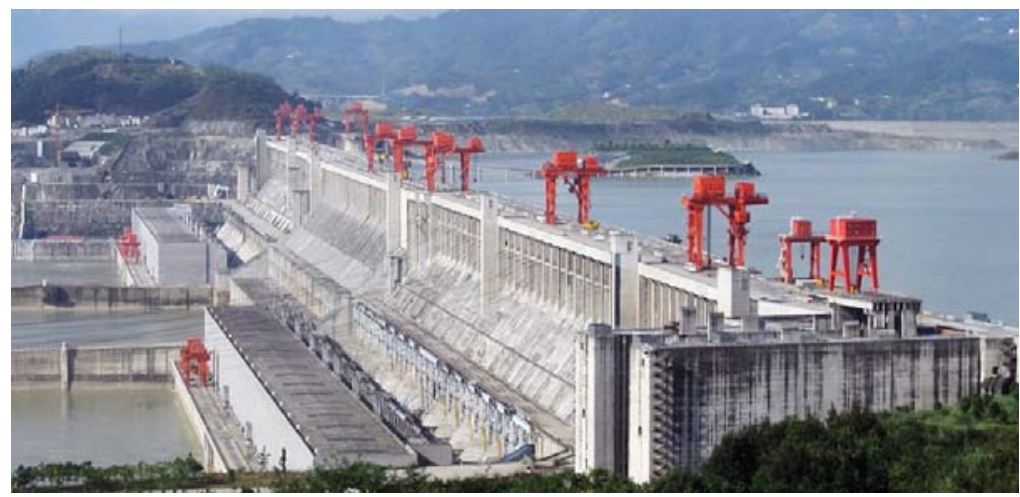

Figura 96: Presa de las Tres Gargantas, China (Foto: Wikipedia)

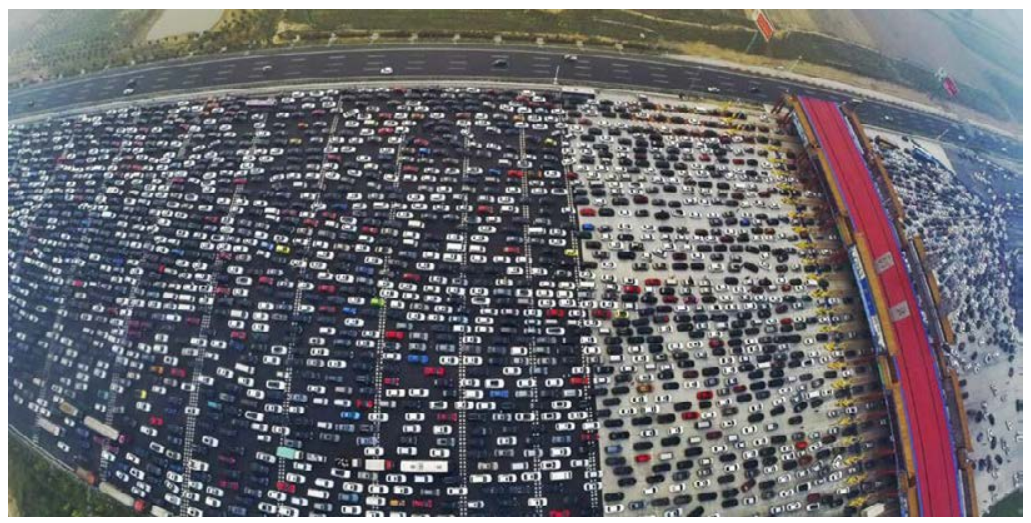

Figura 97: Peaje en una autopista cerca de Pekín, China (Foto: dailypakistan.com.pk)

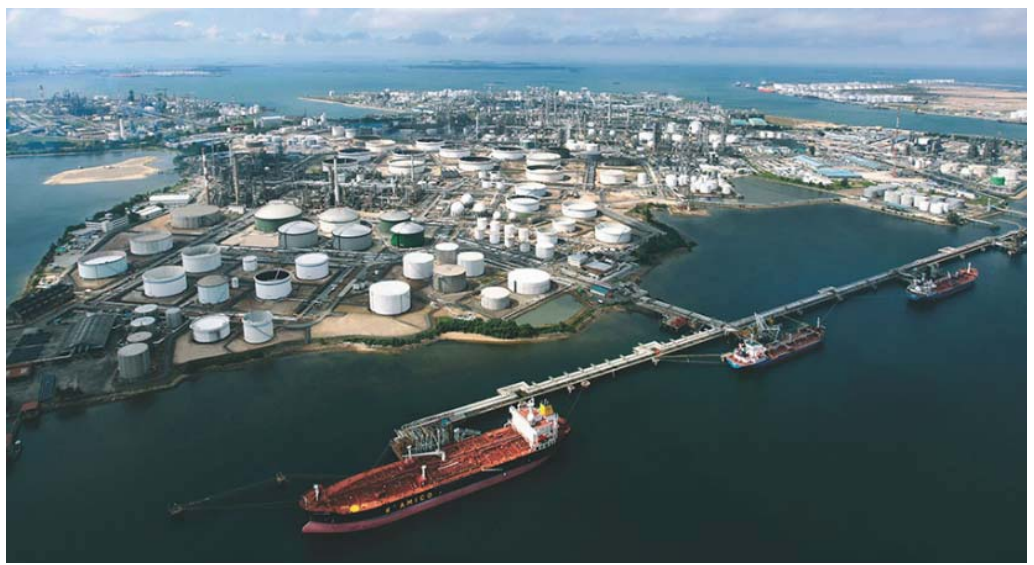

Figura 98: Terminal petrolífera del Puerto de Singapur (Foto: exxonmobil.com)

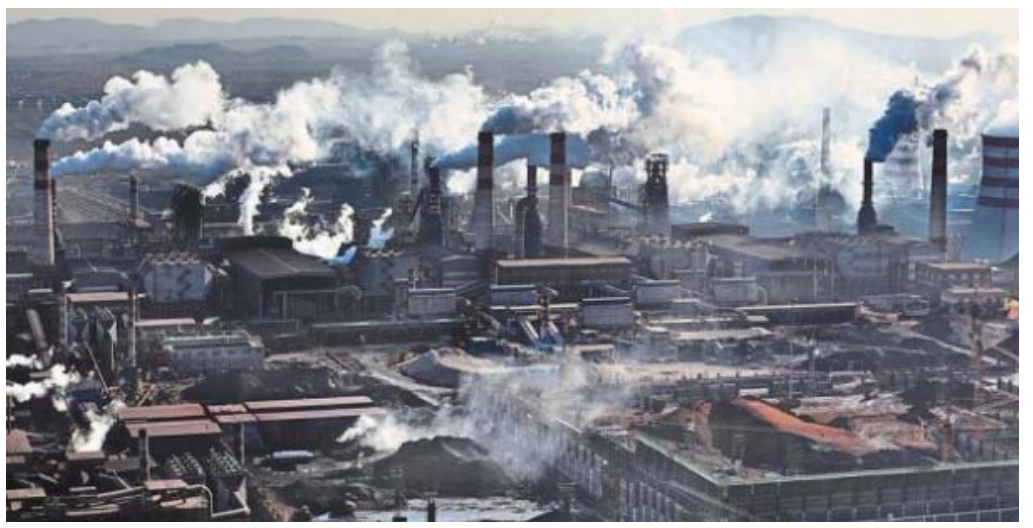

Figura 99: Industria metalúrgica en Hebei, China (Foto: thestar.com.my) 


\section{CAPÍTULO 3: RESULTADOS Y DISCUSIÓN}

El tercer epígrafe de esta tesis doctoral se ha planteado haciendo una introducción de cada uno de los artículos que componen el cuerpo central de la Tesis Doctoral, describiendo la idea del mismo, los objetivos perseguidos, un resumen y sus principales conclusiones. Los principales artículos serán mostrados a continuación. En los indicios de calidad se mostrará la documentación completa relativa a los mismos.

Estos artículos recogidos en indexados, no indexados y comunicaciones a Congresos con doble arbitraje permiten la discusión de cada uno de los objetivos de la presente Tesis Doctoral, facilitando la pulsación del ser en la naturaleza y la redacción de las conclusiones sobre las bases del paisaje reflexión y del paisaje subjetivo.

El orden no corresponde a la fecha de publicación sino a su importancia en la tesis para seguir un hilo conductor. Se empieza con dos artículos (uno de ellos indexado) relativo al concepto de paisaje natural, paisaje construido y paisaje destruido en España. Se sigue con el artículo 3 (indexado y presentado en congreso internacional) sobre terrenos ganados al mar e islas artificiales, con la idea de paisaje destruido costero y conquista. Estos dos conceptos se desarrollan de una manera más general en el ámbito de la Ingeniería Civil y la construcción en el cuarto artículo (indexado), donde se trata el gigantismo asiático. Posteriormente se tienen los artículos 5 y 6 que tratan sobre un caso específico, y es la estética en los espaldones, uno con ejemplos de España y otro con ejemplos también de Reino Unido, ya que se presentó en un congreso internacional allí. Finalmente, se aborda la temática de la tesis de manera conjunta en Sydney, como ejemplo de ciudad costera con todos los elementos tratados en la tesis. 


\subsection{ARTÍCULO 1 Y 2:}

Martín-Antón, M.; Negro, V.; del Campo, J.M., López-Gutiérrez, J.S., and Esteban M.D. (2017). "The Impact of Public Works in Spain: Natural, constructed and destroyed landscape". Revista de la Construcción - Journal of Construction, vol.16, n.1, pp.82-91. ISSN 0718-915X. doi:10.7764/RDLC.16.1.82.

Martín-Antón, M.; Negro, V.; del Campo, J.M., López-Gutiérrez, J.S., and Esteban M.D. (2016). "El impacto de las obras públicas en España: paisaje natural, paisaje construido y paisaje destruido". Ingeniería Civil n184, pp 64-74. ISSN 0213-8468

Idea: Se desarrolla el concepto de paisaje natural, paisaje construido y paisaje destruido, poniendo ejemplos de todas las obras de ingeniería civil, con especial mención a la ingeniería de costas.

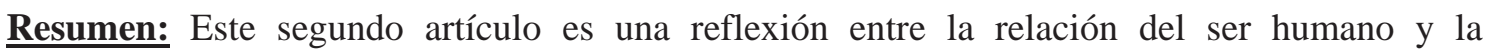
naturaleza. Ésta es salvaje, dinámica, simbólica, tan lenta en su evolución como dramáticamente vertiginosa en sus catástrofes. La humanidad está presente en el planeta, habita en él, deja su huella, y, por ello, construye con un sentido, el de "estar en el mundo". Su acción, a través de la construcción de Obras de Ingeniería Civil y la expansión de las ciudades, constituye una "agresión" externa que modifica el entorno natural. Esa relación ha pasado por cuatro etapas a lo largo de la historia (sumisión, adaptación, conquista y respeto). Así es como aparecen los conceptos de Paisaje Natural, Paisaje Construido y Paisaje Destruido sobre la base de los criterios funcionales, estéticos, ambientales, culturales, urbanos, económicos y de abstracción donde se asienta la obra en el medio físico y en su marco territorial.

Conclusión y reflexión: Esta segunda parte de la investigación es una indagación entre la relación del ser humano y la naturaleza. Cuando éste pretende perpetuarse en ella mediante el arte de construir para "estar en el mundo" y sus obras, se convierten en referentes del paisaje. Un paisaje que sustituye al natural, que algunos autores llaman paisaje cultural, y, se convierte en construido, imprimiendo al "sitio" el concepto de "lugar". Lo dota de vivencias, sensibilidad y emoción, le da espíritu. Qué pensamiento tan acertado del filósofo Nietzsche, "Si nos sentimos tan a gusto en la naturaleza, es porque ésta no tiene opinión sobre nosotros".

De la misma manera, la ingeniería como disciplina debe buscar la "sorpresa". Debe "encajar" en lugar de "colocar". Es la localización de un emplazamiento olvidado, un lugar perdido, pero encontrado, un elemento ausente, pero evidente, donde la sensibilidad del ingeniero cambia lo natural por lo trascendente y sensible, dotándolo de movilidad (carretera), paso (puente), refugio (puerto), vivencia (ciudad) o silencio (catedral).

Cuando se desorganiza, se agrede, se ataca a la naturaleza, el paisaje es irreflexivo queda destruido, muchas veces, por décadas, algunas de manera irreversible para la historia de los tiempos. El paisaje es la asociación entre el tiempo y la vida, el estar en el mundo, el habitar, el construir y respetar la naturaleza. El medio natural esculpe monumentos que el ser humano debe integrar en trascendentes en vez de desmoronar el espíritu emocional del lugar. Un pensamiento de Heiddeger resume esta introspección sobre el paisaje, sobre la ingeniería que no siempre es estética, pero que el arte debe integrase en la ingeniería, "construir en habitar" y "la forma es el guardián del ser".

La tecnología actual, los avances en el conocimiento de las fuerzas de la naturaleza y las características de los nuevos materiales nos permiten proyectar verdaderas maravillas estructurales técnicas, pero éstas no deben estar reñidas con la conservación del entorno y la concepción del "paisaje trascendente", aunque en la mayoría de los casos no requieran el uso de conocimientos tan avanzados. Así, debe primar ante todo el respeto frente a la funcionalidad y la economía. 


\title{
The Impact of Public Works in Spain: Natural, constructed and destroyed landscape
}

\section{El impacto de las Obras Públicas en España: Paisaje natural, construido y destruido}

Mario Martín-Antón (Main Author, Corresponding Author)

Universidad Politécnica de Madrid. Profesor Aranguren 3, 28040 Madrid (Spain)

mario.martin.anton@alumnos.upm.es

Vicente Negro

Universidad Politécnica de Madrid. Profesor Aranguren 3, 28040 Madrid (Spain)

vicente.negro@upm.es

José María del Campo

Universidad Politécnica de Madrid. Profesor Aranguren 3, 28040 Madrid (Spain)

josemaria.delcampo@upm.es

José Santos López-Gutiérrez

Universidad Politécnica de Madrid. Profesor Aranguren 3, 28040 Madrid (Spain)

josesantos.lopez@upm.es

María Dolores Esteban

Universidad Politécnica de Madrid. Profesor Aranguren 3, 28040 Madrid (Spain)

mariadolores.esteban@upm.es

\author{
Manuscript Code: 688 \\ Date of Acceptance/Reception: 11.02.2017/18.09.2015 \\ DOI: 10.7764/RDLC.16.1.82
}

\begin{abstract}
This article reflects on the relationship between the human being and nature. Nature is wild, dynamic, symbolic, and as slow in her evolution as she is dramatically quick in her catastrophes. Humankind is present on the planet, inhabits it, leaves its mark and, therefore, constructs with a meaning, that of "being in the world". Its action, through the construction of Civil Engineering Works and spread of cities, constitutes an external "aggression" which changes the natural surrounds. That relationship has evolved throughout the history of four phases (submission, adaptation, conquest and respect). This is how the concept of natural landscape, constructed landscape and destroyed landscape appears on the basis of functional, aesthetic, environmental, economic and abstraction criteria, where the item constructed settles into the physical environment.
\end{abstract}

Key words: Natural Landscape, constructed landscape, destroyed landscape, civil engineering, environment.

Resumen

Este artículo es una reflexión entre la relación del ser humano y la naturaleza. Ésta es salvaje, dinámica, simbólica, tan lenta en su evolución como dramáticamente vertiginosa en sus catástrofes. La humanidad está presente en el planeta, habita en él, deja su huella, y, por ello, construye con un sentido, el de "estar en el mundo". Su acción, a través de la construcción de Obras de Ingeniería Civil y la expansión de las ciudades, constituye una "agresión" externa que modifica el entorno natural. Esa relación ha pasado por cuatro etapas a lo largo de la historia (sumisión, adaptación, conquista y respeto). Así es como aparece el concepto de Paisaje Natural, Paisaje Construido y Paisaje Destruido sobre la base de los criterios funcionales, estéticos, ambientales, económicos y de abstracción donde se asienta la obra en el medio físico.

Palabras clave: Paisaje natural, paisaje construido, paisaje destruido, ingeniería civil, medio ambiente.

Introduction

Nature is a "place" for emotion. This reflection emerges from subjective perception in certain localities. They come to life and become wrapped in feelings and emotions. "Site" is beginning, origin, a general reference to a location which is not yet understood and has not become existential. Every construction work is a human action that turns a site into a place. It changes the location, gives character to the land, modules it, organizes it, gives it backbone and may even disorganize it, on the basis of an artistic and environmental creation whilst being respectful with it (Figure 1). 
In the conversion process from site to place conflicts arise between urban development pressures and conservation planning, and presents challenges for planners and landscape ecologists around the World (Sanderson et al., 2002). The idea of the bridge, "to cross over"; of the harbour, to "shelter"; of the dam, to "store water"; of the road, to "improve mobility"; of the lighthouse, to "guide"; of the castle, "to defend oneself"; of the town, to "live and live with"; of the church and monastery, to "pray or perceive silence", lead to constructing in order to transcend and acquire meaning (Egypt, Greece or Rome); or to occupy the natural setting, at times irrespectively and negligently. For some years now, we have also had to take into account the tunnel, to "shorten distances" and the airport, to "connect the world". This study is an investigation into the landscape, the place, the significance or attack on the natural location by the human being.

Figure 1. Golden Gate Strait before the construction of the bridge (Site) and afterwards (Place).Source: www.goldengate.org, Mario Martín-Antón.

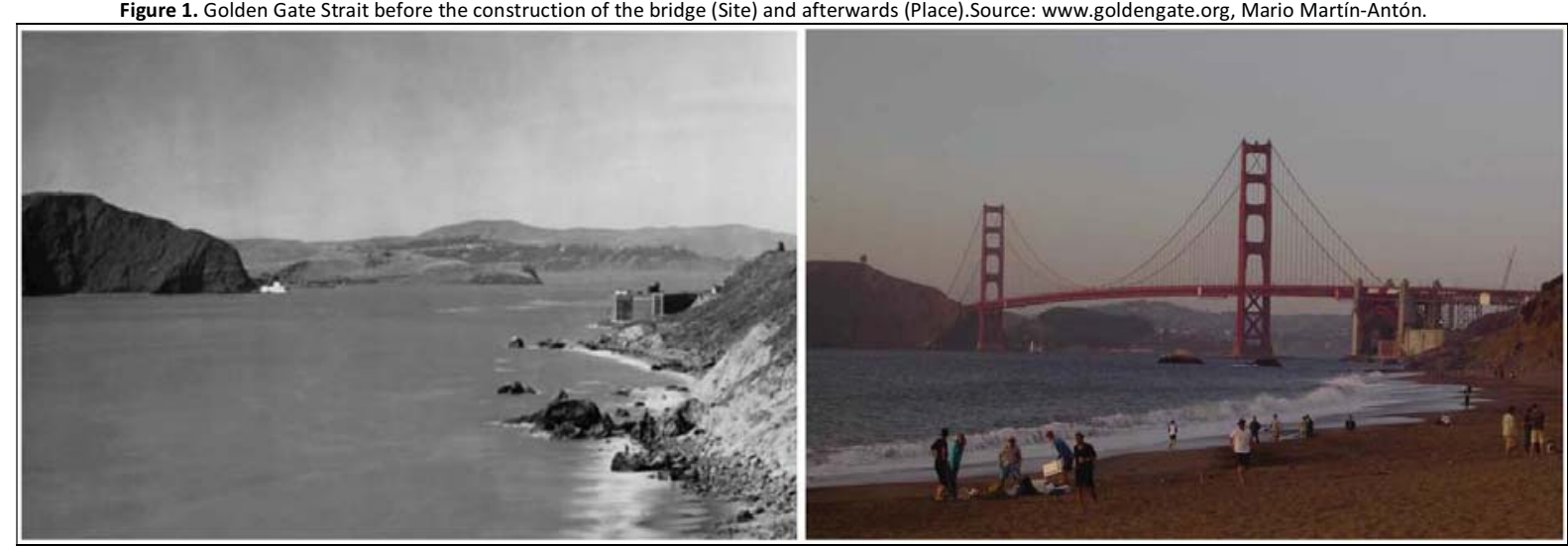

State of the Art: The four phases of the relationship between the human and the nature

The human being's evolution in the "art of construction and being in the world" (Aguiló, 2013) has moved through four stages with the passing of time (Aguiló, 1999). The search for high sites to make a defense from the enemies' attacks; river mouths to obtain water and shelter before departing for the violent ocean; paths and bridges to guarantee communication and mobility, led to the species passing through a first phase of "submission" (Figure 2) to, and even fear of nature. This vulnerability might not solely be determined by the human-environmental stress, but it might rather be influenced by the changes of society's adaptive capacities (Renaud et al., 2010).

Figure 2. Submission. Storm at the breakwater of Deba (Guipúzcoa), and flooding of the River Castro in Ventosa de Fuentepinilla (Soria). Source: Goio, www.diariovasco.com, Mario Martín-Antón.

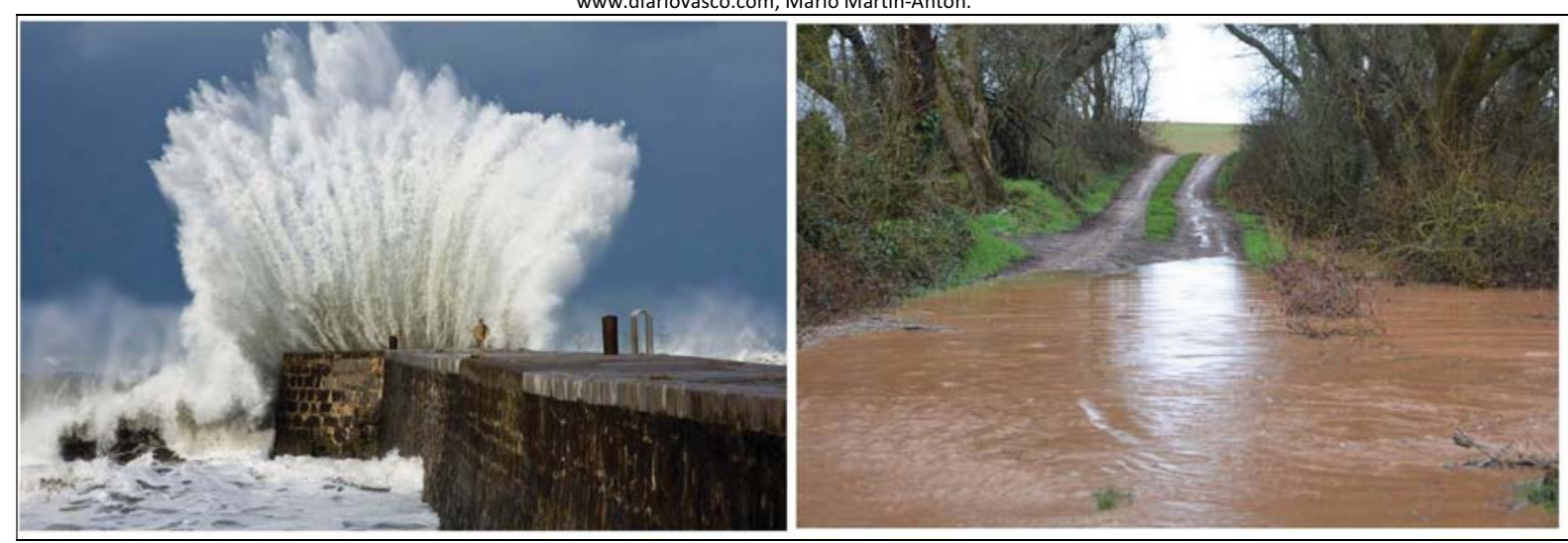

Agriculture, cattle rearing and trade together with an increase in population led to "adaptation" (Figure 3), a sedentary lifestyle and the birth and growth of towns and Communication Routes. Villages live and coexist within the town's framework. This second stage is characterized by construction works that minimize environmentally destructive impacts and the effective adaptation to and integration with nature's processes (Van der Ryn \& Cowan, 
2007). Both "submission" and "adaptation" extended over thousands of years. The human being appropriated the land over time. With his constructions, he demonstrated power and dominance and reached a third stage, the "conquest" (Figure 4), in this case, of nature (Aguiló, 1999).
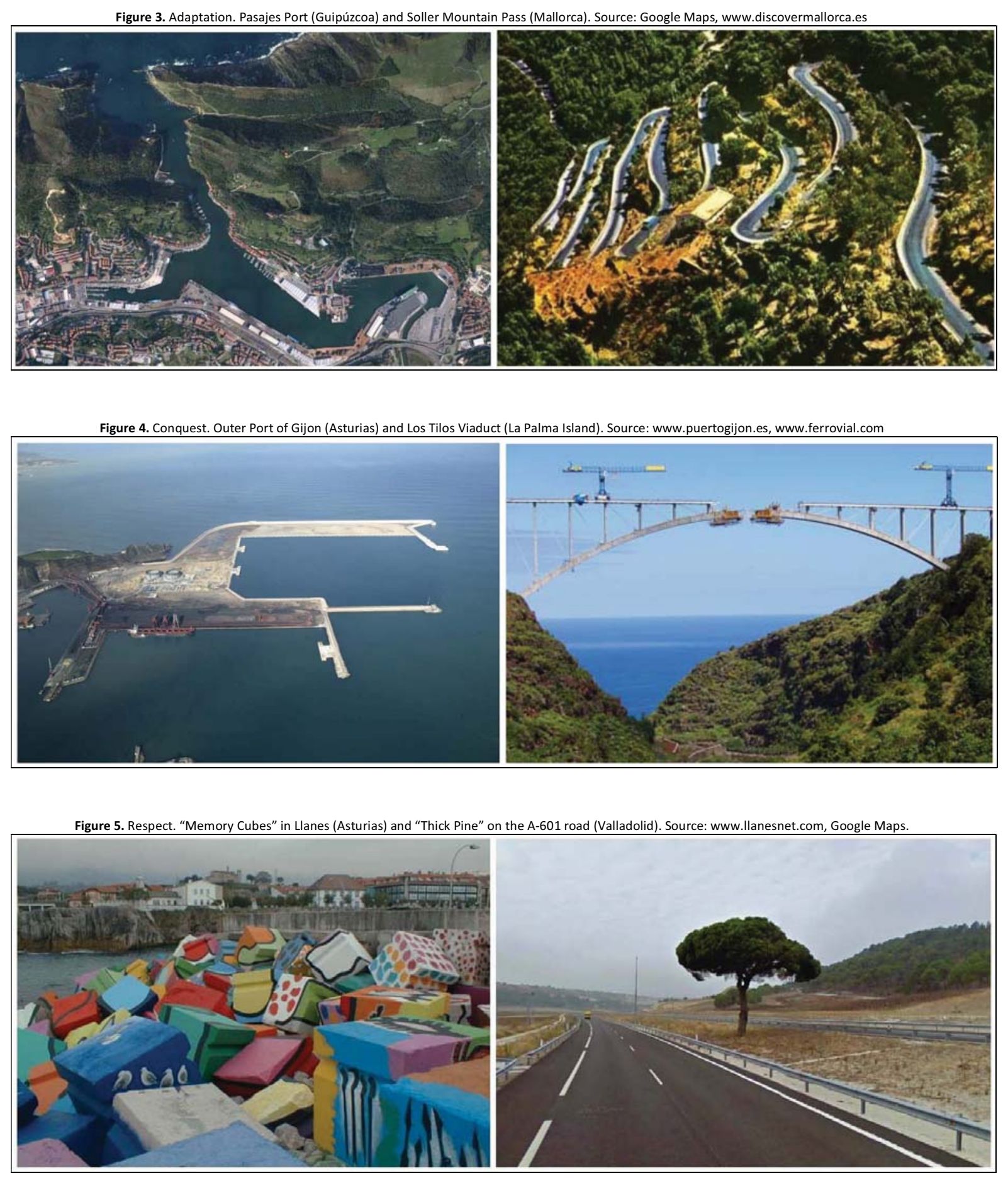

Caused by mass growth, the indiscriminate exploitation of natural resources, social and population inequalities, hostility towards the natural environment and lack of environmental sensitivity, over the last few decades, engineering has discovered and encouraged "respect" (Figure 5), cooperation with the surroundings, the "place" of 
emotion from where we have departed and to where we shall return, although it is true that some constructions undertaken in ancient times had that commitment (Aguiló, 1999).

How complicated will the future be and how obtuse the past if we do not preserve roots and land is fought over without perception, destroying instead of constructing, far from the "genius loci", from the spirit of the place, from the transcendence of the construction. This spirit gives life to people and places, accompanies them from birth to death, and determines their character or essence (Norberg-Schulz, 1979).

\section{Description of the problem: Transcendent and rash landscape}

The natural landscape is transformed by the art of constructing, by the relationship of the construction with nature, creating a new, emotional, living and, above all, transcendent landscape, the constructed landscape. Any other human action which alters, attacks and assaults the physical environment is framed within the concept of destroyed landscape. In the "built landscape or transcendent landscape" there is a magical link between the construction and the surroundings, transcending its own use and acquiring meanings" (Aguiló, 1999). The physical environment embodies new dimensions which, above all, are touching, and sentiments and emotions appear giving character to the land and granting its protagonism.

Other times, the conjunction between what is natural and what has been constructed is unfortunate, excessive, unsubstantial, unbalanced, lacking in meaning and disproportionate. The relationship connecting the action of constructing and what is natural is not an "art" but a failure to meet up, disorder, an inappropriate, negative transformation of surroundings, which disorganizes instead of giving backbone to and separates instead of drawing closer. This is the "destroyed or rash landscape".

The transformation of a location into a place, the visual and functional connection, the creative manifestation gives meaning to what is neutral by adding vegetation, water and climate to the relief, a human action modelling and modulating the land and "fabricating" landscape. The physical environment, human activity, history, culture and traditions configure the spirit and character of the place. "Beautiful landscapes are irreplaceable in that they fulfil our longing to be part of the natural World and heal the rift between subject and nature, both the nature out there and the nature in us" (Krebs, 2014). Nowadays, constructions are real symbols of towns if they have turned into the latter's constructed landscape. The perception of the Eiffel Tower in Paris during the 1889 Universal Exposition is different to the "symbol" it represents today. The same may happen with the Golden Gate in San Francisco (1937) (Figure 1) or the Segovia aqueduct (1st century A.D.). They have become facts when they were born as landmarks that yearned for utopia.

However, a construction often loses its roots, its meaning and essence. It is undertaken on the basis of inexistent needs, tackled for instrumental or economic reasons as a drive and impulse or a mistaken philosophy, to make it increasingly bigger and more useless. Nevertheless, this mistaken meaning also happens in small constructions, "in passing" which, in turn, are the most numerous and in which the priority of speed in construction or economics do not allow the designer to "think and repose" on what is going to transcend and change the physiognomy of the place (Thompson, 2002).

In this way, the shape is not fragmented, is integrated, becomes authentic and turns into a monument. It dominates the space and eliminates the void, becomes a dream and, with it, transcends constructed landscape. If it does not blend in, it breaks the balance with nature and then land becomes ill, losing its harmony and vertebration. Nature is assaulted, attacked, becomes defective, waiting for time to straighten up its gait. The new art may mean its dismantling, returning to the natural scenario, which is only fully recovered in most cases in long lapses of time.

Time, like space is two features of human actions on the environment to be considered separately (Turner et al., 1994). The question we should ask ourselves when intervening in the environment is: What does Nature want to be in this place? The answer depends on the spatial scale and timeframe, to identify its unique essence ("genius loci"), its aspirations and its potential (Du Plessis, 2012).

\section{Discussion: Built and destroyed landscape in Spain}

The target landscape is divided into two categories: necessary (constructed) and superfluous (destroyed); transcendent (constructed) and rash (destroyed); spiritual and symbolic (constructed) and inefficient and cold (destroyed); utopia, beauty and dream (constructed) as against useless, ugly and real (destroyed). A design must make itself loved, otherwise, testing must continue. Some of the many examples of civil engineering in Spain, the bridge, the 
road, the dam, the harbour and the coast plus the town where the foregoing thoughts are exemplified are reviewed below.

The integration and harmony of the Navalosa mediaeval bridge over the river Alberche (Ávila) has been altered and assaulted, challenging the initially natural landscape of the river's rough waters; later, to be built by the art of being in the world to communicate and guarantee mobility achieved with the arch bridge (Antrop, 2005). This construction grants the place a symbol, today broken by progress and the mass growth of rural tourism, which has demanded new, faster, safer means of transport but in no way integrated into the surroundings and to end up in a new construction. The piers of the new bridge clash in an unbalanced, rash dimension (Figure 6). Proper maintenance of heritage constructions is essential to avoid the risk of ruin and to avoid a new construction (González Rodrigo et al., 2015) but also a minimum care should be taken when building a new bridge next to a medieval one.

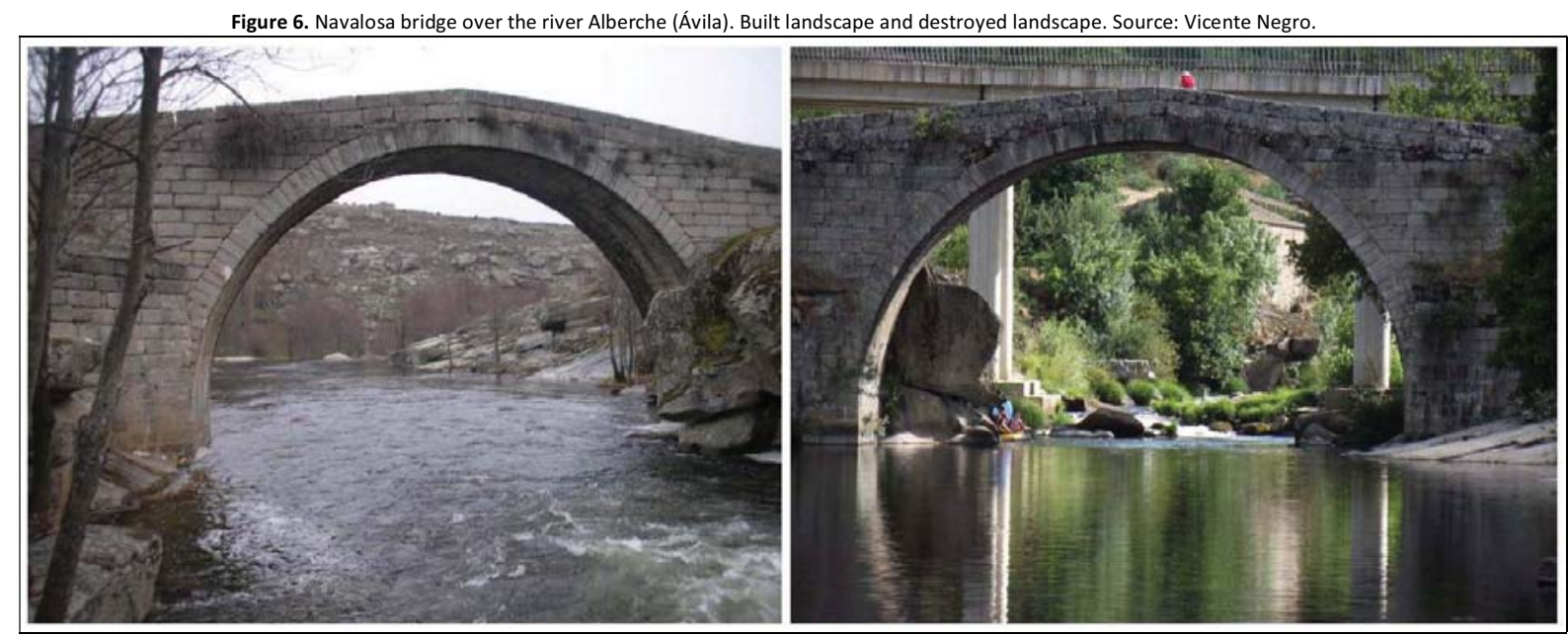

In constructing of roads in mountainous terrain, landscape may be affected to a greater extent than in flat areas. The need for embankments, cuttings, bridges and tunnels, leads to a dispute between two aspects: technical, wanting to be the least expensive; and environmental, seeking to interfere as little as possible with the environment. Road should be in harmony with the surrounding environment and that includes the public on both sides of the road slope and berm as well as the route of the natural landscape in a macroscopic position (Hu et al., 2012).

One of the major aberrations in Spain has occurred in the A-6 road in the ascent to the Piedrafita Pass, producing huge land clearance works that have led to heavy landslides causing the need for protecting it with a cover tunnel (Figure 7). However, in the photo on the left, the integration into the landscape has been achieved in a masterly fashion. The first idea was to build a curved false tunnel, creating a "rhythm" in the perception of the road, making it much more pleasant for drivers and more respectful of the environment. There is not always a perfect solution to the problems of banks; it depends on the characteristics of the landscape (Martín et al., 2012).

Figure 7. False tunnel on the TF-5 road in Garachico (Tenerife) and landslide on the A-6 road in Piedrafita Pass (León). Source: www.ferrovial.com, www.fomento.es 


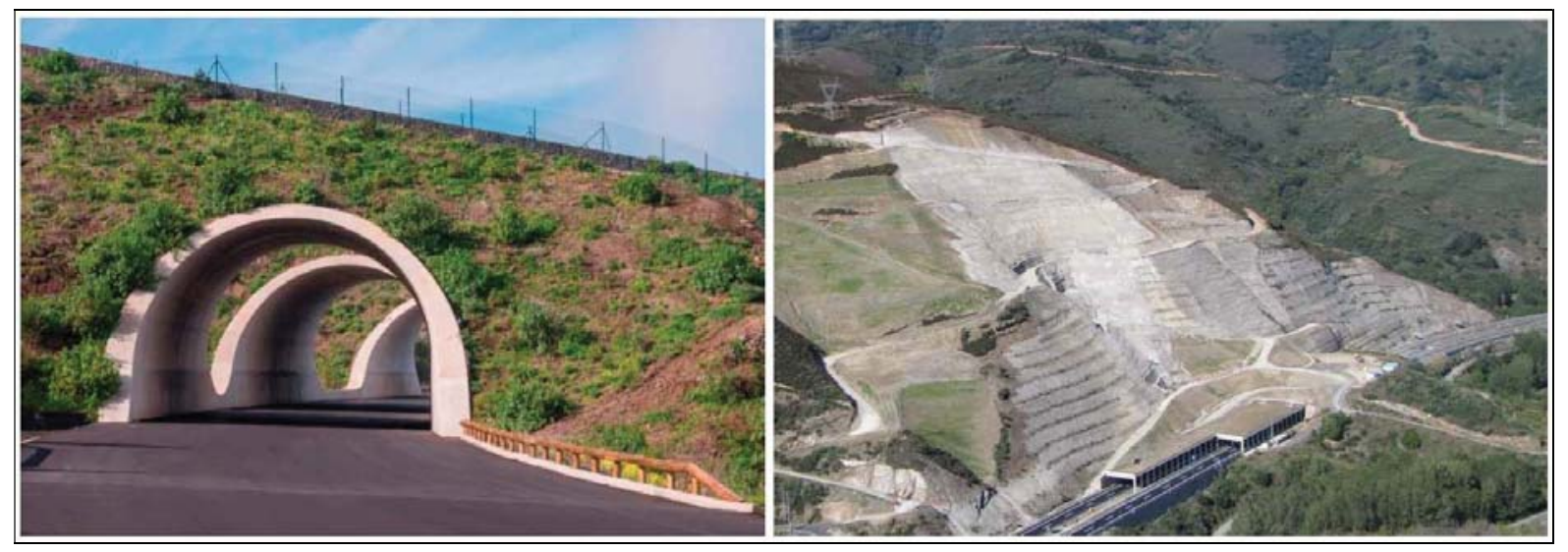

In the field of waterworks, we can also find examples of this difference between built and destroyed landscape. In the case of dams, midstream and downstream landscapes are more affected by construction, becoming more complex and fragmented (Zhao et al., 2012). Alcántara bridge (2nd Century A.D.) is one of the best examples of Roman bridges in the world in terms of conservation, dimensions and importance. For nearly 2000 years this building has survived solitary, and the landscape is not conceived without it. In the late 20th century, with the construction of a dam, everything changed. What was constructed landscape became destroyed, and is also producing further deterioration of the Roman bridge. In some cases, the limit of aesthetic and landscape aspects is exceeded and reaches aspects of heritage conservation. Likewise, the bigger the construction, the heavier and more extended is the impact, as per the example of the Three Gorges Dam on the Yangtze River (China), which is expected to have a major impact not only on ecosystems along the river, but on the Sea as well (Hara et al., 2014).

Figure 8. Almendra dam (Salamanca-Zamora) and Alcántara dam and bridge (Cáceres). Source: www.arribesturismo.es, www.alcantaraenred.es

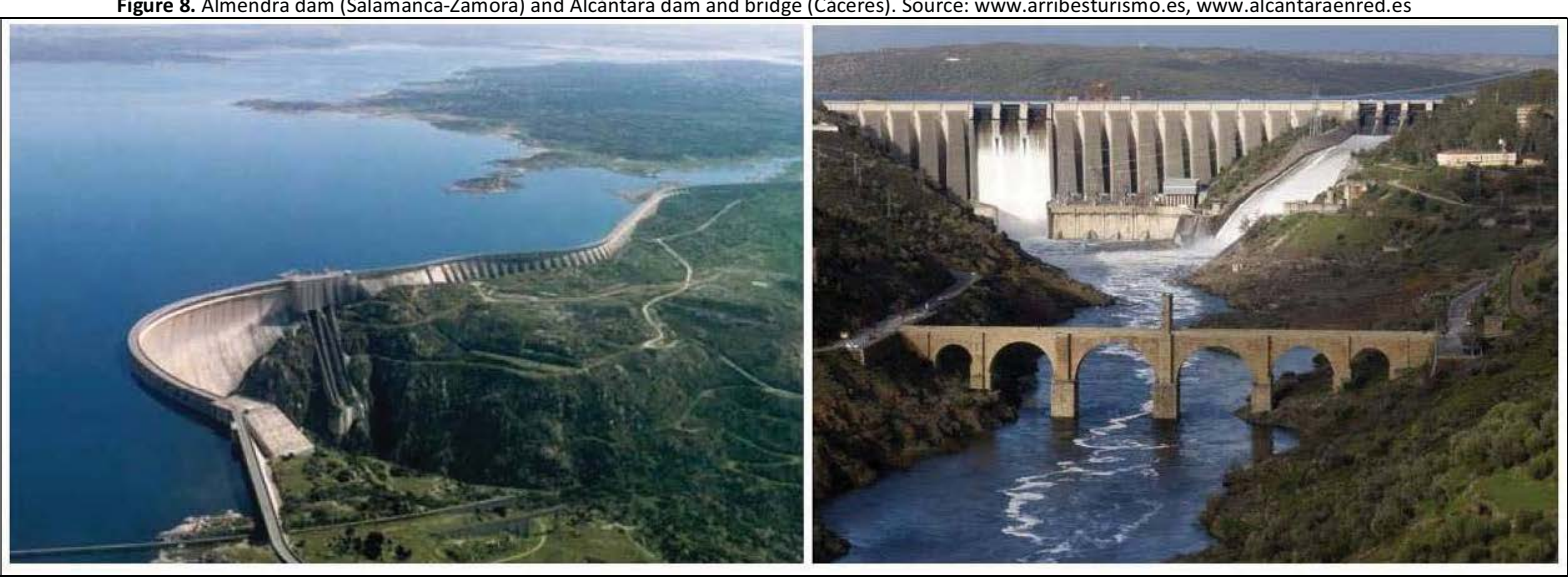

As shown in the first picture (Figure 8), the Almendra dam is much more integrated into the landscape, with its curvilinear forms and the tension occurring when containing reservoir water. Zero impact is impossible since it creates a huge lakeshore, isolating areas previously connected, and transforming the environment into a mosaic of fragmented habitats, but it can sometimes be positive because new surface water produces new wildlife habitats and new uses (Lopes et al., 2014). It is a clear example of how a civil engineering work can improve the landscape in certain aspects and produce a benefit to society, such as electricity production and regulation of river flows. 


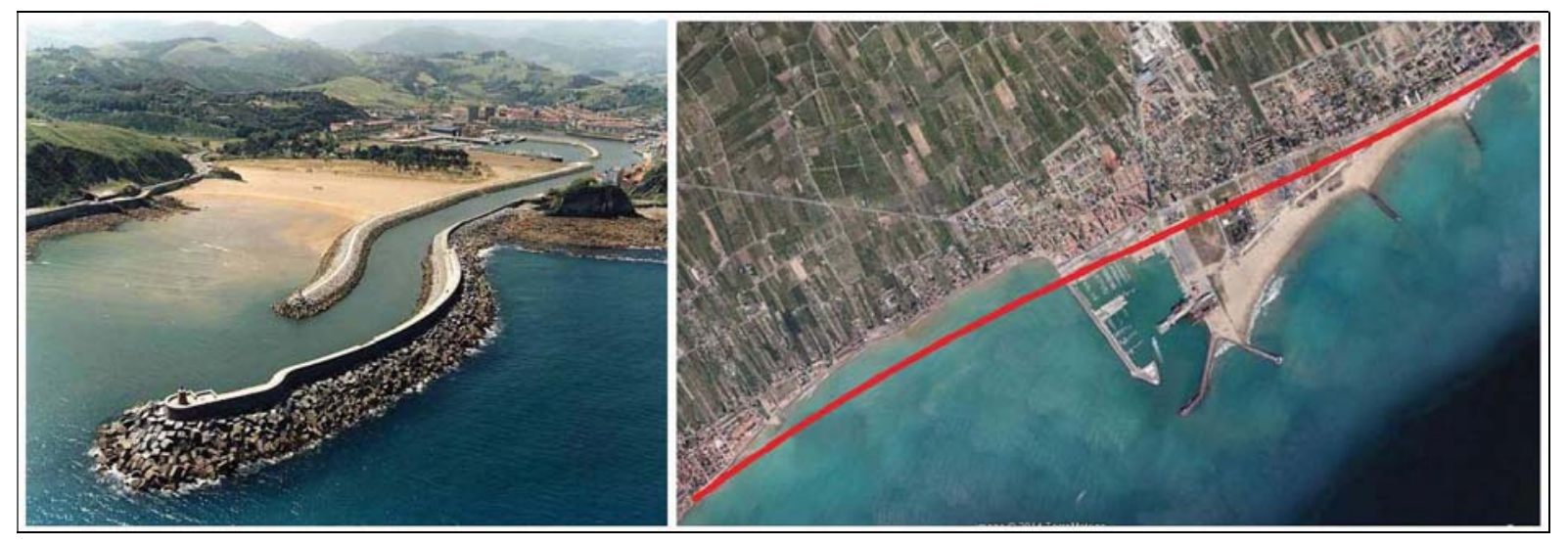

The port is a breach for sailing and led to the birth of the town (Aguiló, 2013). Human activity and contact with the sea combine. The cultural maritime landscape signifies human utilization (economy) of maritime space by boat: settlement, fishing, hunting, shipping and its attendant subcultures, such as pilotage, lighthouse and seamark maintenance (Westerdahl, 1992). However, tourist occupation and change in uses and customs have not made neighborly relations between them good. The town keeps drawing closer to the port and it is now an obstacle, a fence that economic progress and the sun-sand-sea system's value expels (Fusco Girard, 2013). The new system's hierarchy views the constructed landscape as a beach close to the natural one, with a very profound footprint on the weak, fragile and erosive strip that dunes and sand shapes configure. The symbolic frontier which the coast is, the land-sea contact, is taken apart with breakwaters, breaking emotion and creating a deep, rootless regression. The second picture (Figure 9) shows how the Burriana harbour breakwater (Castellón) has become an obstacle to sediment transportation which has led to an increase in the width of beach on the right, and erosion on the left, due to a conservation of mass. On the other hand, with a good study of marine dynamics and sediment transport, and a careful design of shapes, the port can become the seed of new urban planning and the generation of uses in the city that did not exist before, as is the case of Zumaia in Guipúzcoa (Negro, 2008).

The impact on the coast is not only produced by structures at sea, but also by those built on land, many of them more harmful than a breakwater. The coast is a very delicate "living organism", under constant tension and change, so any element that is placed on it will have an effect in some way. The coastline includes an extensive cultural and natural heritage, whether on land or under water, so it has to be examined from a broader point of view in an attempt to cause the least impact possible (Westerdahl, 2006). The problem is that littoral projects are often judged on the basis of a political criteria rather than their functional and formal value for the territory (Aurín \& Muñoz-Pérez, 2002).

Lighthouses are a very particular case. These buildings have been necessary for centuries to guide ships and avoid collisions or grounding near land. Until recently, they played an important role in coastal life. They provided jobs and a home for entire families before technological developments did away with them. Nowadays, many of these buildings are destinations of the "Robinson Tourism", converted into small hotels for single, more educated, well-off and ecologically conscious tourists (Opacic et al., 2010). This tourism can provide benefits and money for the preservation of lighthouses, but the "genius loci" is not the same. 


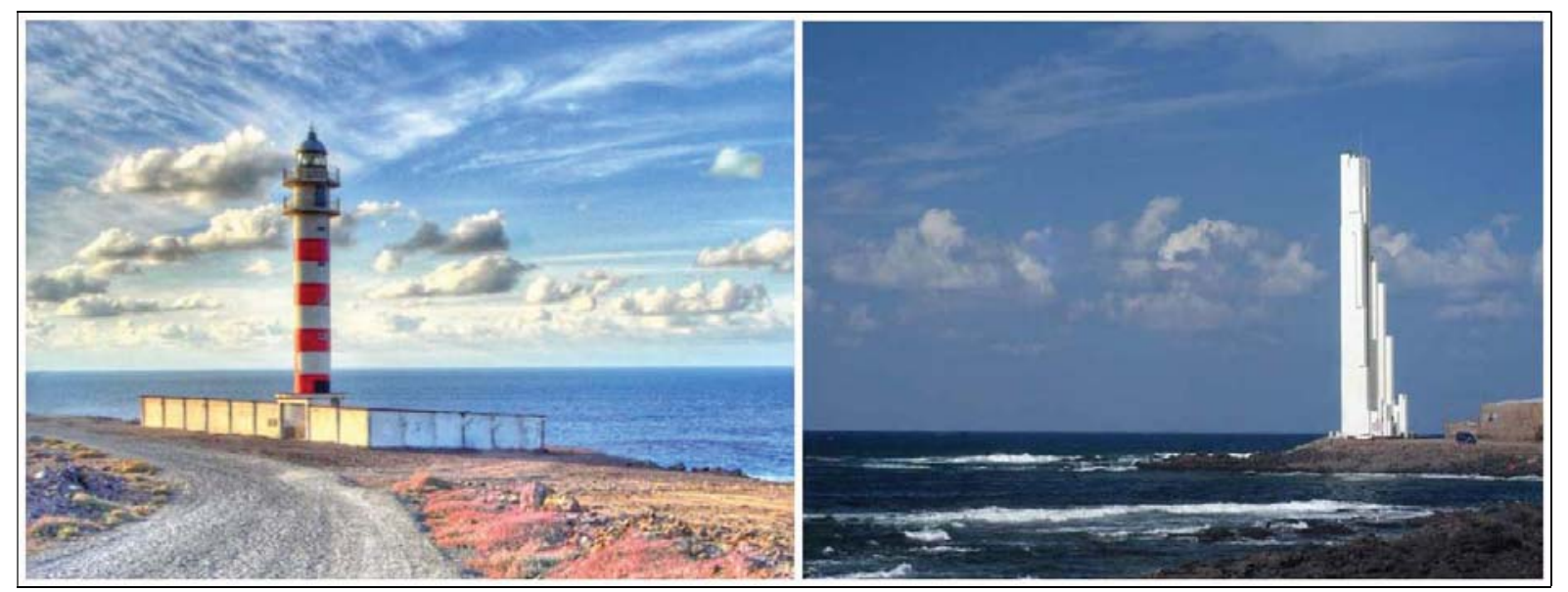

Usually located on high cliffs and natural areas without nearby buildings, lighthouses make of their design a key element when integrated into the landscape. Most lighthouses in the nineteenth century became obsolete and were replaced in the late twentieth century by other automated lighthouses, many of them without much regard in the history and landscape of the place. While in the first picture (Figure 10) the 1980s lighthouse can be seen as keeping the aesthetics of similar, older buildings, the second lighthouse (built in 1992) was intended to alter them by innovating in construction and formal methods and causing a major impact on the fragile coastline, although it fulfils its functions.

Landscapes are combinations of natural and cultural phenomena. We understand that cities are a product of cultural adaptation (Steiner, 2014), but often the natural part is not taken into account in urban development. In coastal areas, especially those of Spain, due to the tourist pressure in recent years, a deeply profound land use mark has occurred, although this phenomenon has been relatively little studied with respect to the actual transformation of the urban landscape and built environment (Hof \& Blázquez-Salom, 2013) and very significantly affects maritime space which is related to both land and sea (Freire, 2013).

The evolution of uses and customs has changed the distribution of water sheltered in harbours. Traditional fishing has given way to boating for sport, providing the town with a "living" for leisure based on the magnificent climate, the many hours of sunlight a year, scarce precipitations and a calm sea suited to recreational boating and for children and grown-ups to be bathed by waves. However, abusive growth, i.e., urban development occupying active beach areas, has created an artificial, harmful, rash landscape in a continuous process of change to artificially restore natural sand areas (Negro, 2014), as can be seen in Santa Pola, Alicante (Figure 11). What has happened to the dune field? What has happened with the east lee shore and the crops? The town's invasion destroys natural landscape with economicist aims, simulated, increasingly larger and less sensitive populations. The town is often not a "place" for coexistence but the clearest example of the insignificant landscape devoid of emotions.

Figure 11. Santa Pola coast (Alicante): 1956 and 2012. Source: sig.magrama.es/geoportal

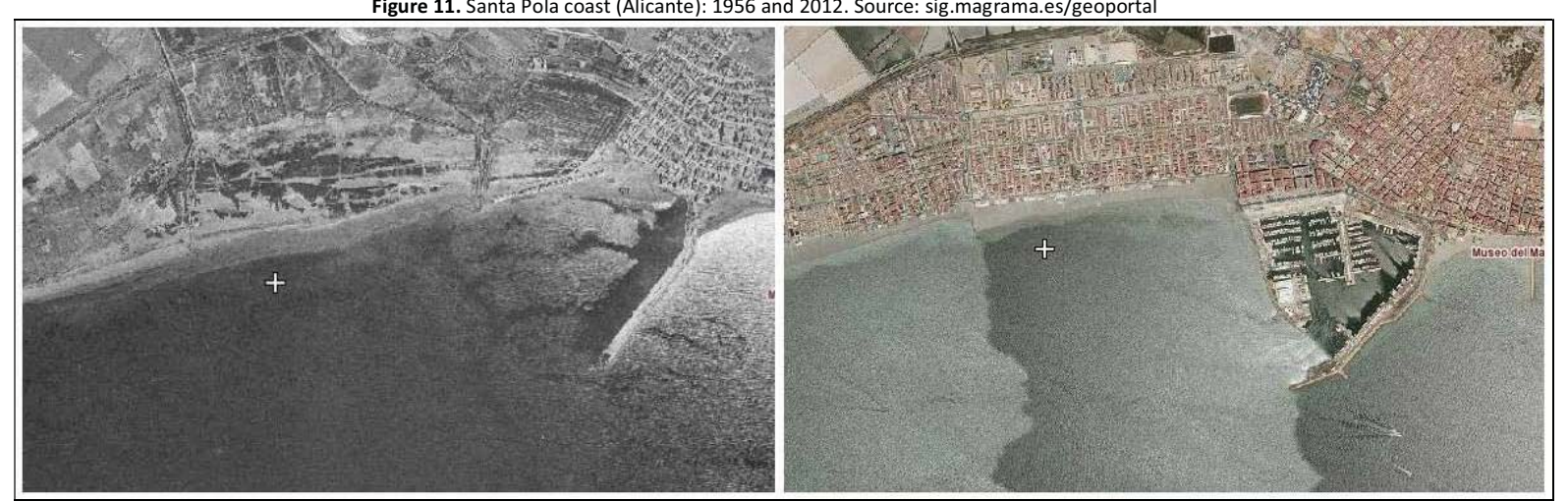


If the coast were a human being, ports would be the arm that shelters, cities, the brains, lighthouses, the eyes and waves, the beating heart that never stops. We must care for all of this to have it living on for many years in the best of health possible.

\section{Conclusion}

This article delves into the relationship of the human being with nature. When the former intends to perpetuate himself in the latter by means of the art of constructing in order to "be in the world" and its constructions, they turn into models of a landscape, a landscape replacing the natural landscape and becoming a constructed one, stamping the concept of "place" on the "site". It endows it with experiences, sensitivity and emotion. It provides it with spirit. How right is the thinking of the philosopher Nietzsche, "If we feel so much at ease in nature, it is because the latter has no opinion of us" (Nietzsche, 1878).

In the same way, engineering as a discipline should seek the "surprise". It should "fit in" rather than "place". It is the localisation of a forgotten location, a lost but found place, an absent but evident element, where the engineer's sensitivity changes what is natural for what is significant and sensitive, providing it with crossing (a bridge), mobility (a road), refuge (a harbour) and experience (a town).

When nature is disorganised, assaulted or attacked, landscape is rash, often destroyed for decades, some in an irreversible manner for the history of time. The natural environment sculptures monuments which the human being should integrate as transcendent rather than crumbling the emotional spirit of the place. A thought of Heidegger sums up this introspection on landscape, on engineering which is not always aesthetic, but that art should be integrated into engineering, "construct into inhabit" and "shape is the guardian of being" (Heidegger, 1947).

Current technology, advances in knowledge of nature's forces and the characteristics of new materials enable us to design real technical marvels, but they should not be at loggerheads with the preservation of the surroundings and conception of "transcendent landscape", even though in most cases, they do not call for the use of such advanced knowledge. Above all, respect as against functionality and economics should prevail.

References

Aguiló, M. (2013). ¿Qué significa construir?: claves conceptuales de la ingeniería civil. Spain: Editorial Adaba. ISBN: 978-8415289760.

Aguiló, M. (1999). El paisaje construido: una aproximación a la idea de lugar. Spain: Colegio de Ingenieros de Caminos, Canales y Puertos. ISBN: 9788438001523.

Antrop, M. (2005). Why landscapes of the past are important for the future. Landscape and Urban Planning, 70(1-2): 21-34. http://dx.doi.org/10.1016/j.landurbplan.2003.10.002

Du Plessis, C. (2012). Towards a regenerative paradigm for the built environment. Building Research \& Information, 40(1), 7-22. http://dx.doi.org/10.1080/09613218.2012.628548

Freire, J. V. (2013). Maritime Cultural Landscape: A New Approach to the Cascais Coastline. Journal of Maritime Archaeology, 9(1), $143-157$. http://dx.doi.org/10.1007/s11457-013-9122-4

Fusco, L. (2013). Toward a Smart Sustainable Development of Port Cities/Areas: The Role of the 'Historic Urban Landscape' Approach. Sustainability, 5(10): 4329-4348. http://dx.doi.org/10.3390/su5104329

González Rodrigo, B., Roig i Olària, S., Fernández-Ordoñez, D. \& Conde-Salazar Gómez, J. M. (2015). Rehabilitation of Historic Masonry Bridges: Lessons Learned from a Medieval Bridge in Northeast Spain. Revista de la construcción, 14(2), 9-13. https://dx.doi.org/10.4067/S0718915X2015000200001

Hara, K., Da, L., Fujihara, M., \& Tomita, M. (2014). Landscape change and sustainable development in the Yangtze River basin, China. Landscape and Ecological Engineering, 10(1), 123-124. http://dx.doi.org/10.1007/s11355-014-0248-9

Heidegger, M. (1947). Platons Lehre von der Wahrheit (Fourth Edition). Vittorio Klostermann.

Hof, A. \& Blázquez-Salom, M. (2013). The Linkages between Real Estate Tourism and Urban Sprawl in Majorca (Balearic Islands, Spain). Land, 2(2): 252-277. http://dx.doi.org/10.3390/land2020252

Hu, S. N., Fan, Q. D., Hu, Z. H., \& Xiao, X. H. (2012). Applications of Visual Characteristics in Highway Alignment Landscape Design. Architecture and Urban Development, 598, 260-263. http://dx.doi.org/10.4028/www.scientific.net/AMR.598.260

Krebs, A. (2014). Why Landscape Beauty Matters. Land, 3(4), 1251-1269. http://dx.doi.org/10.3390/land3041251

Lopes, S. F., Vale, V. S., Prado, J. A., Schiavini, I. \& Oliveira, P. E. (2014). Landscape changes and habitat fragmentation associated with hydroelectric plant reservoirs: insights and perspectives from a central Brazilian case history. Bioscience Journal, 30(4), 1205-1212. 
Martín, B., Loro, M., Arce, R. M. \& Otero, I. (2012). Different landscaping integration techniques in roads. Analysis of efficacy through public perception. Informes de la Construcción, 64(526), 207-220. http://dx.doi.org/10.3989/ic.11.035

Negro, V. (2008). Las formas en la ingeniería del mar. Revista Ingeniería y Territorio, 84,4-9. ISSN: 1695-9647. 84: 2-12.

Negro, V. (2014). Una aproximación a la percepción de la costa. Revista UPM Universidad Politécnica de Madrid. ISSN: 1699-8162, 27: 10.

Nietzsche, F. (1878). Human, All too Human, a Book for Free Spirits. Ernst Schmeitzner

Norberg-Schulz, C. (1979). Genius Loci: Towards a Phenomenology of Architecture. Rizzoli. ISBN: 0-8478-0287-6

Opacic, V. T., Favro, S., \& Perisic, M. (2010). Tourism valorisation of lighthouses on Croatian islands and along the coast. Island Sustainability, WIT Transactions on Ecology and the Environment, 130, 37-48. http://dx.doi.org/10.2495/ISLANDS100041

Renaud, F., Birkmann, J., Damm, M.; \& Gallopin, G. C. (2010). Understanding multiple thresholds of coupled social-ecological systems exposed to natural hazards as external shocks. Natural Hazards, 55(3), 749-763. http://dx.doi.org/10.1007/s11069-010-9505-x

Sanderson, E. W., Jaiteh, M., Levy, M. A., Redford, K. H., Wannebo, A. V. \& Woolmer, G. (2002). The human footprint and the last of the wild: The human footprint is a global map of human influence on the land surface, which suggests that human beings are stewards of nature, whether we like it or not. BioScience, 52(10): 891-904.

Steiner, F. (2014). Urban Landscape Perspectives. Land, 3(1): 342-350. http://dx.doi.org/10.3390/land3010342

Thompson, C. W. (2002). Urban open space in the 21st century. Landscape and Urban Planning, 60(2): 59-72. http://dx.doi.org/10.1016/S01692046(02)00059-2

Turner, M. G., Gardner, R. H., O’Neill, R. V., \& Pearson, S. M. (1994). Multiscale Organization of Landscape Heterogeneity. In M. E. Jensen \& P. S. Bourgeron Volume II: ecosystem management: principles and applications (73-79). PNW-GTR-318: U.S. Dept. Agric., For. Serv., Pacific North Res. Sta.

Van der Ryn, S., \& Cowan, S. (2007). Ecological Design, 10th Anniversary Edition. Washington, DC., Island Press, Westerdahl, C. (1992). The maritime cultural landscape. International Journal of Nautical Archaeology, 21(1): 5-14. http://dx.doi.org/10.1111/j.1095-9270.1992.tb00336.x

Westerdahl, C. (2006). From river to sea catching the monsoon, concepts of the maritime landscapes. In L. Indo-Portuguese encounters, journeys in science, technology and culture (334-350).

Zhao, Q., Liu, S., Deng, L., Dong, S., Cong, Wang, Yang, Z., \& Yang, J. (2012). Landscape change and hydrologic alteration associated with dam construction. International Journal of Applied Earth Observation and Geoinformation, 16, 17-26. http://dx.doi.org/10.1016/j.jag.2011.11.009 


\subsection{ARTÍCULO 3:}

Martín-Antón, M.; Negro, V.; del Campo, J.M., López-Gutiérrez, J.S., and Esteban M.D. (2016). "Review of coastal Land Reclamation situation in the World". In: Vila-Concejo, A.; Bruce, E.; Kennedy, D.M., and McCarroll, R.J. (eds.), Proceedings of the 14th International Coastal Symposium (Sydney, Australia). Journal of Coastal Research, Special Issue, No. 75, pp. 667671. Coconut Creek (Florida), ISSN 0749-0208. DOI: 10.2112/SI75-133.1

Idea: Paisaje destruido. Efectos de la conquista. Ciudad invadida.

Resumen: Los rellenos ganando terreno al mar han estado realizándose desde la antigüedad, especialmente en las obras marítimas y en los puertos. La gran mayoría de los muelles del mundo ahora ocupan espacios que antes eran agua y esto influye fuertemente en el paisaje costero.

Japón ha sido uno de los países que más necesitaron expandirse al mar debido a su topografía y los requerimientos del sedentarismo, la agricultura, la ciudad y su urbanización y, especialmente, las industrias y las instalaciones portuarias. El 90\% de la costa de la Bahía de Tokio es tierra ganada al mar con casi $250 \mathrm{~km}^{2}$ de superficie de relleno.

En el siglo XXI, esta proporción ha cambiado. En el Golfo Pérsico, la costa ha sido invadida de manera indiscriminada. Los proyectos de islas artificiales para fines residenciales demuestran conceptos de "ciudad invadida" y "paisaje destruido". Algunos de ellos están encontrando algunas dificultades, como las Palmeras y el Mundo en Dubai, con una pérdida de arena, por el efecto de las corrientes y las olas.

La expansión económica y las necesidades de exportación han hecho que crezcan las zonas industriales y éstas se están extendiendo por la costa. Caofeidian (Bahía de Bohai) es la isla de relleno más grande del mundo con $150 \mathrm{~km}^{2}$, más del doble de la suma de la zona de las islas de Dubai.

Esta desproporción es un gran contraste con la Bahía de Algeciras con 2,5 km² de rellenos, 100 veces menos que la Bahía de Tokio. A esto se debe añadir la problemática de la interacción suelo - estructura que en el caso de Japón es demostrable por los efectos de los terremotos, maremotos y la licuefacción de los suelos arenosos.

Este primer artículo responde a la reflexión de las etapas (conquista) y los conceptos de paisaje destruido, paisaje industrial y ciudad invadida.

Conclusión y reflexión: Cuando se discute y analiza el paisaje costero de las islas artificiales, Dubai es casi siempre el tema principal debido al espectacular crecimiento, sus necesidades, naturaleza de sus formas y tamaños.

Este primer artículo muestra la conquista que "el Mundo" como relleno indiscriminado produce en el paisaje y en la ciudad. Mucho más de lo esperado y se está desarrollando en estos momentos son China, Japón, Corea y el Golfo Pérsico más que el resto del mundo.

El uso portuario ha quedado relegado por el residencial en términos de superficie total. El centro de gravedad mundial ya no es Europa o Estados Unidos y se desplaza a Asia.

Todo este "desarrollo áspero" se asocia con desprecio por el paisaje en la mayoría de los casos. Sin embargo, las necesidades del mundo globalizado, se centran y basan en la integración con el entorno en conceptos de "paisaje cultural", "ciudad reconquistada" y "paisaje reconstruido". 
